
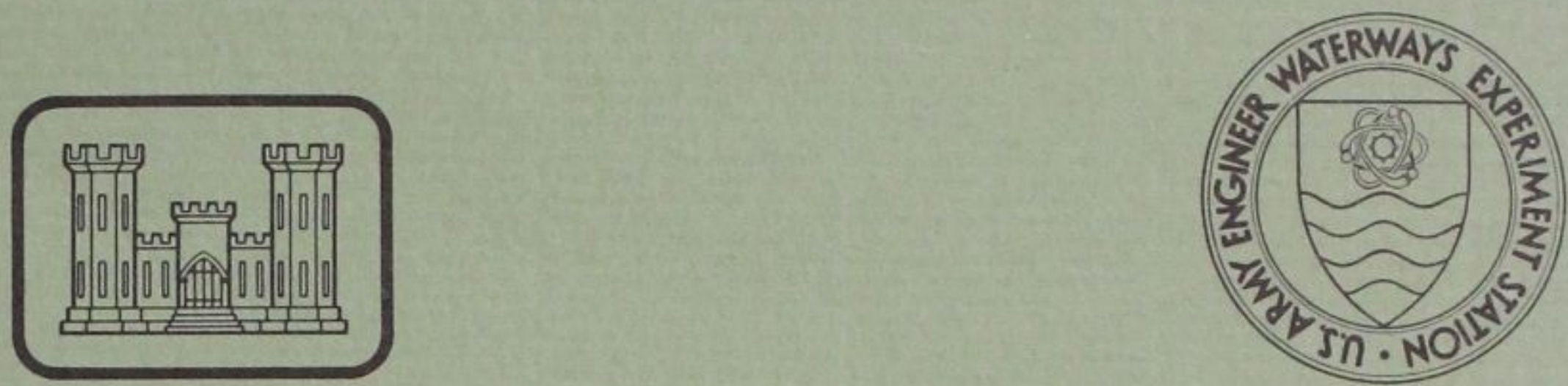

TECHNICAL REPORT A-81-3

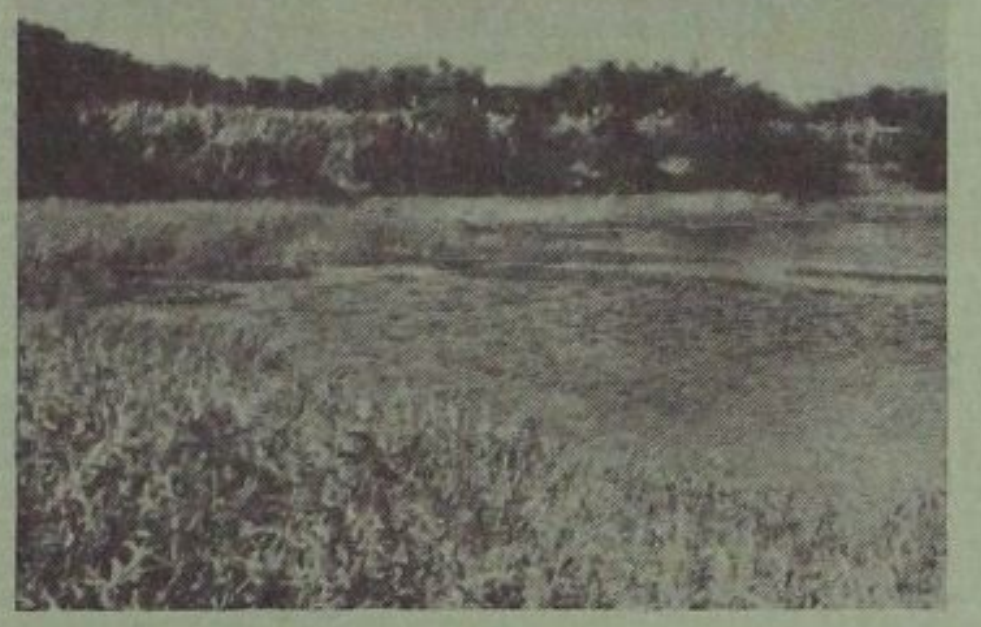

\title{
RELEASE AND ESTABLISHMENT \\ OF SAMEODES ALBIGUTTALIS FOR BIOLOGICAL CONTROL OF WATERHYACINTH
}

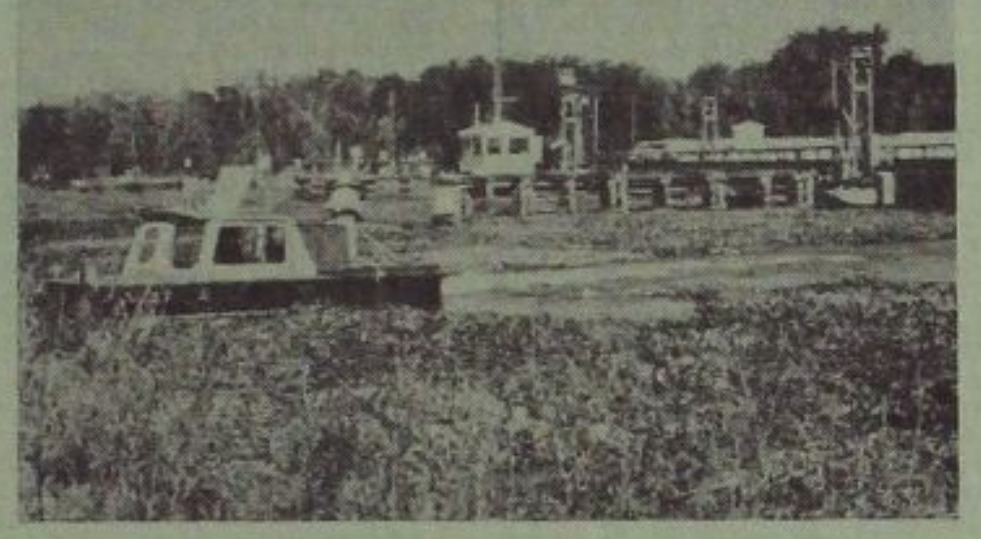

\author{
By T. D. Center
}

Aquatic Plant Management Laboratory U. S. Department of Agriculture Science and Education Administration

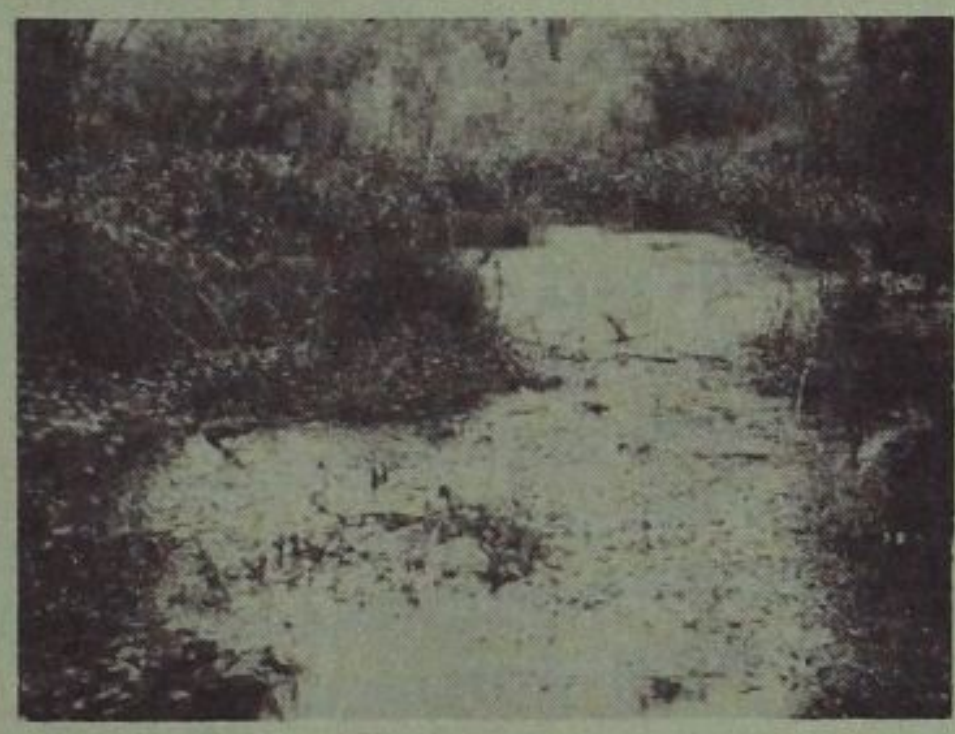
Fort Lauderdale, Fla. 33314

February 1981

Final Report

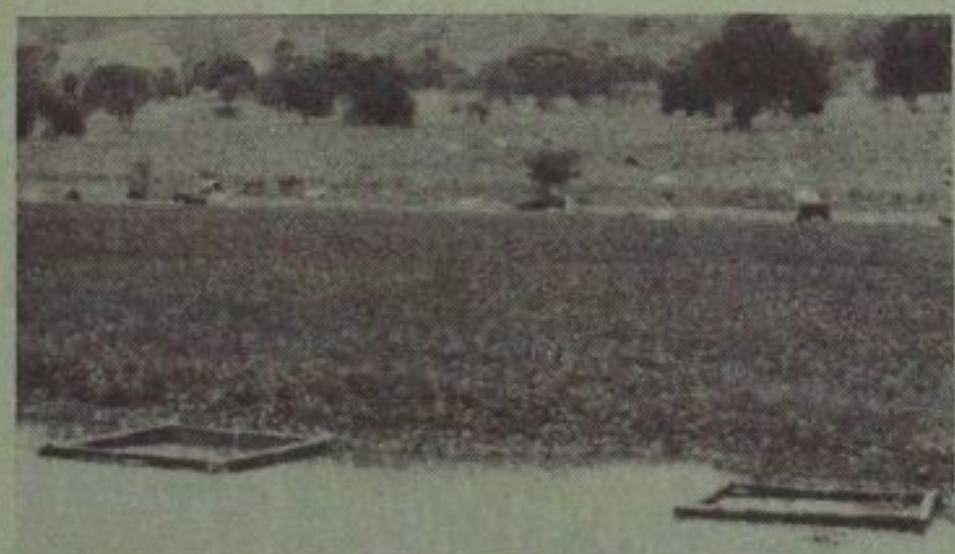

Prepared for Office, Chief of Engineers, U. S. Army Washington, D. C. 20314

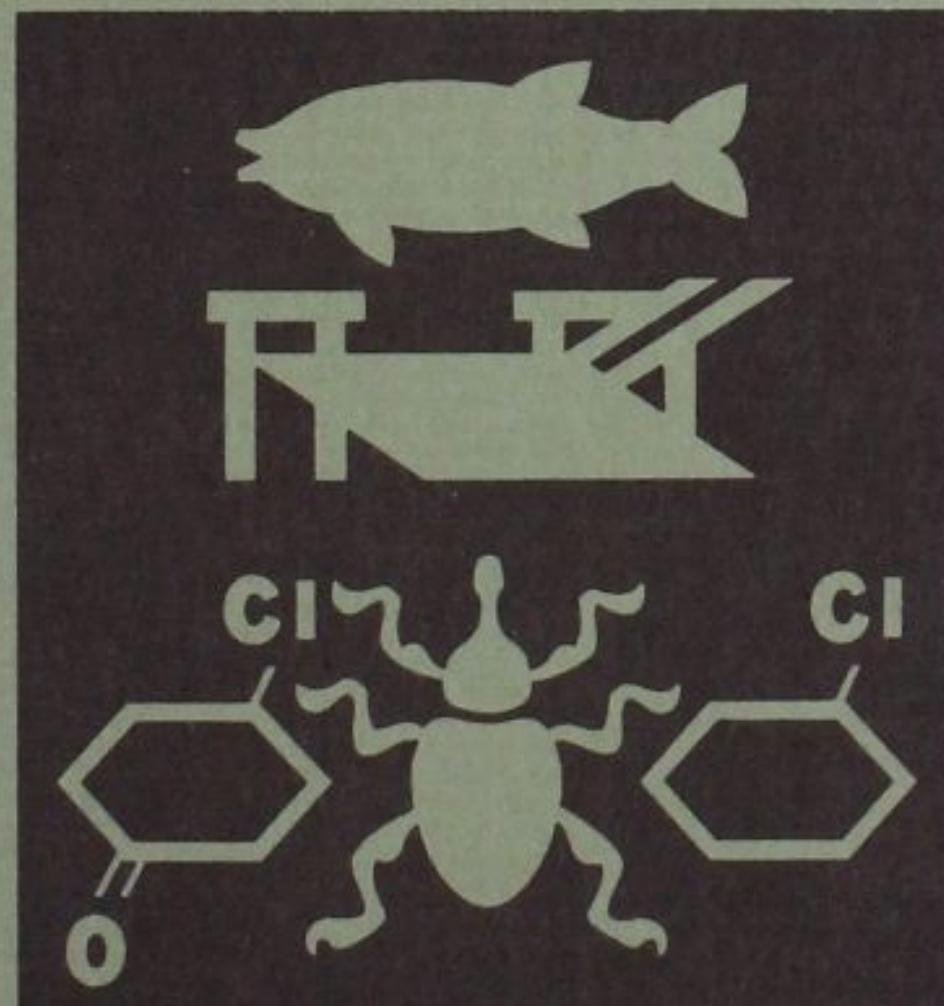

Approved For Public Release; Distribution Unlimited

Monitored by Environmental Laboratory

U. S. Army Engineer Waterways Experiment Station

P. O. Box 631, Vicksburg, Miss. 39180

LIBRARY BRANCH

TECHNICAL INFORMATION CENTER

US ARMY ENGINEER WATERWAYS EXPERIMENT STATION YICKSBURG, MISSISSIPPI 


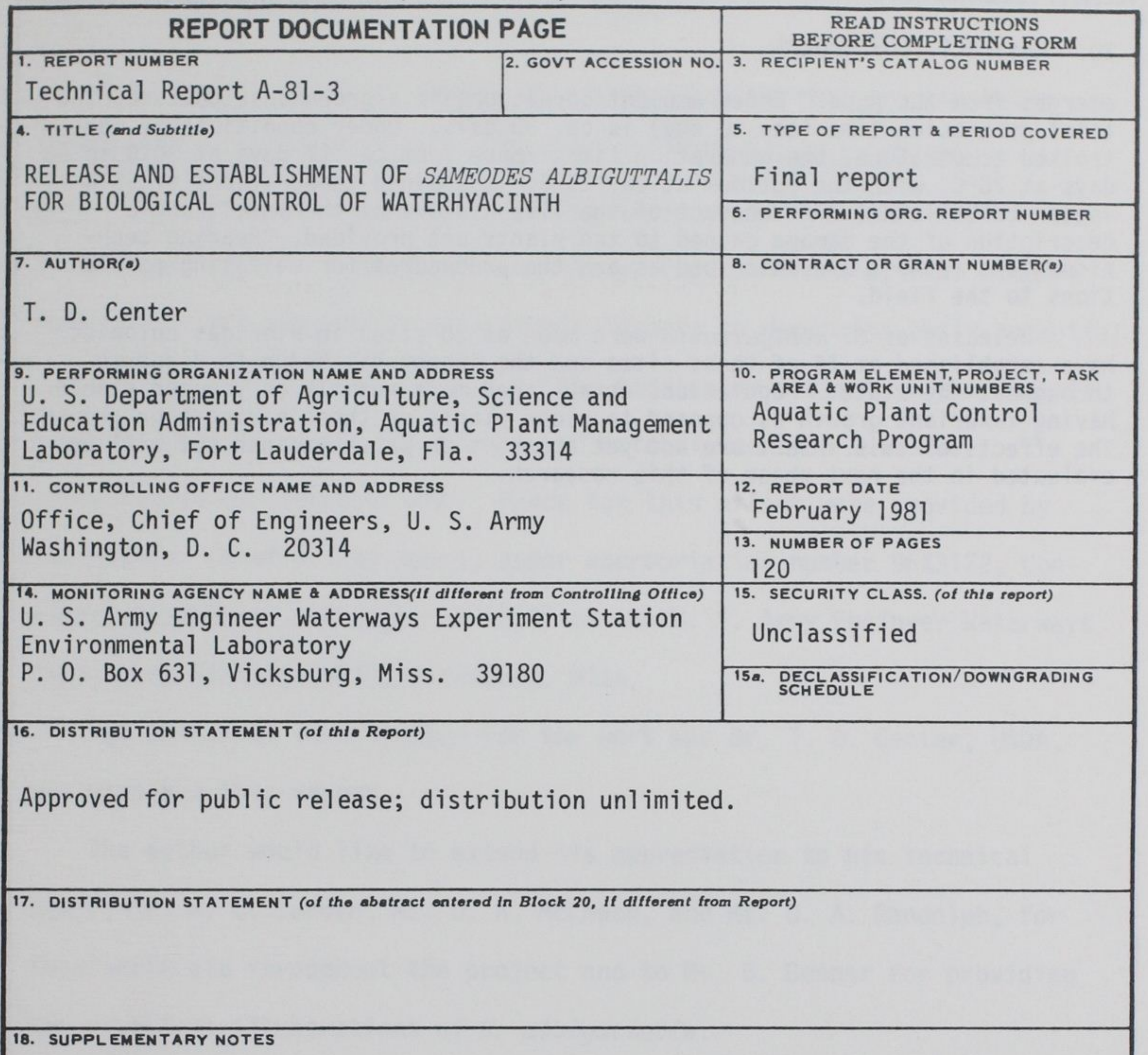

18. SUPPLEMENTARY NOTES

19. KEY WORDS (Continue on reverse side if nocessary and identify by block number)

Aquatic plant control

Aquatic plants

Biological control

Water hyacinths

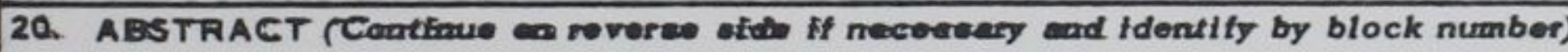

Sameodes albiguttalis (Warren), a South American pyralid species, having recently been imported into the United States for the biological control of waterhyacinth has been released and is now well established in southern Florida. Because it is new to the North American fauna, detailed descriptions are provided of the egg, larval instars, pupae, and adults of this species. Biological studies indicate that the female normally oviposits 400 to 500 eggs, the majority of which are laid during the early evening hours the day after she (Continued) 


\section{ABSTRACT (Continued).}

emerges from the pupa. Under ambient conditions in a greenhouse culture, the total generation time (egg to egg) is ca. 30 days. Under conditions of controlled temperature, the generation times range from $\mathrm{ca}$. 21 days at $30^{\circ} \mathrm{C}$ to 40 days at $20^{\circ} \mathrm{C}$, with the optimum at ca. $25^{\circ} \mathrm{C}$. Sustained temperatures of $35^{\circ} \mathrm{C}$ appear to be lethal. An account of the life history of the insect and a description of the damage caused to the plants are provided. Rearing techniques and methods are described as are the procedures for releasing populations to the field.

Releases of $S$. albiguttalis were made at 20 sites in Florida; colonies have established at 16 of these sites and the insect has begun to disperse throughout the state. Populations established more readily on younger plants having luxuriant growth as opposed to older plants or those having poor growth. The effects of this insect are not yet apparent on waterhyacinth but will be evaluated in the next phase of this research. 


\section{Preface}

This report presents results of a biological control program being conducted for the Aquatic Plant Control Research Program (APCRP) by the U. S. Department of Agriculture (USDA), Science and Education Administration, Aquatic Plant Management Laboratory, Fort Lauderdale, Fla. The purpose of this program is to evaluate insects to determine their potential for use in aquatic plant control. This particular project in the overall program involved the field release and establishment of Scomeodes albiguttalis on waterhyacinth. Funds for this effort were provided by the Office, Chief of Engineers, under appropriation number 96×3122, Construction General, through the APCRP at the U. S. Army Engineer Waterways Experiment Station (WES), Vicksburg, Miss.

The principal investigator for the work was Dr. T. D. Center, USDA, who prepared this report.

The author would like to extend his appreciation to his technical staff, Mr. W. C. Durden, Ms. D. A. McKewen, and Ms. D. A. Randolph, for invaluable aid throughout the project and to Ms. B. Benner for providing the excellent illustrations of $S$. albiguttalis.

The research was monitored at WES by Dr. D. R. Sanders, Sr., and Mr. R. F. Theriot of the Environmental Laboratory (EL) Wetland and Terrestrial Habitat Group (WTHG). The study was conducted under the general supervision of Dr. John Harrison, Chief, EL, Dr. C. J. Kirby, Jr., Chief, Environmental Resources Division, and the direct supervision of Dr. H. K. Smith, Acting Group Chief, WTHG, and Mr. J。L. Decell, Manager, APCRP. Commanders and Directors of WES during the study and preparation of 
this report were COL John L. Cannon, CE, and COL Nelson P. Conover, CE. Technical Director was Mr. F. R. Brown.

This report should be cited as follows:

Center, T. D. 1981. "Release and Establishment of Sameodes albiguttalis for Biological Control of Waterhyacinth," Technical Report A-81-3, U. S. Army Engineer Waterways Experimental Station, CE, Vicksburg, Miss. 


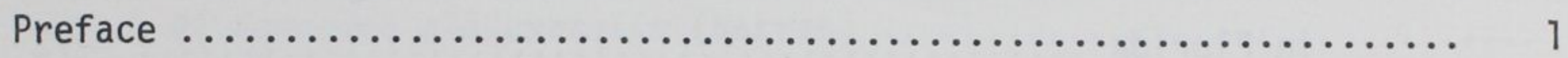

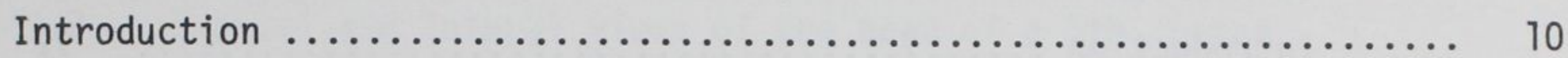

Section I. Descriptions of the eggs, larvae, pupae, and adults of Scomeodes albiguttalis (Warren) .................... 13

Introduction ............................... 13

General Characters of the Pyralidae ............... 15

General Characters of the Pyraustinae ............. 16

Description of Sameodes albiguttalis ............... 16

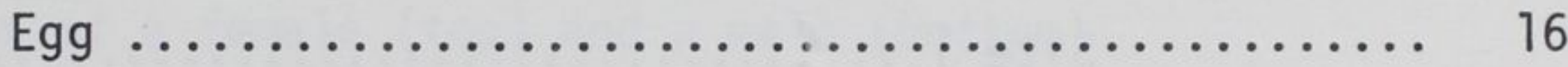

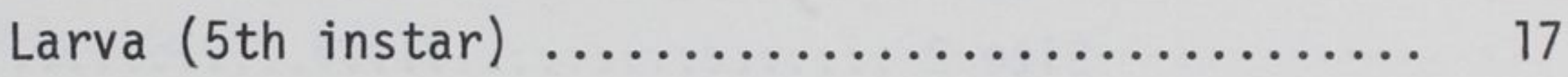

Thorax ............................... 19

Abdomen ................................ 21

Diagnostic characters for determining larval

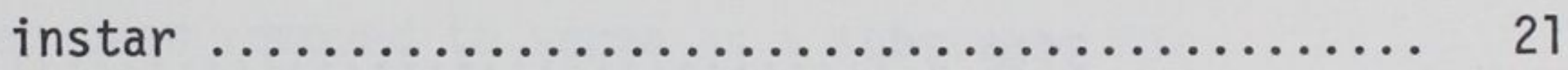

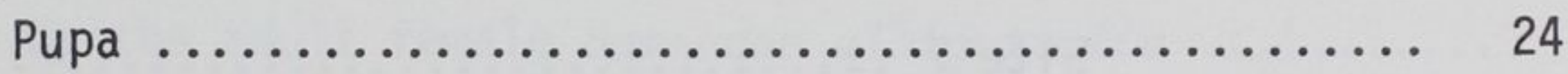

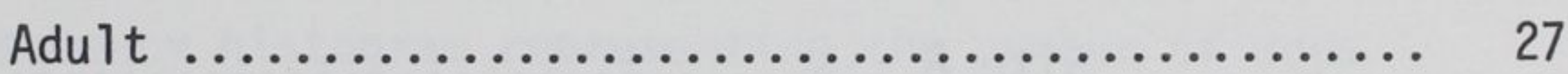

Section II. Bionomics of Sameodes albiguttalis (Warren) .......... 30

Introduction ............................... 30

Methods and Materials ....................... 30

Oviposition and fecundity ................. 30

Developmental times ...................... 34

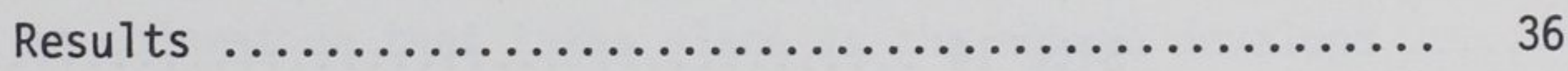

Oviposition and fecundity $\ldots \ldots \ldots \ldots \ldots \ldots \ldots . \quad 36$

Developmental times ...................... 42

Larval feeding behavior .................. 49

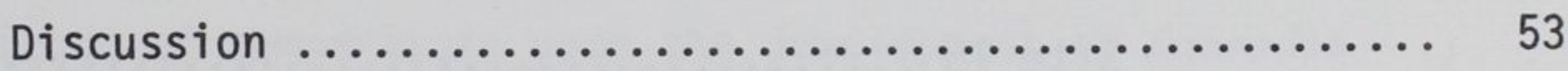

Section III. Procedures for culturing and rearing Scomeodes albiguttalis .............................. 58

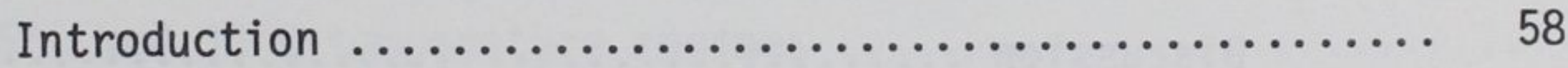

Acquiring an Initial Stock $\ldots \ldots \ldots \ldots \ldots \ldots \ldots \ldots \ldots . . . \ldots \ldots$

Collecting and Rearing Pupae ................... 59

Obtaining Adults ............................. 65 
Obtaining Eggs $\ldots \ldots \ldots \ldots \ldots \ldots \ldots \ldots \ldots \ldots \ldots \ldots \ldots \ldots \ldots \ldots \ldots, 66 \ldots$

Starting a Greenhouse Colony .................... 68

Discussion ................................... 70

Section IV. The release and establishment of Sameodes albiguttalis in Florida ................................ 72

Introduction $\ldots \ldots \ldots \ldots \ldots \ldots \ldots \ldots \ldots \ldots \ldots \ldots \ldots \ldots \ldots, 72$

Methods and Materials ......................... 72

Parent stock ............................. 72

Release methods ......................... 73

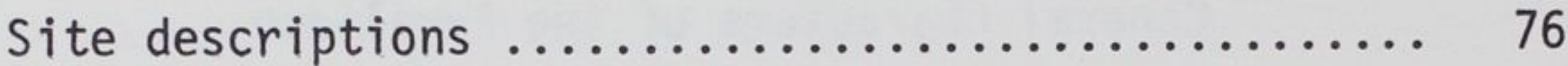

Results, Insect Releases and Chronological

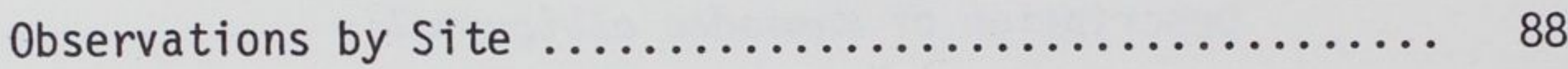

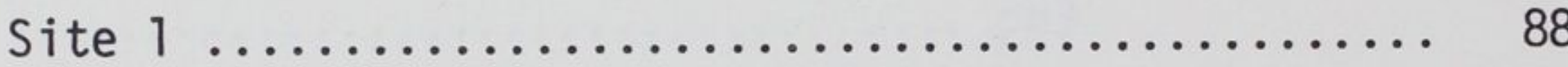

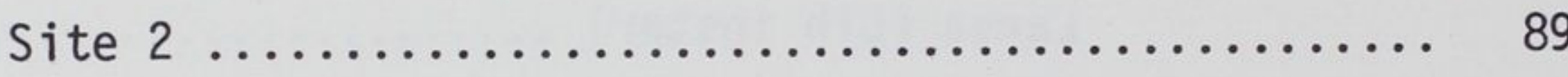

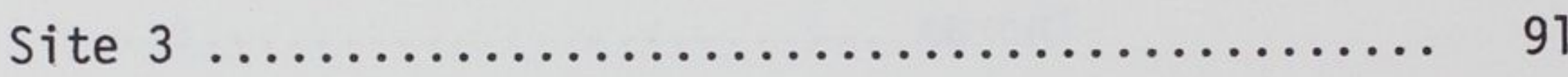

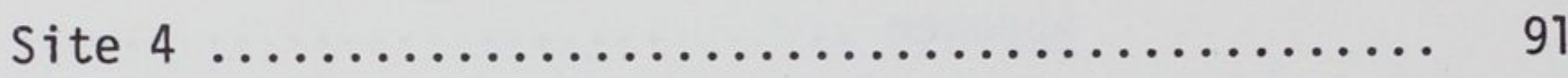

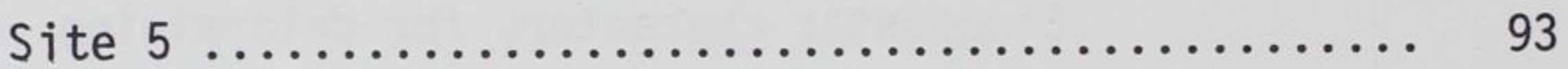

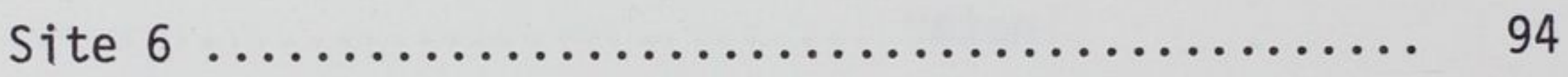

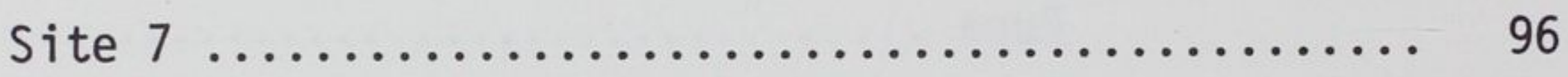

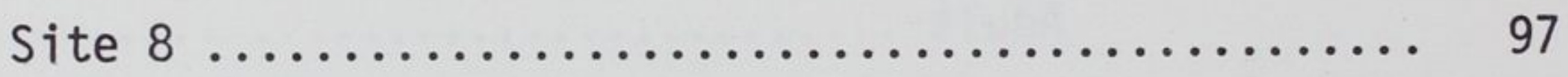

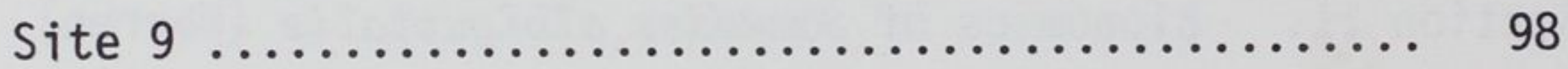

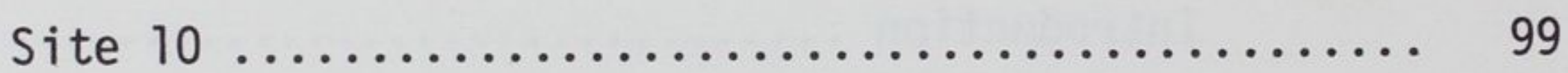

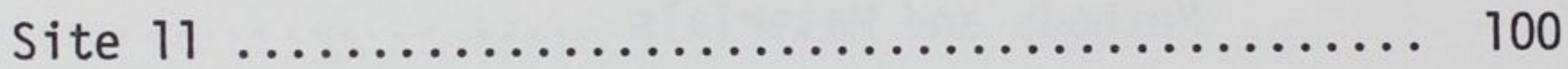

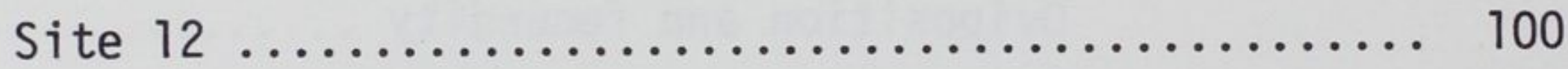

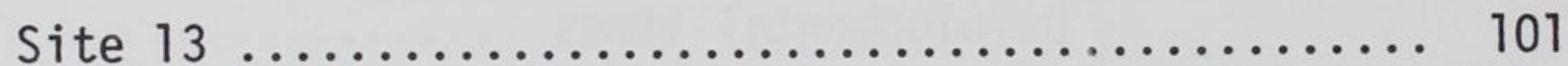

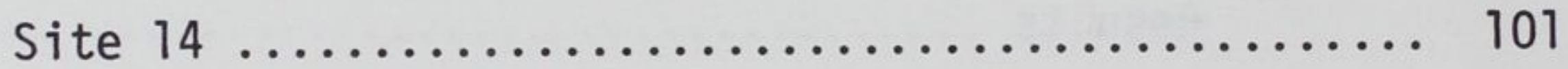

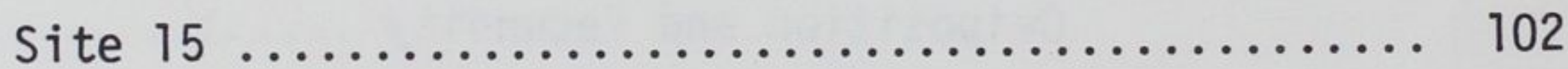

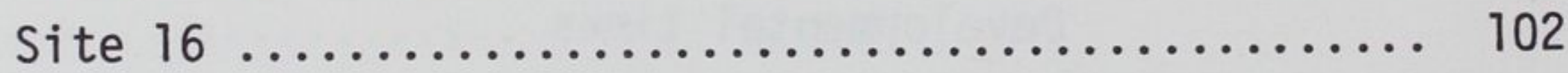

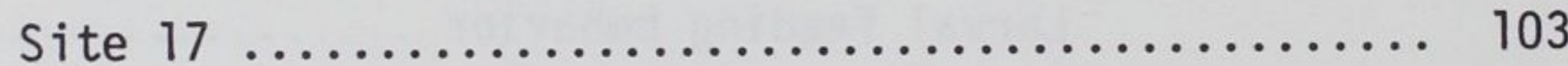

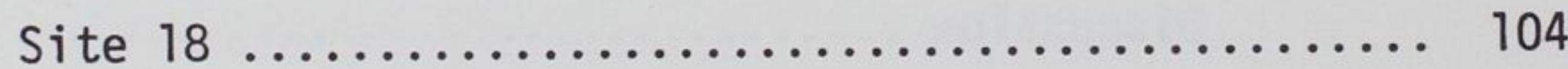

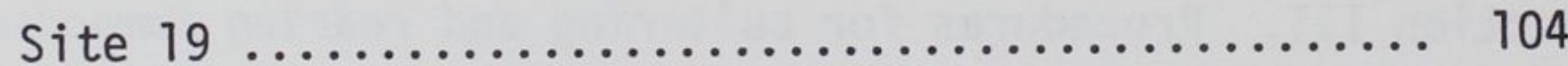

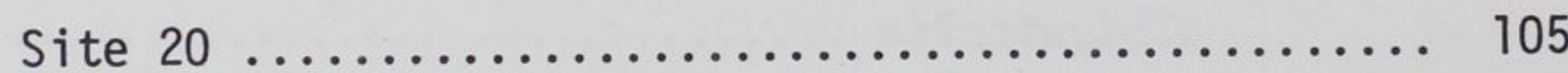

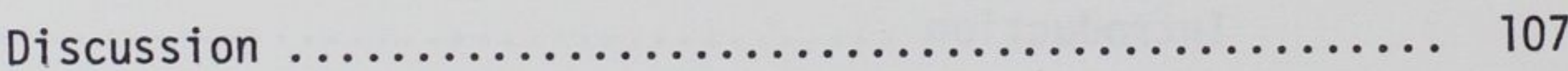

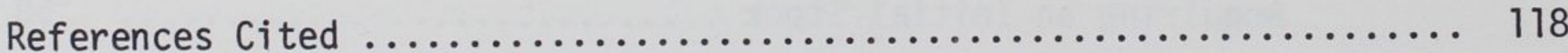




\section{LIST OF FIGURES}

Figure

1. Map of South America showing the known collection localities of Scomeodes albiguttalis (Warren) ....................... 14

2. Frontal and lateral views of the head of a 5 th instar S. albiguttalis larva ................................ 18

3. Dorsal and lateral views of a 5 th instar S. albiguttalis

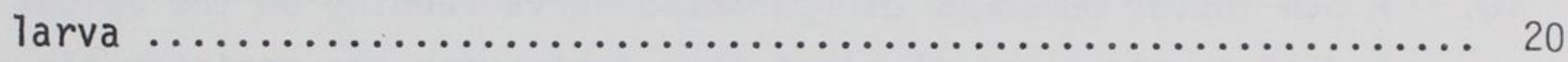

4 Dorsal view of the anal plate of a 5 th instar sameodes

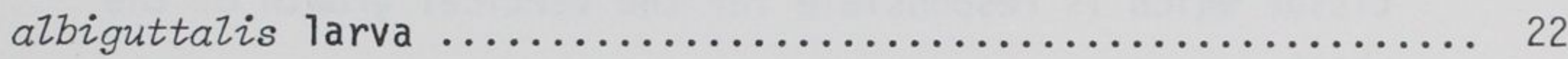

5. Ventral view of a male Sameodes albiguttalis pupa $\ldots . \ldots \ldots \ldots . . .25$

6. Dorsal views of a female (top) and a male (bottom) Scomeodes albiguttalis adult ........................... 29

7. Ovipositional timing unit used to determine the periodicity of oviposition rates of Scomeodes albiguttalis ................ 32

8. A radiograph of a piece of waterhyacinth lamina from which the epidermis has been removed to serve as a substrate for oviposition by the adult female scomeodes albiguttalis ............

9. Relative frequency histogram representing the number of eggs deposited per adult female Scomeodes albiguttalis ................

10. A curve for the average oviposition rates of adult female Someodes albiguttalis the first 3 days after emerging from the pupae

11. Photomicrograph of Scomeodes albiguttalis eggs illustrating the change in coloration that takes place as the embryo develops .....

12. Relative frequency histograms of each scomeodes albiguttalis instar present in the greenhouse culture for each day of age following larval eclosion

13. The effects of temperature upon the development of Scomeodes albiguttalis larvae

14. Average larval weights for successive ages when reared under $20^{\circ}, 25^{\circ}$, and $30^{\circ} \mathrm{C}$ temperature regimes 
15. First instar Someodes albiguttalis larva on a waterhyacinth lamina which shows the irregularly shaped lesions created by the scraping feeding behavior of the larva $\ldots \ldots \ldots \ldots \ldots \ldots .50$

16. A waterhyacinth petiole which shows evidence of early instar

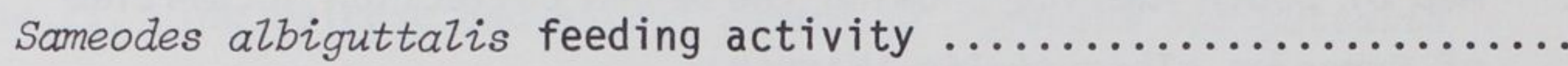

17. Stereo pairs of X-ray images of a waterhyacinth leaf showing the internal damage resulting from the feeding activity of a

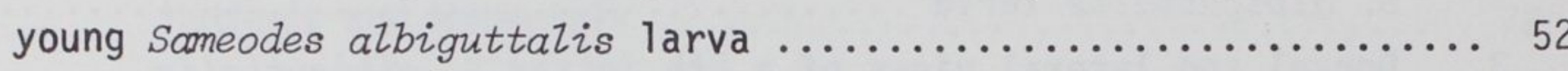

18. A 5th instar Sameodes albiguttalis larva feeding on the apical bud of a waterhyacinth plant thus destroying the meristematic tissue which is responsible for the vertical growth of the

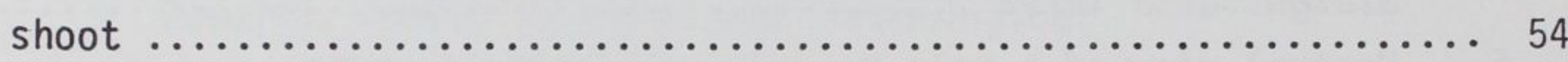

19. A radiograph which $i l l u s t r a t e s$ the selection of leaves by

a 5 th instar Sameodes albiguttalis larva ................... 55

20. The "window" of a Someodes albiguttalis pupa evident on the surface of a waterhyacinth petiole as a round, hyaline spot

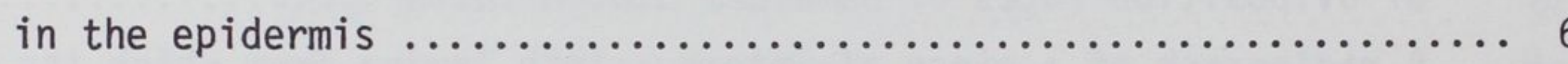

21. A Sameodes albiguttalis cocoon within a waterhyacinth petiole which has been split open to show the silken emergence tunnel leading to the "window" on the external surface of the petiole ... 62

22. A photograph (left) and a stereo-pair radiograph (right) of

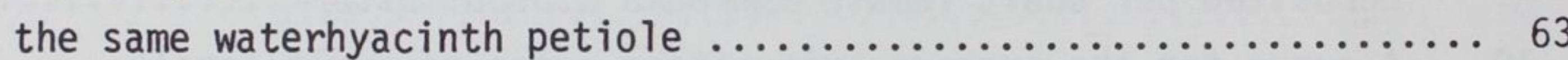

23. A painted pie pan containing moist filter paper and waterhyacinth petiole pieces with Someodes albiguttalis cocoons

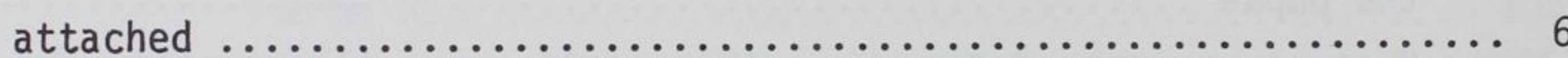

24. A. plastic petri dish containing moist filter paper, a piece of waterhyacinth lamina with a portion of the epidermis removed, and a pair of Someodes albiguttalis adults

25. The method of inserting a piece of waterhyacinth lamina containing Scomeodes albiguttalis eggs or neonates between the central petiole and a newly emerging leaf of a waterhyacinth plant .

26. Populations of Sameodes albigutalis established in Florida by September 1979 
27. Locations of the eight release sites within the Everglades

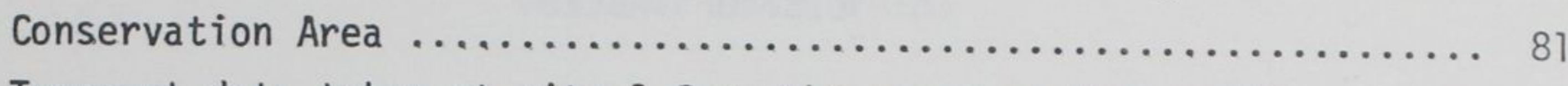

28. Transect data taken at site 2 from the canal at the north-

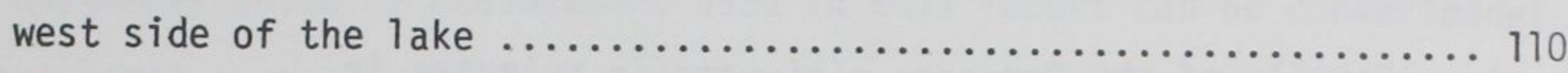

29. A comparison of three ratios of plant characteristics among sites grouped according to whether Sameodes albiguttalis populations became established on the plants (solid dots) or failed to become established (open dots) $\ldots \ldots \ldots \ldots \ldots \ldots \ldots \ldots \ldots \ldots$ 


\section{LIST OF TABLES}

Table

Page

1. Details of the Sameodes albiguttalis releases in Florida

2. A comparison of plant characteristics among sites and the ratios of characteristics considered indicative of plant quality 
U. S. customary units of measurement used in this report can be converted to metric (SI) units as follows:

Multiply
acres
feet
inches
miles (U. S. statute)

$\frac{\text { By }}{4046.856}$
0.3048
25.4
1.609344

To Obtain square metres metres millimetres kilometres 


\section{RELEASE AND ESTABLISHMENT OF SAMEODES ALBIGUTTALIS}

\section{FOR BIOLOGICAL CONTROL OF WATERHYACINTH}

\section{Introduction}

1. Research on the biological control of waterhyacinth (Eichhormia crassipes (Mart.) Solms) with insects was begun by the U. S. Department of Agriculture (USDA) in 1967. Since waterhyacinth originated in South America, an extensive effort was made to identify and test South American insect species potentially useful for waterhyacinth control in the U. S. This preliminary work was conducted by the USDA laboratory staff in Hurlingham, Argentina. Approximately 40 species of insects and mites were subsequently identified which caused some degree of damage to waterhyacinth in South America (Perkins 1974).

2. Of the 40 species which were identified only 6 were deemed worthy of further consideration. The others were disqualified because cursory observations either indicated that they were not specific to waterhyacinth or that they did not significantly damage it. The remaining species were tested to determine which were sufficiently host specific for introduction into the U. S. It was eventually determined that Neochetina eichhormiae Warner (Coleoptera:Curculionidae), Neochetina bruchi (Hustache) (Coleoptera:Curculionidae), Sameodes albiguttalis (Warren) (Lepidoptera:Pyralidae), Acigona infusella (Walker) (Lepidoptera:Pyralidae), and Cornops Zongicorne (Brunes) (Orthoptera:Acrididae) were reasonably specific to the target plant and warranted further consideration (Perkins and Maddox 1976; Silveiro-Guido 1971; Silveiro-Guido and Perkins 1975; Cordo and DeLoach 1978).

3. The importation of all exotic insect species for biological control 
is regulated by the USDA Animal and Plant Health Inspection Service (APHIS). Based upon the recommendation of an interagency advisory group, the Working Group on Natural Enemies (WGNE), APHIS either honors requests for the importation of certain species and issues the necessary permits or denies these applications. Substantial documentation is required for a species to be considered and the requirements are based upon rigorous criteria of host specificity. Of the six species mentioned above, it was felt that only the first three could meet the requirements imposed by the WGNE for introduction into the U.S. Petitions containing the necessary documentation were prepared and submitted and approval for importation of these three species was subsequently granted. As a result, Neochetina eichhorniae Warner was released in 1972 and Neochetina bruchi in 1974. This report documents the release of the third insect Sameodes albiguttalis (Warner) in 1977 and 1978.

4. The purpose of this report is twofold. First, it is intended to summarize the releases of $S$. albiguttalis and to document the resultant establishment of several populations. Second, it is intended to serve as a reference for those who wish to work with this insect for the biological control of waterhyacinth. With this second purpose in mind, this report is organized into four sections. Since it is imperative that one working with the insect be able to identify it, the first section consists of detailed descriptions and illustrations of the adults and immature stages of Sameodes albiguttalis. It is equally necessary to have some knowledge of the life history of the insect and this is dealt with in the second section. An agency hoping to release large numbers of insects must be acquainted with the rearing and handling procedures and these are described in the third 
section. The fourth section details procedures for releasing $S$. albiguttalis in the field and evaluates the releases made in Florida. 
Section 1. Descriptions of the eggs, larvae, pupae, and adults of Scomeodes albiguttalis (Warren).

\section{Introduction}

5. Sameodes albiguttalis (Warren) is indigenous to and apparently widespread throughout South America. It was first described by Warren (1889) from specimens collected by J. H. Trail (three adult females) from Boa Vista, Parita, and Guajaratuba in Brazil on the Rio Purus. Bennett and Zwolfer (1968) collected it in Trinidad, Guyana (Georgetown and New Amsterdam), Surinam (Nickerie, Coesewijne River, Paramaribo, and Brokopondo Lake), and Brazil (Belem). Silveira-Guido (1965) collected it in Uruguay and at Iguazu on the border between Argentina and Brazil, and Cordo and DeLoach (1978) collected larvae from Campana and Dique Lujan in Buenos Aires Province and Dique Los Sauces, La Rioja Province, Argentina. These localities are illustrated in Fig. 1. While these represent very few records and do not reflect the entire range of Sameodes albiguttalis, they do indicate that the insect has a wide distribution in diverse habitats throughout the tropical and temperate regions of South America.

6. Warren (1889) originally dubiously placed this species in the genus Epichronistis. Since that time the group has not received a great deal of attention from taxonomists and the status of the present name is by no means certain. DeLoach and Cordo (1978) present an excellent account of the difficulties involved in determining the proper name for this species. In summary, after Warren (1889) published the name Epichronistis albiguttalis, Hampson (1899) listed the species in the genus Pyrausta Schrank. It was then transferred to the genus Scomeodes Snellen 


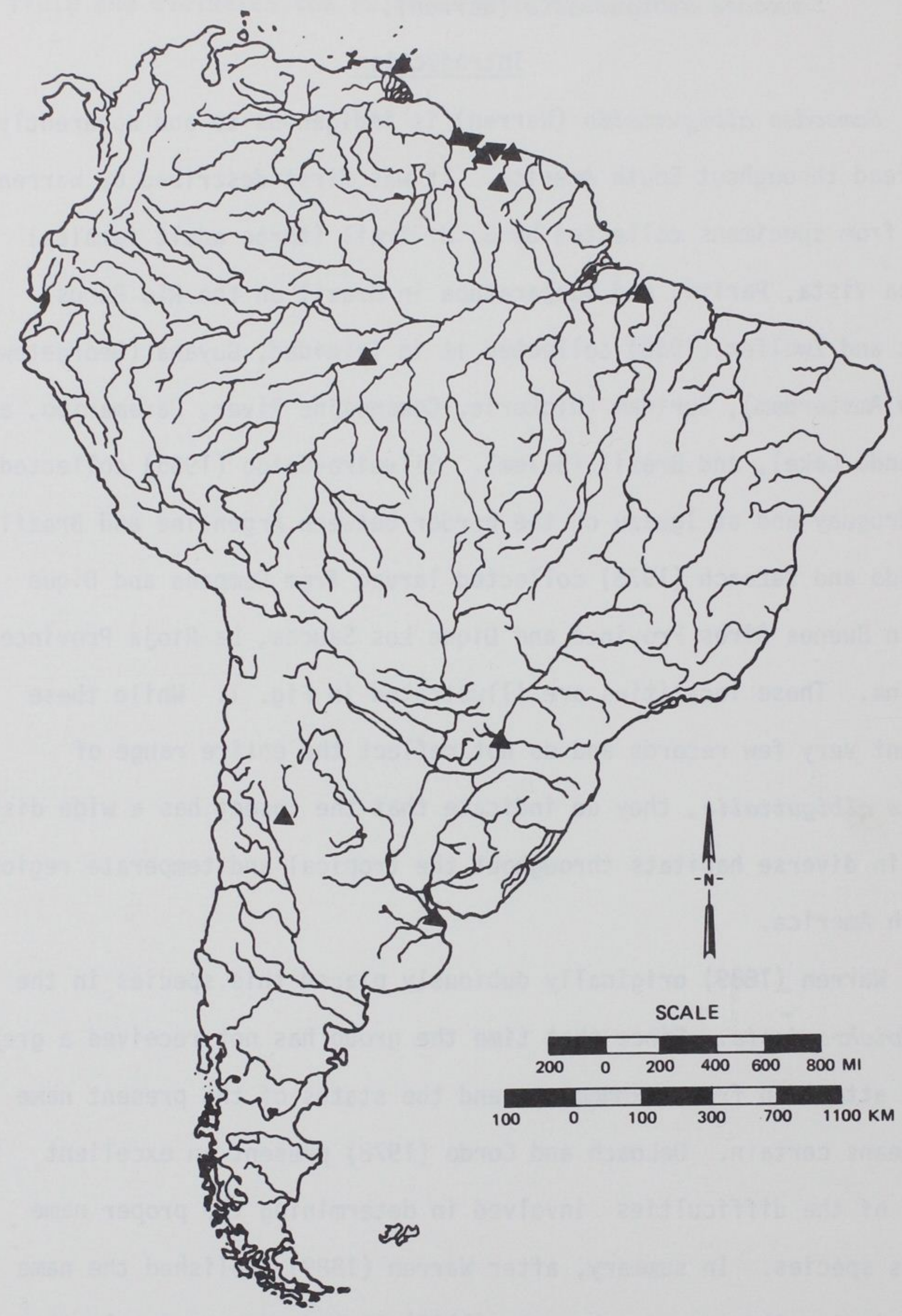

Figure 1. Map of South America showing the known collection localities of Scomeodes albiguttalis (Warren) 
in major collections in the U. S. and Great Britian. Hampson (1918)

regarded Scomeodes as a synonym of Epipagis but he did not actually transfer the species to this genus. The combination Scomeodes albiguttalis was first published in a list of the lepidoptera of Uruguay (Biezanko et al. 1957) but it apparently belongs to an unnamed genus and is neither a species of Sameodes nor Epipagis (DeLoach and Cordo 1978). For want of an alternative, it is advised to continue usage of the name Scomeodes albiguttalis (Warren) for the present.

\section{General Characters of the Pyralidae}

7. Someodes albiguttalis is in the family Pryalidae, a very diverse group which includes over 1100 species in North America. Adults of this family are separated from others by the elongate or triangular fore wings, the cubitus appearing 4-branched, and the usually broad hind wings. Veins Sc and $\mathrm{R}$ of the hind wings are close together and parallel opposite the discal cell (base of R usually atrophied), and are fused or closely parallel for a short distance beyond the discal cell. The labial palps project anterior to the head giving the appearance of a snout (Borror and Delong 1971).

8. The larvae of this family are generally characterized by a more or less uniform color, or are spotted due to pigmented maculations or pinacula at the bases of the primary setae. Most setae are primary and secondary setae are few or lacking, the presipiracular group is bisetose and the SV group on the mesoand metathorax is usually unisetose. Short prolegs are present on the $3 r d-6$ th and 10th abdominal segments. The crochets may be uniserial biordinal (occasionally triordinal, rarely uniordinal), arranged in two transverse bands, in a complete circle or in a mesopenellipse. 


\section{General Characters of the Pyraustinae}

9. The Pyralidae are subdivided into several subfamilies and Scmeodes is included in the subfamily Pyraustinae. Forbes (1923, pp. 541-542) describes the adults of this subfamily as follows:

"Head smooth; ocelli present. Male antennae normal with a few exceptions. Front very often oblique, extending out below, in a few genera conical and in some western and exotic forms with a specialized process. Tongue strong, scaled; maxillary palp̈i small but distinct, rarely if ever as long as second segment of labial palpi. Labial palpi of various shapes usually with short third joint. A distinct row of scales between antennal socket and eye. Hind tibae sometimes with the outer spurs in the male rudimentary. Fore wing usually triangular, ample, rarely as bluntly rounded as in the Glaphyriinae, narrow in Nomophiza. Hind wing of moderate size, ample in Nomophiza. Fore wing with $R_{1}$ and $R_{2}$ free, $R_{3}$ and $R_{4}$ stalked except in a couple of exotic genera; $R_{5}$ free, often approximate to $R_{3}+4$ at the base, $M_{1}$ approximate to $R_{5}$. Hind wing with Sc and $\mathrm{R}$ anastomosing except in upper angle of cell; Cu with a very slight fringe at base, or none; frenulum of female multiple. All veins present in both wings."

\section{Description of Sameodes albiguttalis}

Egg

10. Eggs dissected from the female are irregularly shaped with a soft chorion, creamy white, with no apparent distinguishable markings (a punctate pattern is present but not readily distinguishable). The shape varies from spheroid to ovoid to cuboid. After oviposition, the ventral 
surface is flattened and conforms to the shape of the substrate. Length ca. $0.41 \mathrm{~mm}$ (range $0.35-0.45 \mathrm{~mm}$ ), width ca. $0.35 \mathrm{~mm}$ (range $0.29-0.39 \mathrm{~mm}$ ). Larva (5th instar)

11. Head: subspherical, dark orange-brown with darker brown mottling forming a convoluted pattern on the cranium (Fig. 2). Unmottled area extending from the antennae mesad of setae P1 and P2 and along the crest of the expcranium, encompassing the ultraposterior punctures, setting off a dark mottled area at vertex and appearing as a lighter stripe dorso-medially. Short dark mottled line extending anteriorly from alveolus ring of $\mathrm{Pl}$ to a line drawn from A2 to AFl. Ocellar area dark brown to black forming a dark lateral crescent encompassing ocel1i 1-5 and anterior portion of ocellus 6 . Ocellus 5 projecting slightly cephalad of a circumscribed ocellar semicircle. Ocelli 1 and 2 separated by ca. 1/2 the width of ocellus 2, ocelli 3-5 nearly contiguous, ocelli 5 and 6 separated by a distance greater than the width of ocellus 5 . Ocellus 6 weak, less distinct and separated by seta S02 from ocellus 5. Small distinct notches present on postero-lateral borders of head capsule on posterior border of a dark brown to black area extending ca. 1/2 distance to ocellus 1 . Anteclypeus transparent white, postclypeus orange. Adfrontal and frontal sclerites extend ca. $7 / 8$ and $3 / 4$ distance, respectively, to vertical angle. Brownish adfrontal sclerites strangly tapered anteriorly. Frons orange, as broad at base as 1ong. Labrum orange-brown, acutely notched, notched edged with dark brown or black. Mandible orange-brown at base, red-brown to black distally along cutting margin. Mesal aspect nearly circular in outline, strongly concave. Six distinct dentes along cutting margin, the dorsal most folded at the right angle to the others, and the third dente somewhat longer than the 

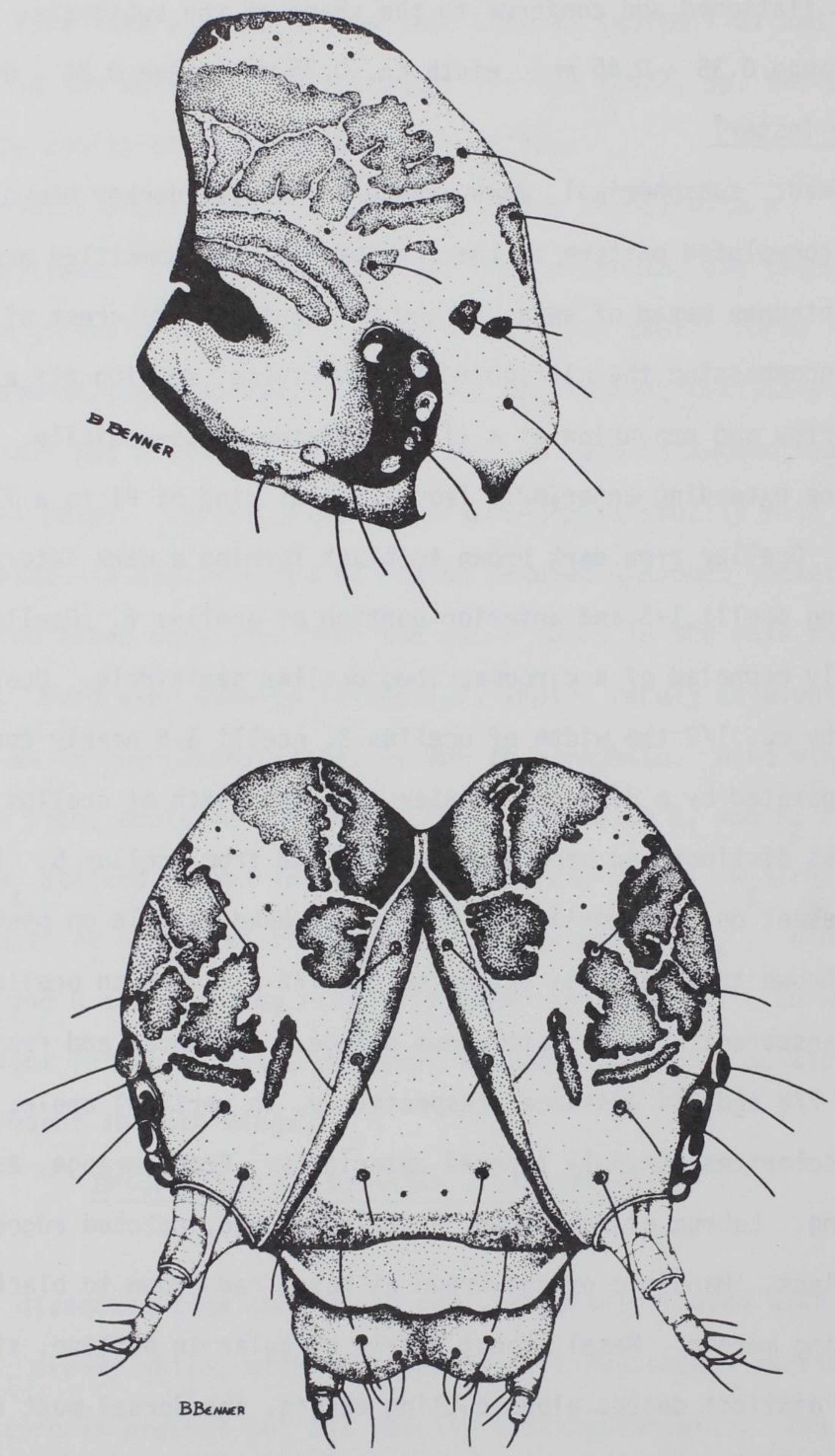

Figure 2. Frontal and lateral views of the head of a 5 th instar $S$. albiguttalis larva 
others, the 6th dente wide with a marginal proximal serrated area along the cutting edge with 5-6 small teeth. Three smaller dentes proximal to the first on the dorso-proximal edge. Spinneret pale brown, pointed anteriorally, elongate, at least $5 \mathrm{X}$ as long as broadest point, ca. $1.5 \mathrm{X}$ as long as labial palpus. Hypopharynx densely spined along the distal and proximo-lateral margins, sparsely so proximomedially. Labial palpi yellow-brown, second antennal segment pale whitish-yellow, sensillum trichodeum as long or longer than antenna.

12. Head setae P2 ca. 1.3X farther apart than P1, seta AF2 slightly closer to AFI than to $\mathrm{PI}$, distance between $\mathrm{AF} 2$ and $\mathrm{P1}$ more than $1.5 \mathrm{X}$ that between $A F 1$ and $P 1$, setae $A F I$ and $F 1$ equidistant and at right angles to one another lying on the corners of an inscribed square. Fa puncture below F1 setal line and ca. 1/3X as far apart as F1 setae; C2 setae about 1.3X farther apart than FI setae; setae A2 slightly closer to Al than to A3 and forming an oblique angle; seta A3 3-5X length of A2. Seta S02 between and slightly below ocelli 5 and 6 ; 01 seta posterior to ocellus 3 , 02 seta postero-ventrad of ocellus 1 , seta 02 directly posterior to 01 , seta $012 \mathrm{X}$ distance from 03 than from 02 , the three forming a right angle.

Thorax

13. Prothoracic shield broad, pale yellow edged with brown, divided medially, and with scattered small dark brown blotches (Fig. 3). Small patches of minute dark spinules with a central bare area apparent under high magnification between and anterior to the dorsal and subdorsal pinacula on segments T2 and T3. Prothoracic spiracle oval, peritreme dark, ca. 1.5X height of Al spiracle. Thoracic legs light yellow or cream, 

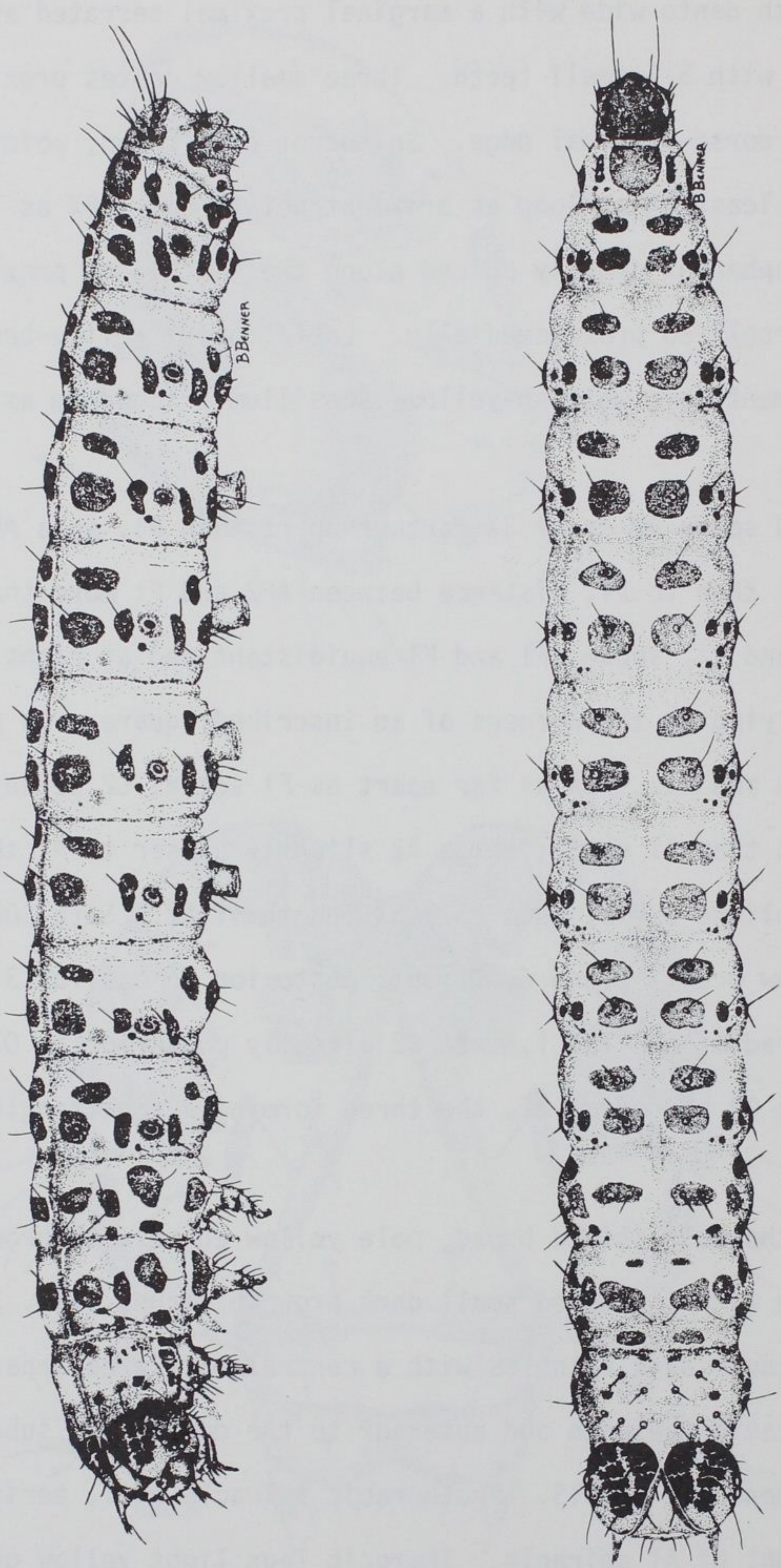

Figure 3. Dorsal and lateral views of a 5 th instar Someodes albiguttalis larva 
tarsus slightly darker, tarsal claw orange-brown, coxae brown, heavily sclerotized, open on dorsal margin. Seta XDI antero-ventrad of seta DI; setae XD1, XD2, and D2 equidistant from one another, seta $L 1$ antero-ventrad of spiracle. Seta DI postero-dorsad of seta D2, L1 closer to L2 than to L3;

L1 and L2 on the same pinaculum and L3 on a separate pinaculum on segments $A 2$ and $A 3$.

Abdomen

14. Spiracles oval, peritreme dark, $A 1$ and $A 7$ spiracles ca. $2 / 3$ height of $\mathrm{Tl}$ spiracle, spiracles A2 - A6 ca. 1/2 height of $\mathrm{Tl}$ spiracle, spiracle A8 equal height to $\mathrm{Tl}$ spiracle. Anal shield broadly triangular, grayishbrown to orange-brown with scattered dark brown blotches, notched on cephalad margin medially (Fig. 4). Ventral prolegs on A3-6 and A10, crochets brown, uniserial, triordinal arranged in a mesal penellipse with 33-34, 33-44, $34-42,37-40$, and 28-36 crochets, respectively. Distance between the sclerotized pinacula of setae $D I$ on each segment less than $\mathrm{ca} .1 / 4$ the lateromesal width of the pinaculum. Seta DI on anterior half of abdominal segments and seta D2 on posterior half postero-ventrad of D1 on segments A1-8; D1 anteroventrad of D2 on segment A9, distance between D1 and D2 $2 X$ greater on A6 than on A9; seta SDI dorsad of spiracle; spiracle intersected by a line from seta $L 1$ to seta SDI on segments Al-A6. Seta SD2 much reduced and anterodorsad of spiracle. D2 setae farther apart than D1 setae. Sma11 patches of dark spinules as described for segments $\mathrm{T} 2$ and $\mathrm{T} 3$ also present on segments Al-A8 anterior to and between the dorsal pinacula and antero-ventrad of seta DI on segment A9.

Diagonstic characters for determining larval instar

15. First instar. Head width $0.18-0.24 \mathrm{~mm}(\bar{x}=0.21$, S.D. $=0.02)$ 


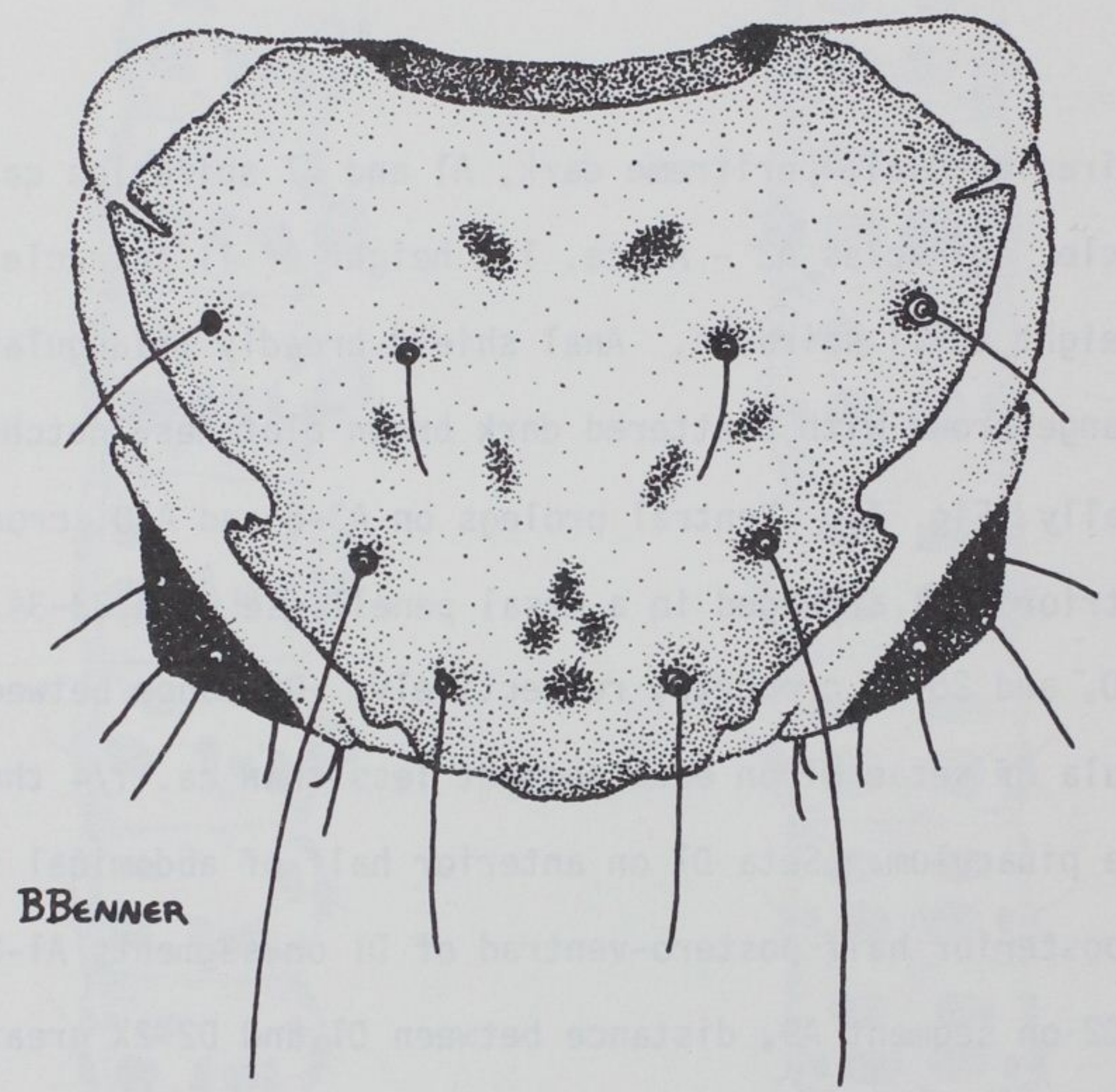

Figure 4. Dorsal view of the anal plate of a 5 th instar Sameodes albiguttalis larva 
head length $0.22-0.30 \mathrm{~mm}(\bar{x}=0.26$, S.D. $=0.02)$, total length $1.4-2.4$ mm $(\bar{x}=1.96$, S.D. $=0.32)$. Head dark brown lacking mottled pattern; prothoracic shield dark brown, notched postero-medially but not divided, fairly evenly colored, darker blotches present but indistinct. Pinacula smal1, space between dorsal pinacula on segment Al $2 X$ width of pinacula and occupying $2 / 3$ the distance between DI setae.

16. Second instar. Head width $0.24-0.36 \mathrm{~mm}(\bar{x}=0.38$, S.D. $=0.03)$ total length $1.8-4.2 \mathrm{~mm}(\bar{x}=3.04$, S.D. $=0.74)$. Head brown, unmottled or mottled pattern vaguely distinguishable; prothoracic shield brown, undivided, blotched with darker brown, notched postero-medially. Pinacula small, space between dorsal pinacula on segment Al 1.5 - $2 \mathrm{X}$ width of pinacula and occupying $1 / 2$ distance between $D 1$ setae.

17. Third instar. Head width $0.40-0.64 \mathrm{~mm}(\bar{x}=0.53$, S.D. $=0.06)$, head length $0.48-0.72 \mathrm{~mm}(\bar{x}=0.59$, S.D. $=0.07)$, total length $3.2-8.0$ $\mathrm{mm}(\bar{x}=4.74$, S.D. $=1.22)$. Head brown with indistinct mottled pattern; prothoracic shield light brown with darker blotches, undivided but notched postero-medially and with a distinct, lighter medial line. Pinacula small, space between dorsal pinacula on segment Al $1.5 \mathrm{X}$ width of pinacula and occupying ca. 1/2 distance between DI setae.

18. Fourth instar. Head width $0.64-0.96 \mathrm{~mm}(\bar{x}=0.84$, S.D. $=0.08)$ head length $0.80-1.12 \mathrm{~mm}(\bar{x}=0.94$, S.D. $=0.10)$, total length $5.2-$ $12.0 \mathrm{~mm}(\bar{x}=7.92$, S.D. $=1.80)$. Head yellow to yellow-brown with a distinct brown mottled pattern on epicranium; prothoracic shield pale yellow, nearly white, mottled with brown, with a distinct lighter medial line, appearing divided but anterior margin distinctly entire. Pinacula large, 
space between dorsal pinacula on segment Al ca. 1/4 X width of pinacula and occupying ca. 1/4 distance between DI setae.

19. Fifth instar. (Figure 3) Head width $0.90-1.50 \mathrm{~mm}(\bar{x}=1.42$, S.D. $=$ $0.15)$, total length $8.0-18.0 \mathrm{~mm}(\bar{x}=14.16, S . D .=2.16)$. Head orange to orange-brown with distinct brown mottled pattern on epicranium; prothoracic shield pale yellow to yellow-brown with distinct darker blotches, completely divided medially. Pinacula large, space between dorsal pinacula on segment Al ca. 1/4 X width of pinacula and occupying ca. 1/6 distance between DI setae.

Pupa (Figure 5)

20. General. Length $9.6-12.6 \mathrm{~mm}(\bar{x}=11.2$, S.D. $=0.30)$, width 2.6 $3.6 \mathrm{~mm}(\bar{x}=3.1$, S.D. $=0.30)$. Integument mostly punctate.

21. Color. Living pupae dark réd-brown, nearly black, caudal half segments A4 - A6 orange, segments A8 - A10 black. Anterior margin of abdominal segments dark brown to black. Spiracles red-brown. Vental surface of thorax red-brown, generally lighter than dorsum. Fore wings dark red-brown. Preserved specimens orange to yellow brown.

22. Head. Width (ventral measurement across widest point of eyes) 1.4 $1.9 \mathrm{~mm}(\bar{x}=1.6, S . D .=0.1)$; length of maxillae $5.5-6.8 \mathrm{~mm}(\bar{x}=6.2$, S.D. $=0.3$ ) extending to the caudal margins of the fore wings; sclerites of the vertex nearly rectangular, the medial edge somewhat shorter (ca. 3/4) than the distal edge, contiguous along medial line. Labrum distinctly 3-lobed, pilifers contiguous. Labial palpi present. Antennae extend to caudal margin of fore wing in males, ending a distance cephalad of the caudal margin of the fore wing equal to the distance between the apices $(0.6-0.8 \mathrm{~mm})$ in the female. 


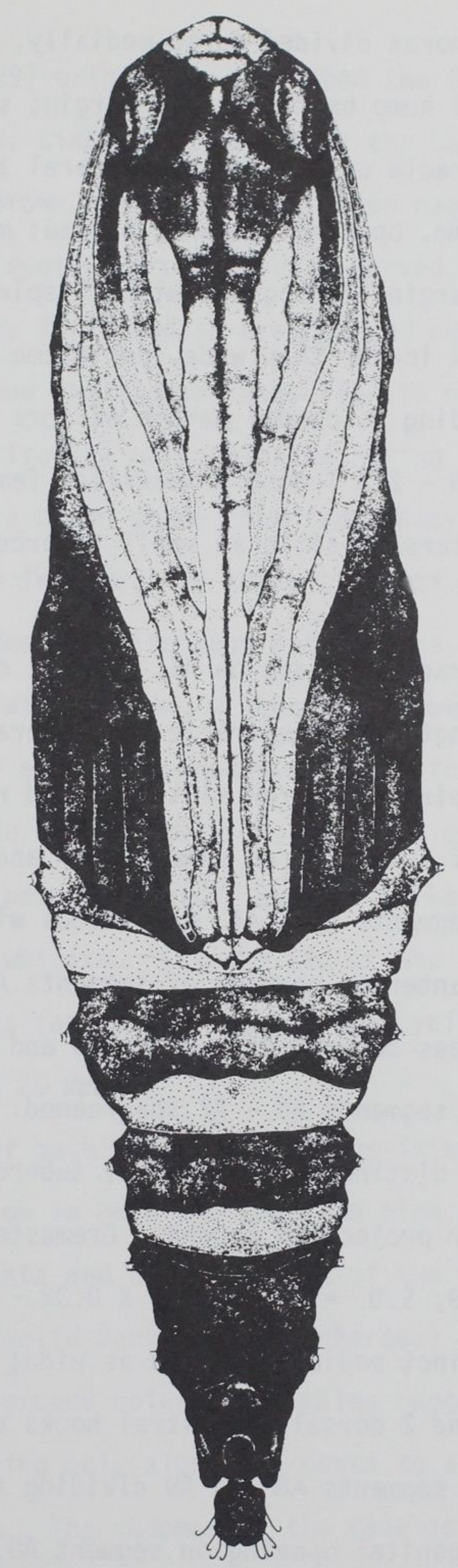

Figure 5. Ventral view of a male someodes albiguttalis pupa 
23. Thorax. Prothorax divided dorso-medially, dorso-medial ridge on T3 and a distinct dorsal hump on the caudal margin; spiracles present on T1 and T2; prothoracic spiracle on the postero-lateral tergal margin, crescent shaped, height ca. $0.2 \mathrm{~mm}$, opening somewhat caudad; mesothoracic spiracle on antero-lateral tergal margin, contiguous with $\mathrm{Tl}$ spiracle, elongate elliptical ca. $0.3 \mathrm{~mm}$ in height, $3 \times$ longer than wide, peritreme with dense spinules. Mesothoracic legs extending to caudal margin of fore wings, prothoracic legs extending caudad ca. 5/8 - 2/3 length of maxilla; femora of prothoracic legs visible; apices of 3rd tarsi visible as small tubercular projections caudad of the maxilla.

24. Abdomen. Spiracles absent on $A 1$, present on $A 2-A 8$, oval, all equal length ca. 1/2 length of T2 spiracle, on lateral tubercles, spiracles on A2 - 7 tubular; A8 spiracle narrow slit-like and recessed in tubercle. Tergites rugose mesad of spiracles on segments A2 and A3. Distinct dorsal longitudinal ridge on segments A1 - A4, continuous with ridge on T3. Circumferential ridge on the anterior portion of segments A5 - A7 producing deeply cleft intersegmental areas between $A 4$ and $A 5, A 5$ and $A 6$, and $A 6$ and $A 7$. Posterior $1 / 5$ to $1 / 3$ of segments A4 - A7 shagreened. Segments A8 - A10 dark, shiny, and smooth. Two distinct rugose apical tubercles on segment A10 laterad of the cremaster projecting caudad. Cremaster rugose, rectangular $0.40-0.61 \mathrm{~mm}(\bar{x}=0.49$, S.D. $=0.05)$ long $x 0.32-0.54 \mathrm{~mm}(\bar{x}=0.40$, S.D. $=$ $0.05)$ wide, with a distinct pedicel ca. $1 / 3$ as wide; 2 ventral cremastral hooks curved dorsally and 2 dorsal cremastral hooks curved ventrally. Female with genital opening on segments $A 8$ and $A 9$ dividing the posterior margin of segment A8. Male with genital opening on segment A9, not dividing posterior margin of segment A8, bordered by lateral rounded pads. A pair of distinct alveoli on ventral surface of segments $A 5$ and $A 6$. 


\section{Adult (Figure 6)}

25. Warren (1889) originally described the female as follows:

"Forewing yellow, tinged with brown at the base, along the costa, and hind margin; a brown nearly vertical line near the base preceeded by a faint whitish spot; a brown, double-curved, submarginal line running inwards along the first median branch, and curving again into the inner margin just beyond the middle; this line is edged externally by a series of semi-circular white blotches lying between the veins, which are followed by a brown shade that fades away into the yellow ground color before the fringes; the three stigmata all large roundish, distinct, brown-edged; a white spot between the orbicular and reinform stigmata. Hind wing yellow, without any brown suffusion; with the submarginal line exactly reproduced, and with a large brown central spot. Under side shining whitish, with the markings showing through. Head and thorax pale yellowish; abdomen darker yellow, the incisions of the segments whitish. Extreme tip of the palpi brown. Fringes of both wings, as far as can be made out, yellowish spotted with brown. Expanse of wings $20 \mathrm{~mm} . "$

26. The color of both males and females is extremely variable in the amount of brown suffusion in both the fore and hind wings. The females range from brown along the costa and distal margin of the fore wing with a yellow to gold ground color to a solid dark brown to charcoal gray fore wing with no lighter yellow or gold ground color. The males range from yellow to gold fore wings with brown occurring only along the costa to a distinct brown suffusion along the distal margin. The abdomen of the male is sharply tapered apically 
and is held in somewhat of an upward curve. The abdomen of the female is more tubular apically and is not held in an upward curve. 

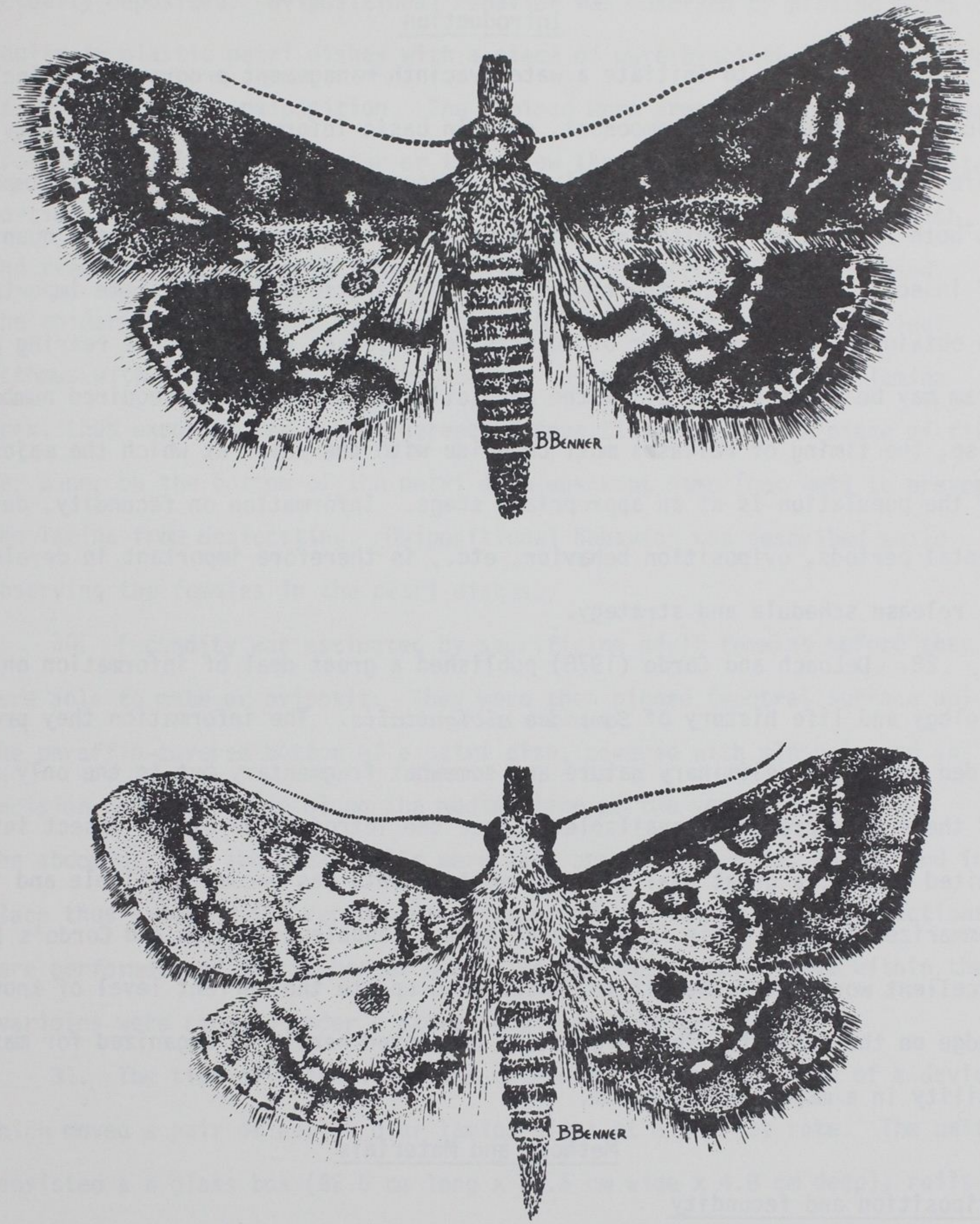

Figure 6. Dorsal views of a female (top) and a male (bottom) Someodes albiguttalis adult 
Section II. Bionomics of Sameodes albiguttalis (Warren).

\section{Introduction}

27. In order to initiate a waterhyacinth management program which includes biological control as a component, certain basic information on the ecology and life history of the insects involved is necessary. This information is important in both release and monitoring programs. In release programs both the quantity of insects liberated and the timing of the liberations is of extreme importance. To obtain the desired number of insects for release, a small-scale rearing program may be necessary to allow the population to build to the required numbers. Also, the timing of releases must coincide with the point at which the majority of the population is at an appropriate stage. Information on fecundity, developmental periods, oviposition behavior, etc., is therefore important in developing a release schedule and strategy.

28. DeLoach and Cordo (1978) published a great deal of information on the biology and life history of Someodes albiguttalis. The information they provided was of a preliminary nature and somewhat fragmentary but is the only source of these data presently available. Since the introduction of the insect into the United States, a great deal of supplementary data has become available and is summarized herein. This is not an attempt to supplant DeLoach and Cordo's (1978) excellent work but rather it is intended to update the current level of knowledge on the subject. The information presented herein is organized for maximum utility in a management program.

\section{Methods and Materials}

Oviposition and fecundity

29. The purpose of these data is to describe the ovipositional behavior of the female and the sites selected for oviposition, to determine the quantity 
of eggs a female is capable of producing, and to determine the number of eggs actually deposited. Ovipositional behavior was observed by placing pairs of adults in plastic petri dishes with a piece of waterhyacinth lamina prepared as a substrate for oviposition. The laminae were prepared by severing them from the petioles a centimeter or two below the isthmus, trimming the distal portion of the lamina to enable it to fit into a 100 - by $15-\mathrm{mm}$ petri dish, and removing the epidermis from the thicker basal portion of the lamina. The epidermis was removed by grasping a thin layer of tissue on the leaf isthmus with fine-tipped jewelers forceps and pulling towards the lamina apex, thus exposing the spongy aerenchymatous tissue below. A piece of filter paper on the bottom of the petri dish was kept damp (not wet) to prevent the lamina from desiccating. Ovipositional behavior was described while observing the females in the petri dishes.

30. Fecundity was estimated by sacrificing adult females before they were able to mate or oviposit. They were then pinned (ventral surface up) to the paraffin-covered bottom of a petri dish, covered with alcohol, and an incision carefully made along the median line of the ventral surface of the abdomen. The abdominal walls were laid open to the sides and pinned in place thus exposing the reproductive system of the female. The dissections were performed and the number of ovarioles and the number of ova within the ovarioles were counted under a stereoscopic microscope.

31. The time of oviposition was determined through the use of a device which moved a pair of adults over lamina disks at a pre-set rate. The unit consisted a a glass box $(62.5 \mathrm{~cm}$ long $\times 25.5 \mathrm{~cm}$ wide $\times 4.8 \mathrm{~cm}$ deep), rails constructed from glass tubing and mounted lengthwise in the box, a sled (which rode on the rails) with 4 chambers $(3 \mathrm{~cm} \times 2.5 \mathrm{~cm} \times 2.5 \mathrm{~cm}$ ) which were open on the bottom, and an electric timer (Fig. 7). A line attached to 


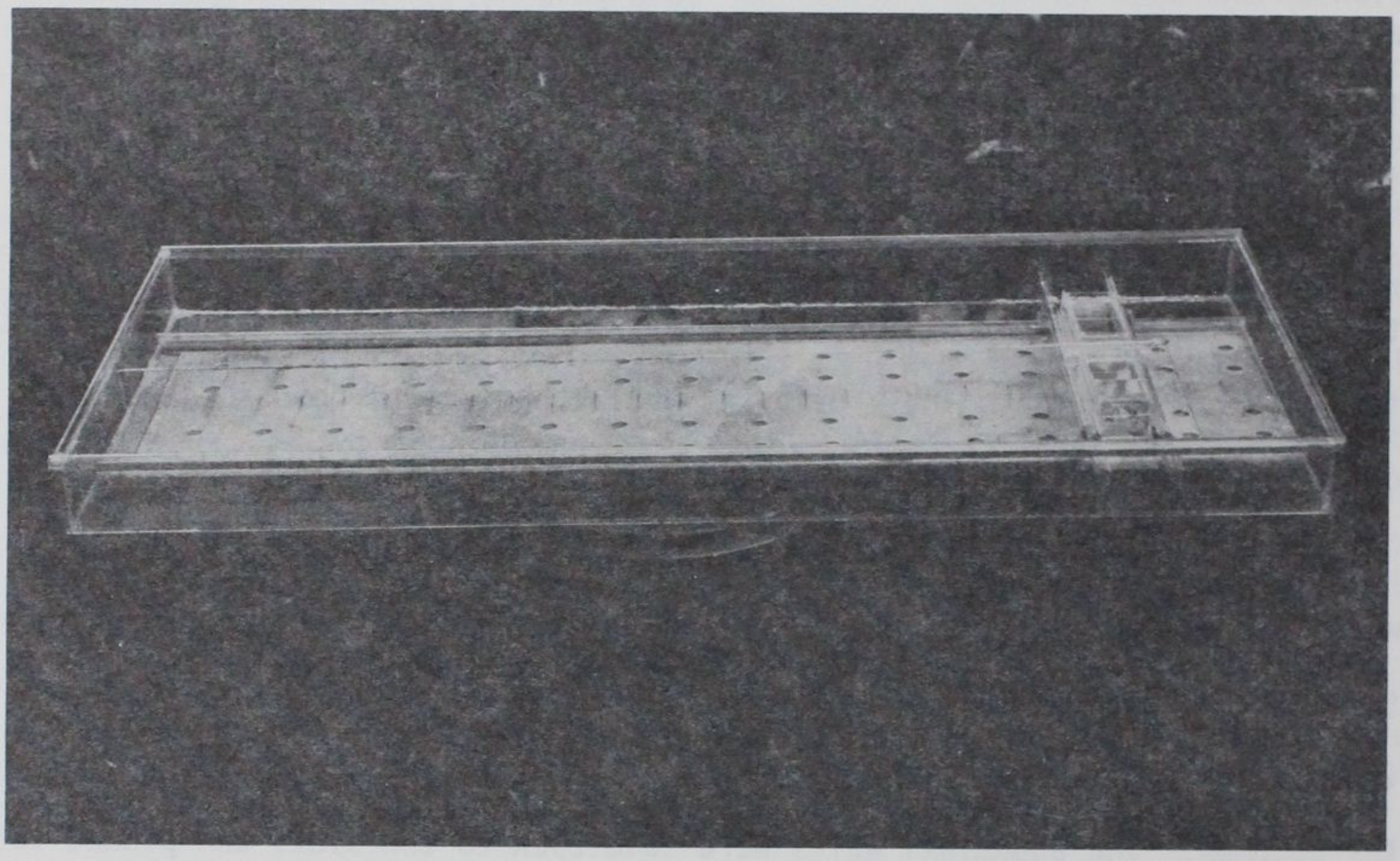

a. Sled being pulled over the template by a line attached to a pulley on a timer

Figure 7. Ovipositional timing unit used to determine the periodicity of oviposition rates of $S$. albiguttalis (Continued) 


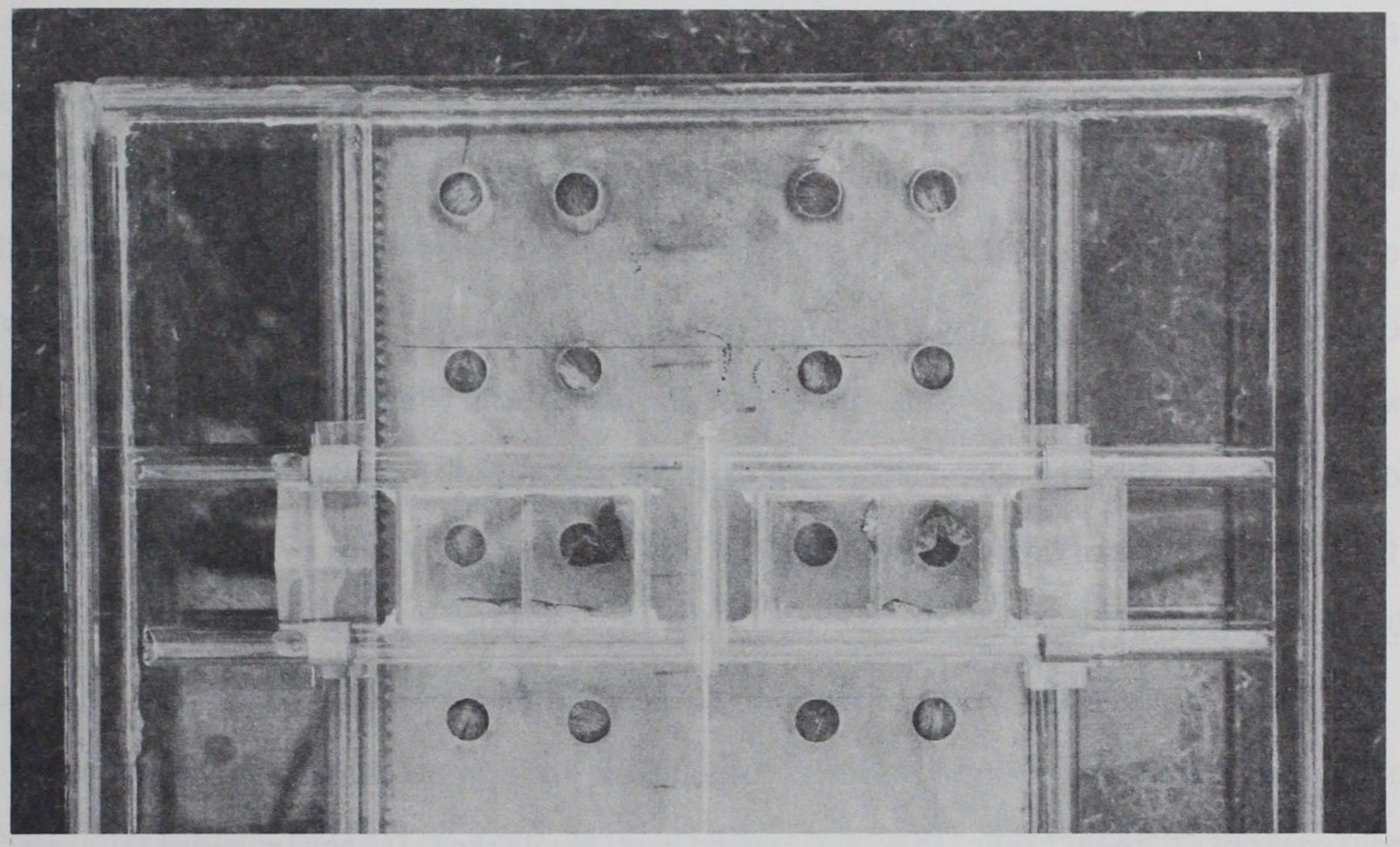

b. Close-up of the adults in the sled, leaf disks under the holes in the template

Figure 7. (Concluded) 
the sled was taken up on a $20-\mathrm{cm}$ pulley mounted on the dial of the timer thus pulling the sled along the rails the length of the box at a constant rate $(0.365 \mathrm{~mm} / \mathrm{min})$. In use, four rows of lamina disks (one for each sled chamber) with the epidermis removed from the upper surface were placed in a line at even intervals along the length of the box. A plastic template with holes $(1 \mathrm{~cm}$ diam) spaced $2.0 \mathrm{~cm}$ apart was placed over the leaf disks. The sled was placed over one end of this template with the open bottoms of each chamber over a hole and lamina disk. A virgin female was paired with a male in each sled chamber and the timer was activated, thus gradually pulling the chambers over successive lamina sections. The female moth was free to oviposit in the exposed aerenchyma as she was moved over each section. The lamina sections were later removed, the time interval during which the adults were over each disk determined, and the number of eggs on each disk counted. This was continued until the death of the female.

Developmental times

32. Two studies were conducted to determine the duration of the stadium of various instars. The first was conducted in a greenhouse under ambient environmental conditions and the second was conducted in environmental chambers under constant conditions of light and photoperiod.

33. For the environmental chamber studies, cages were constructed from 15.25-cm-diam, clear acrylic cylinders. A square flat piece of acrylic was glued to the end of a short $(\mathrm{ca} .15 \mathrm{~cm})$ piece of cylinder to serve as a base. The outside surface of the cylinder around the open end of the base was milled so that a second piece of cylinder (of slightly larger diameter) could be slipped over it. A waterhyacinth plant was placed in each base which was filled with Hoagland's nutrient solution, and the second section of the acrylic cylinder was placed over the plant and on the base. The top of the cage was covered with screen. The end result was a waterhyacinth 
plant growing in nutrient solution and housed within a plastic tube. The tubes with plants were placed in four environmental chambers (10 plants per chamber) which were set at a constant temperature of $20^{\circ}, 25^{\circ}, 30^{\circ}$, or $35^{\circ} \mathrm{C}$ and a 14:10 L:D photoperiod. Eggs were obtained in oviposition cages (petri dishes with lamina sections as described above) and were held in the environmental chambers until they hatched. The neonates were removed and $1^{0}$ were placed in each acrylic cage on the enclosed waterhyacinth plant. At 4-day intervals, one cage was removed from each environmental chamber, the plant dissected, and the larvae removed. The head capsule width, total length, and weight of each larva were measured and the larvae were preserved in $70 \%$ ethanol.

34. For the greenhouse study, waterhyacinth plants were collected from a site which was free of any infestation of $S$. albiguttalis. Three greenhouse benches, which had been increased in depth to $\mathrm{ca} .30 \mathrm{~cm}$, lined with plastic, and filled with water, were stocked with the field-collected plants. Pupae of $S$. albiguttalis were collected and the adults which subsequently emerged were paired in oviposition cages as described above. The eggs which were collected were held in the laboratory and checked daily. Neonates collected each day were placed on the plants on one of the benches for three successive days with each new group on a separate bench. This enabled the age of the larvae on each bench to be known and larvae of three successive ages, one day apart, were constantly available. One day after the larvae were placed on the last bench, 15 larvae were harvested from each bench, thus providing a sample of 1-, 2-, and 3-day-old larvae. Sampling continued every third day until all of the individuals recovered were pupal exuviae (indicating that the generation was complete) and samples of 
larvae or pupae had been collected for each day of age throughout the generation. Immediately after collection, each larvae was weighed and the width and length of $i$ ts head capsule and its total length were measured. Larval instars were first separated by inspection and then by cluster analysis using the above measurements converted to natural logarithms.

\section{Results}

\section{Oviposition and fecundity}

35. Many attemps were made to observe a gravid female in the act of oviposition, but this behavior was only observed on one occasion. Generally, oviposition occurred during the night and, in this one instance, the adults had been placed in subdued light. The fact that this is apparently a nocturnal or crepuscular behavior makes it very difficult to observe.

36. The female, while searching for oviposition sites, would rapidly walk over the lamina surface in an erratic, zig-zagging pattern. While engaging in this searching pattern, the tip of her abdomen would be held in contact with the leaf surface and she would rapidly wave it from side to side as she walked forward. She would continue actively searching in this manner as long as she was on the smooth leaf surface but, upon coming in contact with an abrasion or opening in the epidermis, she would stop and probe the exposed aerenchyma with her ovipositor while directing the posterior tip of her abdomen ventrally. If the opening was satisfactory, she would either continue probing in the exposed aerenchyma or resume her searching pattern. Eggs were always extruded individually, although she would often place several together overlapping one another. Figure 8 shows an $X$-ray image of a leaf contained in a petri dish in which extensive oviposition has occurred. It should be noted that the eggs are placed in the 


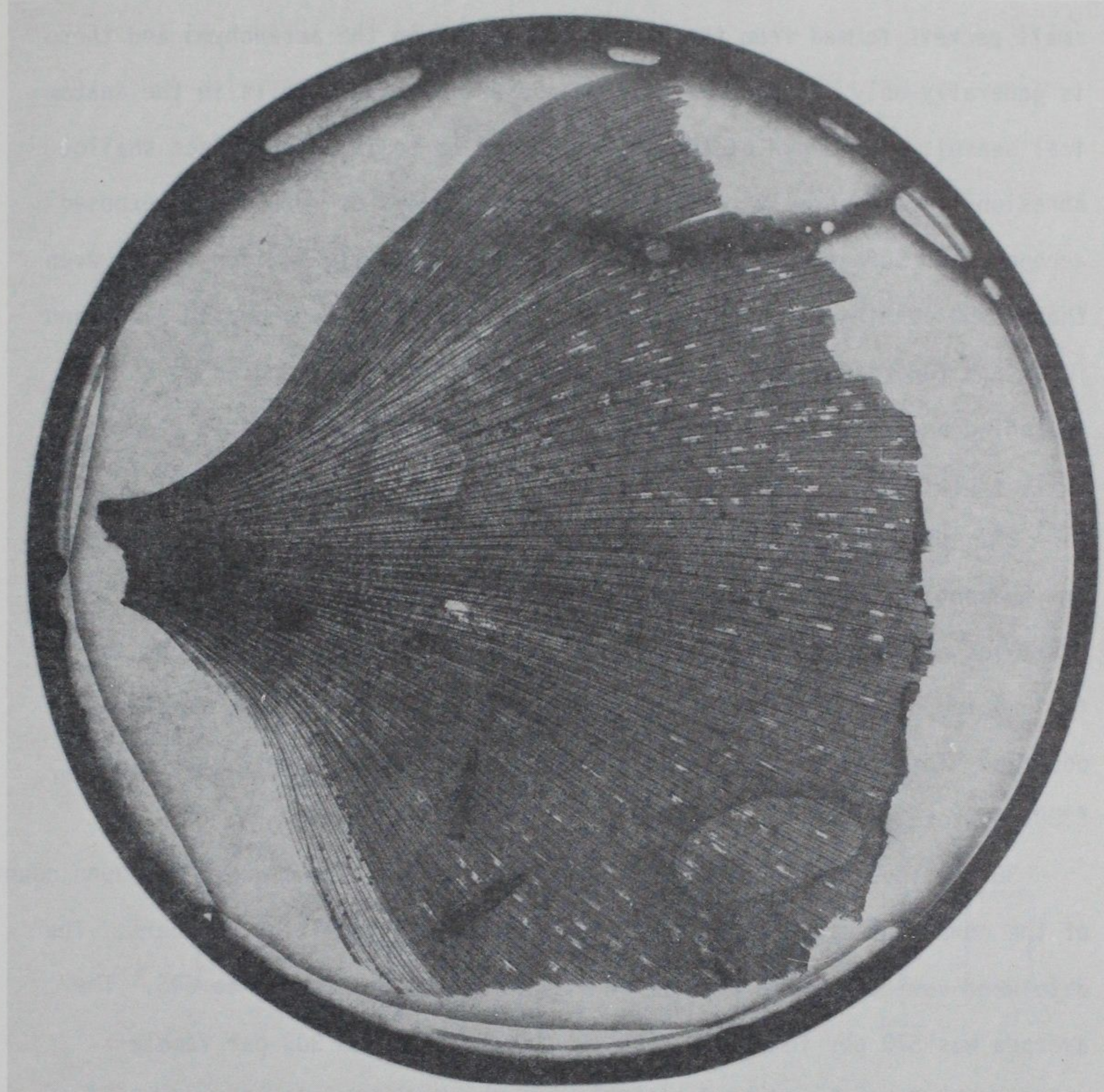

Figure 8. A radiograph of a piece of waterhyacinth lamina from which the epidermis has been removed to serve as a substrate for oviposition by the adult female $S$. albiguttalis. The eggs are apparent as dark spots between the veins concentrated in the basal portion of the lamina. The white spots on the distal portion are waterhyacinth mite (Orthogalumna terebrantis) galleries, many of which contain the immature mites (dark spots). These galleries are suspected oviposition sites for

S. albiguttalis. The images of the adult moths are evident on the right on the lower surface of the lamina. The larger of the two is the female 
small pockets formed from the air-filled spaces in the aerenchyma and there is generally only one egg per cell (these are not truly cells in the anatomical sense). The depth of the pocket seemed to be important since shallow abrasions were generally rejected in favor of areas of more deeply exposed aerenchyma. Suitable oviposition sites were apparently limited since, even though she continued searching and probing, she steadily accepted fewer and fewer and fewer sites and extruded fewer eggs, thereby spending more time searching and less time ovipositing, as the more favorable sites became fully exploited.

37. Dissections of virgin females revealed that fully developed eggs are present in the ovarioles very soon after emergence from the pupa. Eight ovarioles are present which generally contain $600-700$ follicles. As is typical in polytrophic ovarioles, the distal follicles contain immature oocytes. The proximal $50 \%$ appear to contain mature or nearly mature ova (300-400 total).

38. Ovipositional data are illustrated in Fig. 9 and are based upon counts of the number of eggs deposited by 55 females in oviposition chambers. The data were variable and the number of eggs laid ranged from 0 to 646 . The average was 370 per female (S.D. $=138$ ) as compared to 309 per female reported by DeLoach and Cordo (1978), but the mode was with the range of 400-450. Approximately $70 \%$ of the eggs were deposited within two days after the female had emerged from the pupa, and both females and males lived an average of four days (maximum 6).

39. The sites selected for oviposition by females in a natural situation are difficult to determine, primarily because the eggs are seldom found on field-collected plants. DeLoach and Cordo (1978) found, in laboratory tests, 


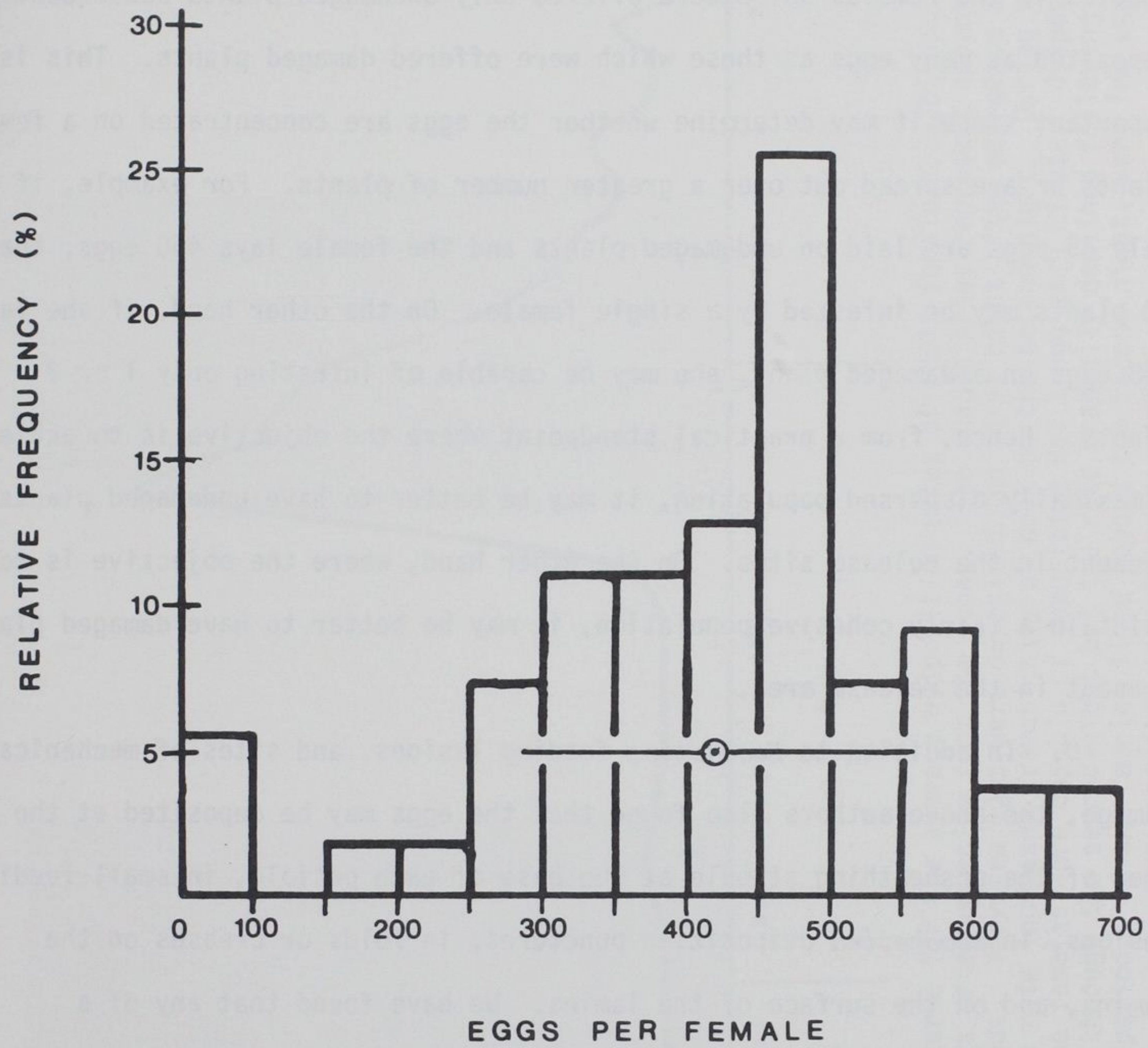

Figure 9. Relative frequency histogram representing the number of eggs deposited per adult female $S$. albiguttalis. The circle and horizontal line represent the mean and standard deviation, respectively. It should be noted that while the mean is ca. 400 eggs/female, the mode falls within the range of $450-500$ 
that the number of eggs deposited on a plant was greater when Neochetina feeding lesions were present and greater still when the petioles were artificially slit as compared to undamaged plants. It is not clear from their studies if the females which were offered only undamaged plants subsequently deposited as many eggs as those which were offered damaged plants. This is important since it may determine whether the eggs are concentrated on a few plants or are spread out over a greater number of plants. For example, if only 45 eggs are laid on undamaged plants and the female lays 450 eggs, then 10 plants may be infested by a single female. On the other hand, if she lays 388 eggs on a damaged plant, she may be capable of infesting only 1 or 2 plants. Hence, from a practical standpoint where the objective is to achieve a maximally dispersed population, it may be better to have undamaged plants present in the release sites. On the other hand, where the objective is to maintain a fairly cohesive population, it may be better to have damaged plants present in the release area.

40. In addition to Neochetina feeding lesions, and sites of mechanical damage, the above authors also found that the eggs may be deposited at the apex of the ensheathing stipule at the base of each petiole, in small feeding lesions, in Neochetina oviposition punctures, in folds or creases on the lamina, and on the surface of the lamina. We have found that any of a variety of soft areas, such as necrotic spots, may also be utilized and, in fact, the females are capable of inserting their ovipositor into the petioles and depositing the eggs directly into the aerenchyma with no previous damage present. This generally seems to be associated with soft, unlignified inflated petioles.

41. Figure 10 illustrates the data for the diel periodicity of oviposition rates and represents an average of 8 females. The data are calculated 


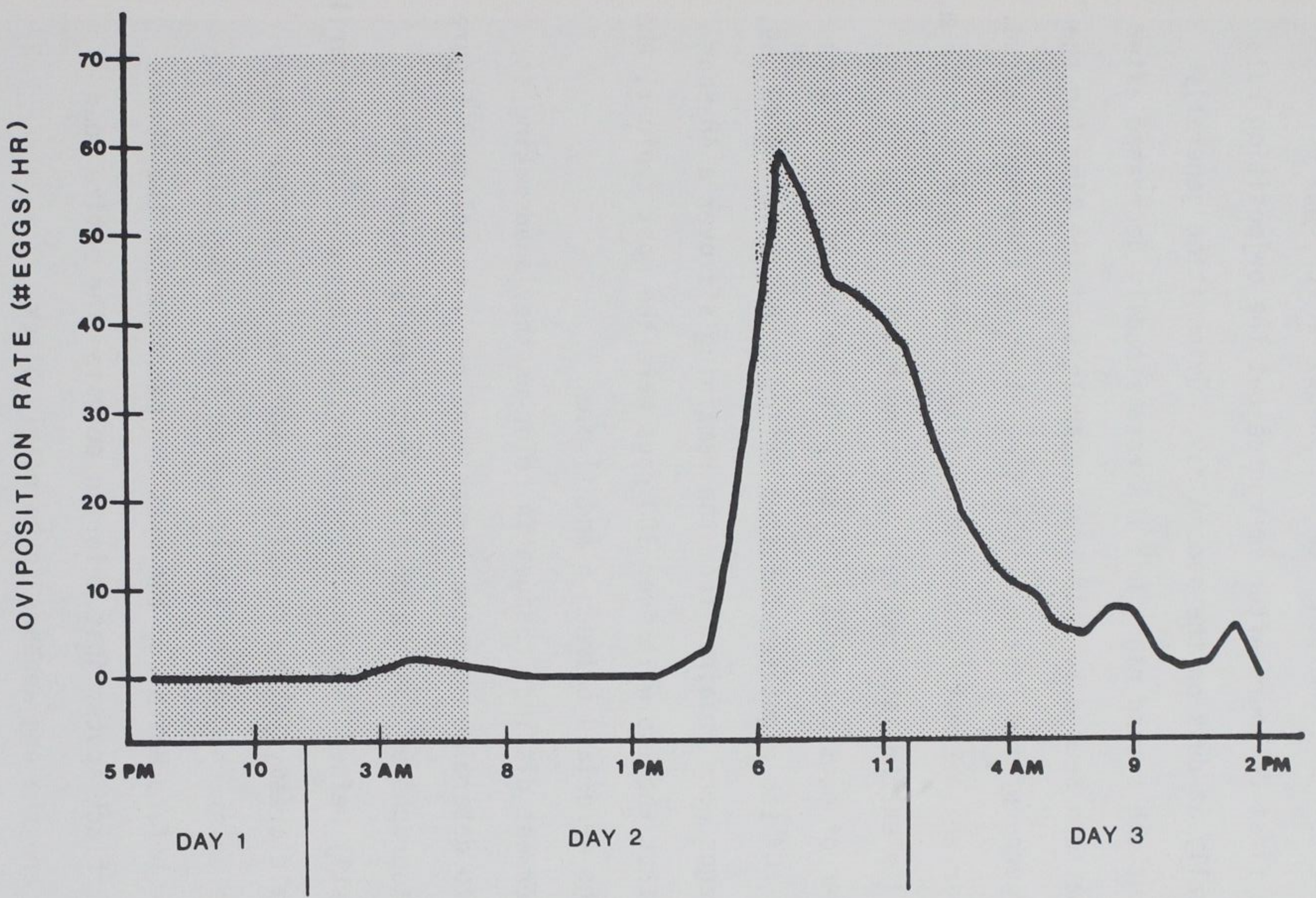

Figure 10. A curve for the average oviposition rates of adult female $S$. albiguttalis the first 3 days after emerging from the pupae. The shaded areas represent approximate dark periods. Very few eggs were deposited the first night after emergence and the oviposition rate increased dramatically at dusk on the second night. During this peak period, the females were capable of depositing ca. 1 egg each minute. Oviposition continued through the second night but the rate gradually declined following the early peak period. If the females lived beyond the second night, very few eggs were deposited on subsequent nights 
as the number of eggs deposited per female per hour. The virgin females were paired with a male immediately before the data collection began and within a few hours after they emerged from the pupae. A few eggs were deposited within the first 24 hours after emergence but the oviposition rate increased dramatically at dusk on the second day. Oviposition generally continued throughout the second night but the rate steadily decreased after ca. 7 p.m. This pattern seemed to hold true regardless of the time (on the first day) of emergence of the female or the time at which they were paired. Peak oviposition varied somewhat, occurring anytime between 5 p.m. and 1 a.m., but did not generally extend into the early morning hours.

42. The number of eggs obtained per female in the oviposition timing unit was variable. Of the eight females, two failed to oviposit and 49, 69, 176 233,318 , and 369 eggs were obtained from the remaining six over a 48-hour period. Assuming that the two with over 300 eggs were the most typical, the majority of the eggs were laid between 5 and 11 p.m.

43. Eggs underwent distinct changes in color as they aged making it relatively simple to determine when the larvae were ready to eclose. Figure 11 consists of photographs of eggs taken daily from several hours after oviposition to shortly before hatching. Initially, the egg consists primarily of yolk and is a pale creamy yellowish-white in appearance. As the embryo becomes larger, the color changes to a pale tan or light brown color. Approximately one day before hatching, the eyes and mandibles of the larvae are visible as dark black spots; just prior to eclosion the entire head capsule is visible and the egg appears to be nearly black. Developmental times

44. Figure 12 illustrates the data for developmental times of S. albiguttalis introduced into greenhouse culture within one day after 
Figure 11. Photomicrograph of $S$. albiguttalis eggs illustrating the change in coloration that takes place as the embryo develops 


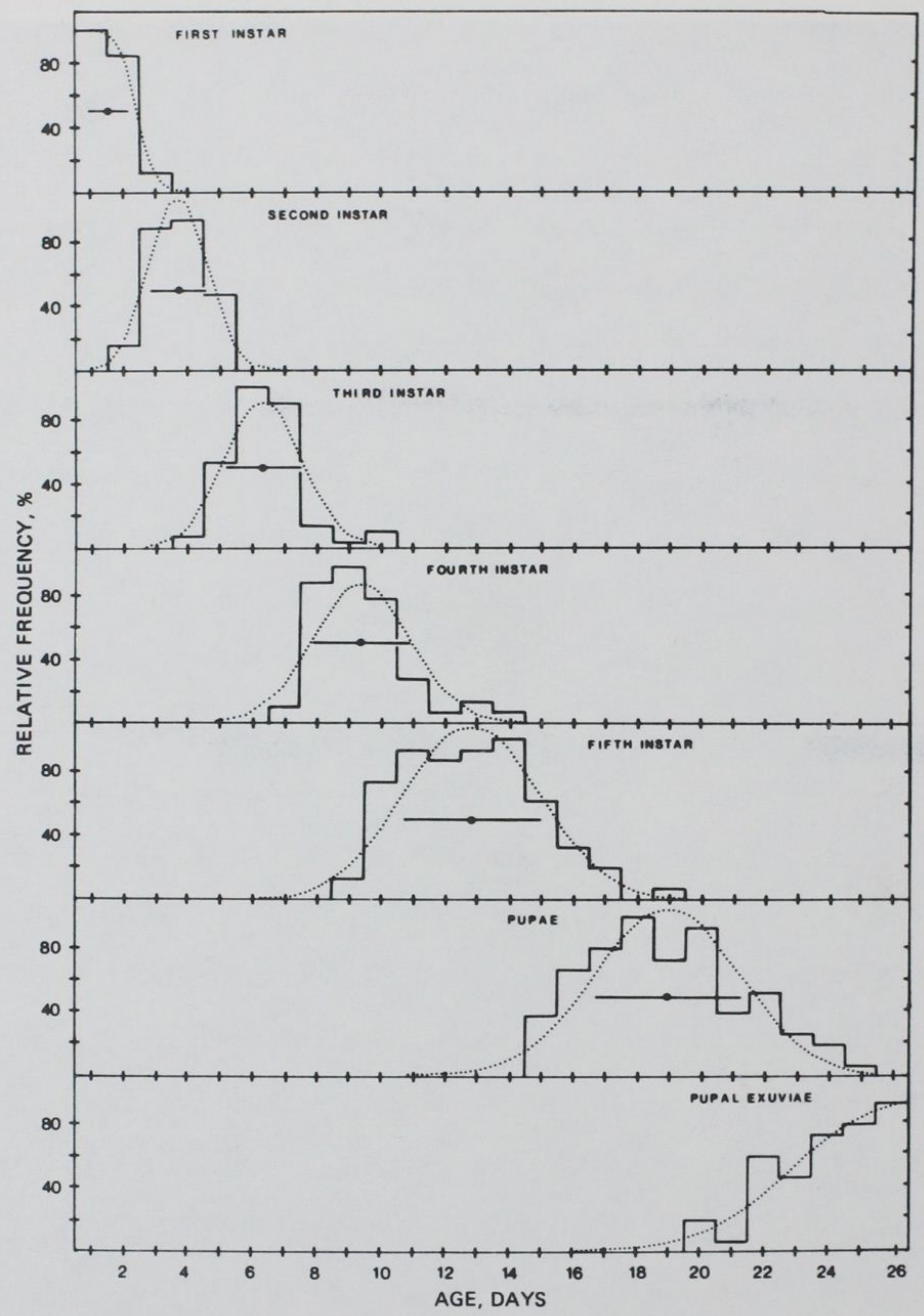

Figure 12. Relative frequency histograms of each S. albiguttalis instar present in the greenhouse culture for each day of age following larval eclosion. The data are based upon a sample of 15 individuals harvested at each day of age. The dot and horizontal bar within each distribution represent the mean and standard deviation for each instar. The dotted line represents calculated hypothetical normal distributions 
eclosion. A11 were first instars initially (Day 0) and on day $1,84 \%$ were first instars on day 2 , and only $12 \%$ on day 3 . Second instar larvae were present on day 2 and peaked on day 4 . Third instar larvae were first collected on day 4 and peaked on day 6 . Fourth instar larvae were first collected on day 7 and peaked on day 9. A single peak for fifth instar larvae was not apparent but they were predominant from day 11 - day 14 and first appeared in the sample on day 9. Pupae peaked between day 18 and day 20 and by day 24 the majority of the population consisted of adults. The population remained fairly synchronous throughout the generation with rarely more than two instars present on any given day.

45. The mean ages of first, second, third, fourth, and fifth instar larvae and pupae were $1.0,3.7,6.4,9.4,13.8$, and 20.0 days, respectively. The stadia as estimated from the differences between the mean ages of successive instars were $2.7,2.7,3.0,4.6,6.2$, and 6.0 days for the first, second, third, fourth, and fifth instar larvae and the pupae, respectively. The total larval developmental period (from eclosion to pupation) was ca. 16-18 days. Since it requires ca. 3 days for the eggs to hatch, 16-18 days for larval development, 6 days for pupation, and assuming a 2-day pre-ovipositional period (DeLoach and Cordo 1978), the approximate generation time (egg to egg under greenhouse conditions) was 27-30 days.

46. DeLoach and Cordo (1978) found the total generation time to be ca. 34 days when reared at $24^{\circ} \mathrm{C}$. It is not unlikely that the somewhat shorter period reported herein was due to the higher temperatures of the greenhouse. Al though ambient air temperature was monitored, the resultant information was of little use since it did not reflect the microenvironment the insects were exposed to, i.e. the temperature within the plant. Ambient air temperature 
within the greenhouse during the 26-day term of this study (20 June to 13 July 1979) ranged from maximums of $31^{\circ}-43^{\circ} \mathrm{C}$ to minimums of $21^{\circ}-26^{\circ} \mathrm{C}$. The water in which the plants were growing was generally within the range of $23^{\circ}-28^{\circ} \mathrm{C}$.

47. To determine the effect of temperature upon the development of $S$. albiguttalis, studies were conducted in controlled temperature cabinets. Eggs hatched $3-4$ days after oviposition at $30^{\circ} \mathrm{C}$ and $4-6$ days after oviposition at $35^{\circ} \mathrm{C}$. None of the eggs held at $20^{\circ} \mathrm{C}$ or $35^{\circ} \mathrm{C}$ hatched. The effects of temperature on the rates of larval development are illustrated in Fig. 13. Development was similar at $25^{\circ} \mathrm{C}$ and $30^{\circ} \mathrm{C}$, al though those at $30^{\circ} \mathrm{C}$ developed somewhat more rapidly. The $20^{\circ} \mathrm{C}$ group was considerably slower with only about $33 \%$ of the pupae having eclosed by day 36 . Comparing pupation between the $20^{\circ}, 25^{\circ}$, and $30^{\circ} \mathrm{C}$ groups, $100 \%$ had pupated at $20^{\circ} \mathrm{C}$ by day 28 , at $25^{\circ} \mathrm{C}$ by day 20 , and at $30^{\circ} \mathrm{C}$ by ca. day 18 . The larvae held at $35^{\circ} \mathrm{C}$ failed to survive beyond 8 days so this group was replicated two more times and the results were identical to the first replicate. Survival to the pupal stage averaged $55,54,47$, and $0 \%$ for the $20^{\circ}, 25^{\circ}, 30^{\circ}$, and $35^{\circ} \mathrm{C}$ groups, respectively.

48. The average weight of the later instars also appeared to be affected by temperature. Fifth instar larvae averaged $50.5 \mathrm{mg}$ (S.D. \pm 4.3 ), $38.9 \mathrm{mg}$ (S.D. \pm 6.1$)$, and $24.6 \mathrm{mg}($ S.D. \pm 10.4$)$ for $20^{\circ}, 25^{\circ}$, and $30^{\circ} \mathrm{C}$ regimes, respectively. The correlation coefficient $(r)$ between the size of the fifth instar larvae and the temperature at which they developed was $-0.998(p<0.05)$. Pupae averaged $39.9 \mathrm{mg}($ S.D. $=11.8), 38.7 \mathrm{mg}$ (S.D. $=12.5)$, and $26.3 \mathrm{mg}$ (S.D. $=7.5)$, respectively, for the $20^{\circ}, 25^{\circ}$, and $30^{\circ} \mathrm{C}$ regimes. Figure 14 illustrates the average weights of the larvae pooled according to age for each temperature regimen. The higher temperatures resulted in early periods of rapid weight 


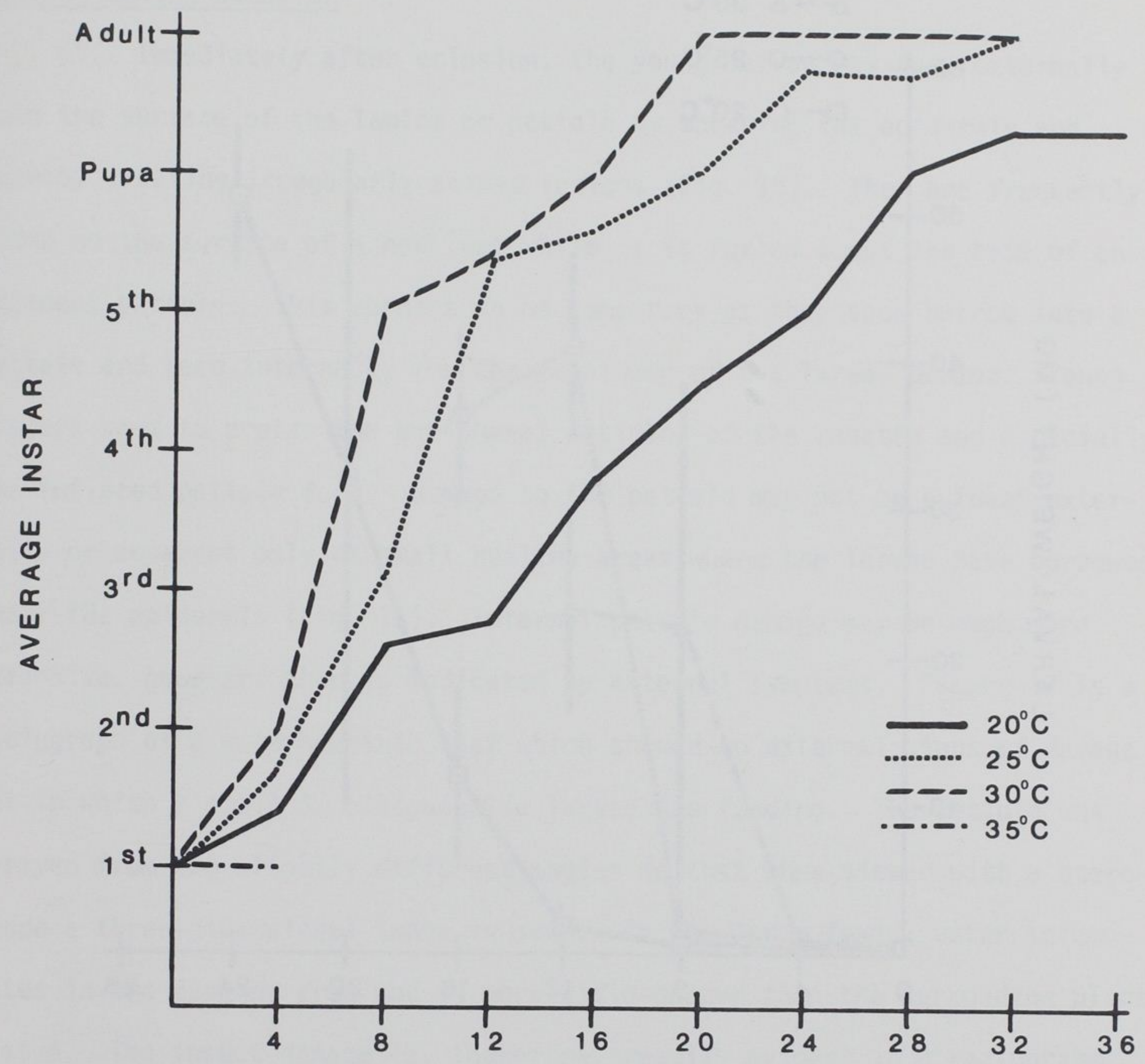

\section{AGE (DAYS POSTECLOSION)}

Figure 13. The effects of temperature upon the development of $S$. albiguttalis larvae. The data represent the average instar present at varying times after the larvae eclose from the eggs for four temperature regimes. The data are truncated for $35^{\circ} \mathrm{C}$ because by day 8 all of the larvae had died. Development was nearly twice as fast at $30^{\circ} \mathrm{C}$ as at $20^{\circ} \mathrm{C}$ 


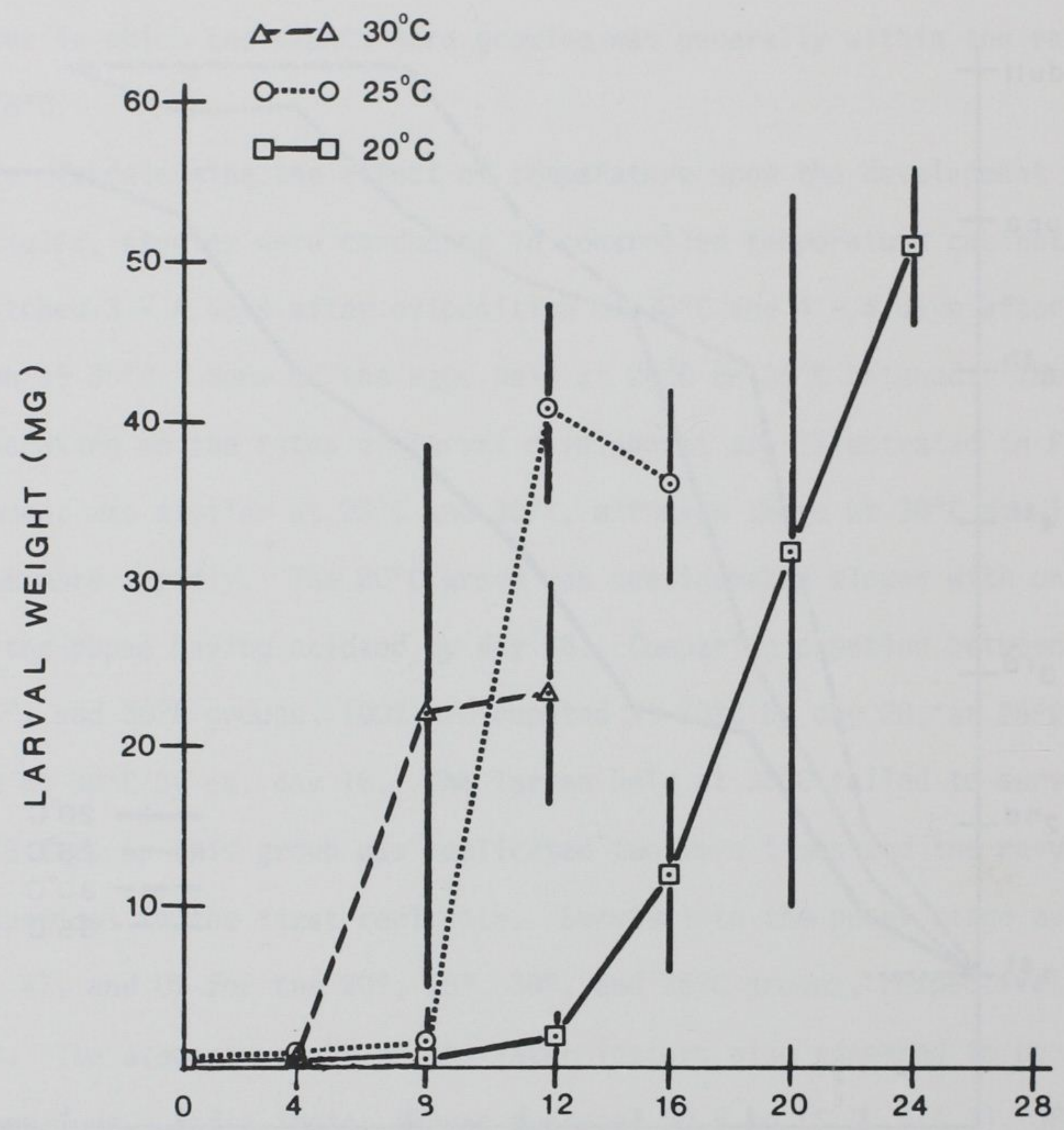

LARVAL AGE (DAYS)

Figure 14. Average larval weights for successive ages when reared under $20^{\circ}, 25^{\circ}$, and $30^{\circ} \mathrm{C}$ temperature regimes. Data were taken at each harvest date as long as larvae were present (i.e. up until the time of pupation). The vertical lines through each mean represent standard deviations. Note that the terminal larval weight was inversely related to temperature. The highest growth rates were achieved at all temperatures just prior to the age at which the larvae were predominantly 5 th instars 
gain but produced smaller larvae; the lower temperatures resulted in later, more gradual weight increases but produced larger larvae.

Larval feeding behavior

49. Immediately after eclosion, the young larvae may feed externally upon the surface of the lamina or petiole by scraping the epidermis and thereby creating irregularly shaped lesions (Fig. 15). They are frequently found on the surface of a new leaf while it is furled about the base of an adjacent petiole. This appears to be temporary as they soon burrow into a petiole and feed internally for the remainder of the larval period. Young instars seem to prefer the peripheral petioles of the rosette and especially the inflated petiole form. Damage to the petiole may not be evident externally or apparent only as small hyaline areas where the larvae have burrowed under the epidermis (Fig. 16). Internal petiole damage may be much more extensive, however, than is indicated by external symptoms. Figure 17 is a radiograph of a waterhyacinth leaf which showed no external signs of damage but in which a small S. albiguttalis larvae was feeding. The petiole was $X$-rayed from two slightly different angles so that when viewed with a steroscope a three-dimensional image is seen. As the larva feeds, water accumulates in the damaged area and is more radio-opaque than the surrouding plant tissue. The insect damage is, therefore, readily evident in a radiograph and is represented by the dark area within the petiole in Fig. 17.

50. As the petiole continues to imbibe water, it ultimately becomes waterlogged and the resultant gain in weight may cause it to reflex and become submerged. The source of the water which accumulates within the petiole is uncertain, but it is presumably deposited through capillary action from the vascular elements severed by the larvae. 


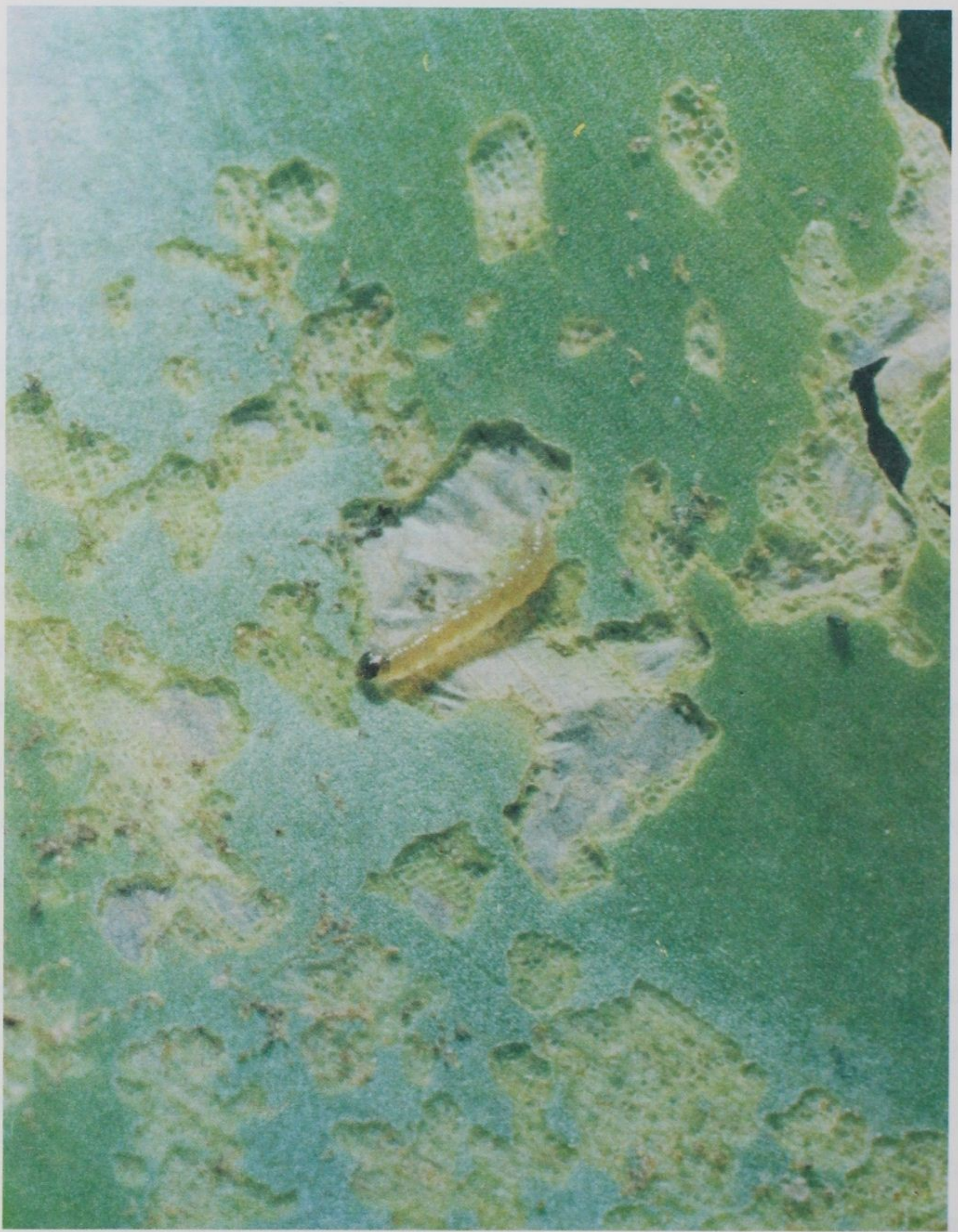

Figure 15. First instar S. albiguttalis larva on a waterhyacinth lamina which shows the irregularly shaped lesions created by the scraping feeding behavior of the larva 


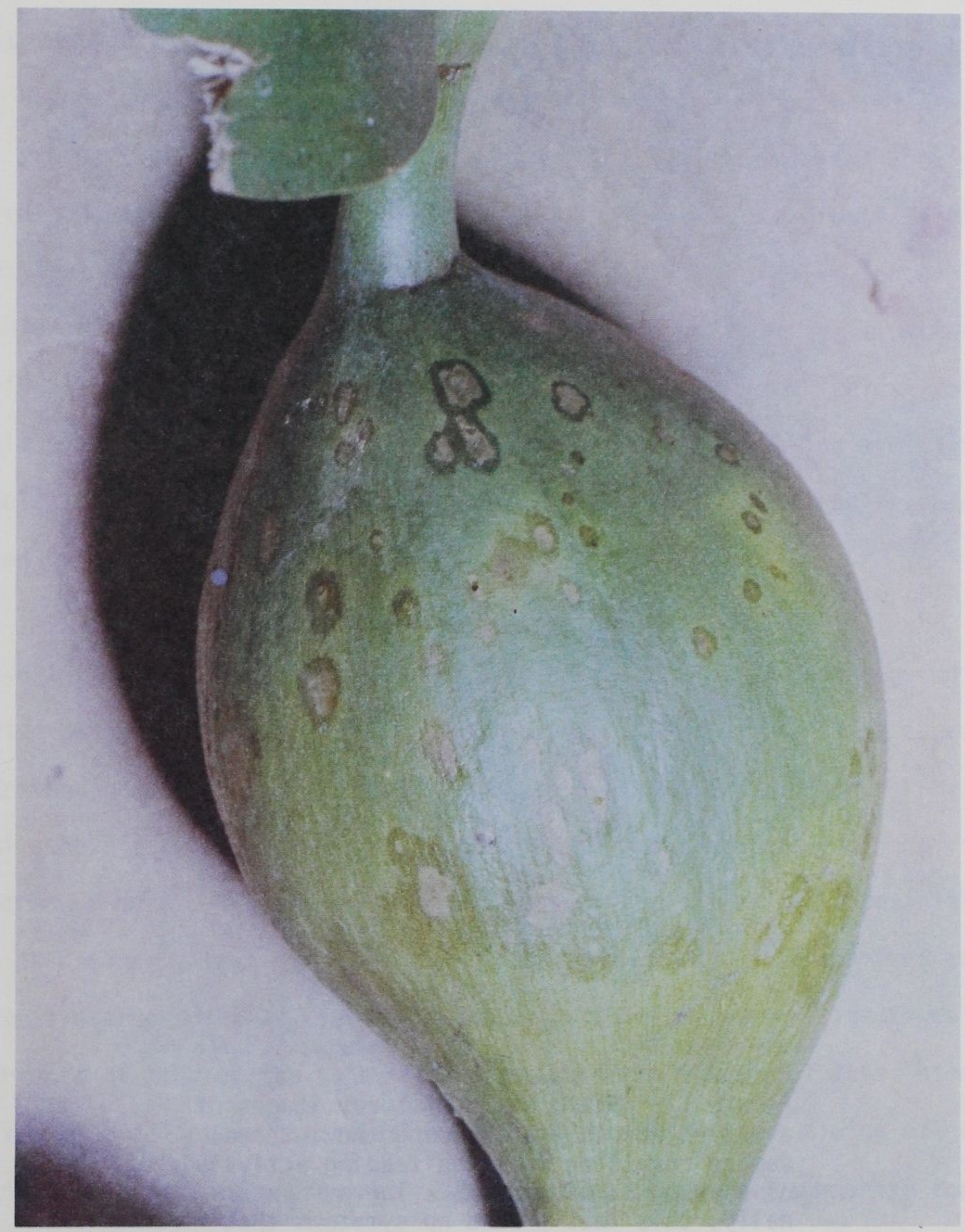

Figure 16. A waterhyacinth petiole which shows evidence of early instar $S$. albiguttalis feeding activity. The larvae burrow within the petiole and scrape the epidermis internally thus creating hyacline "windows" in the petiole 

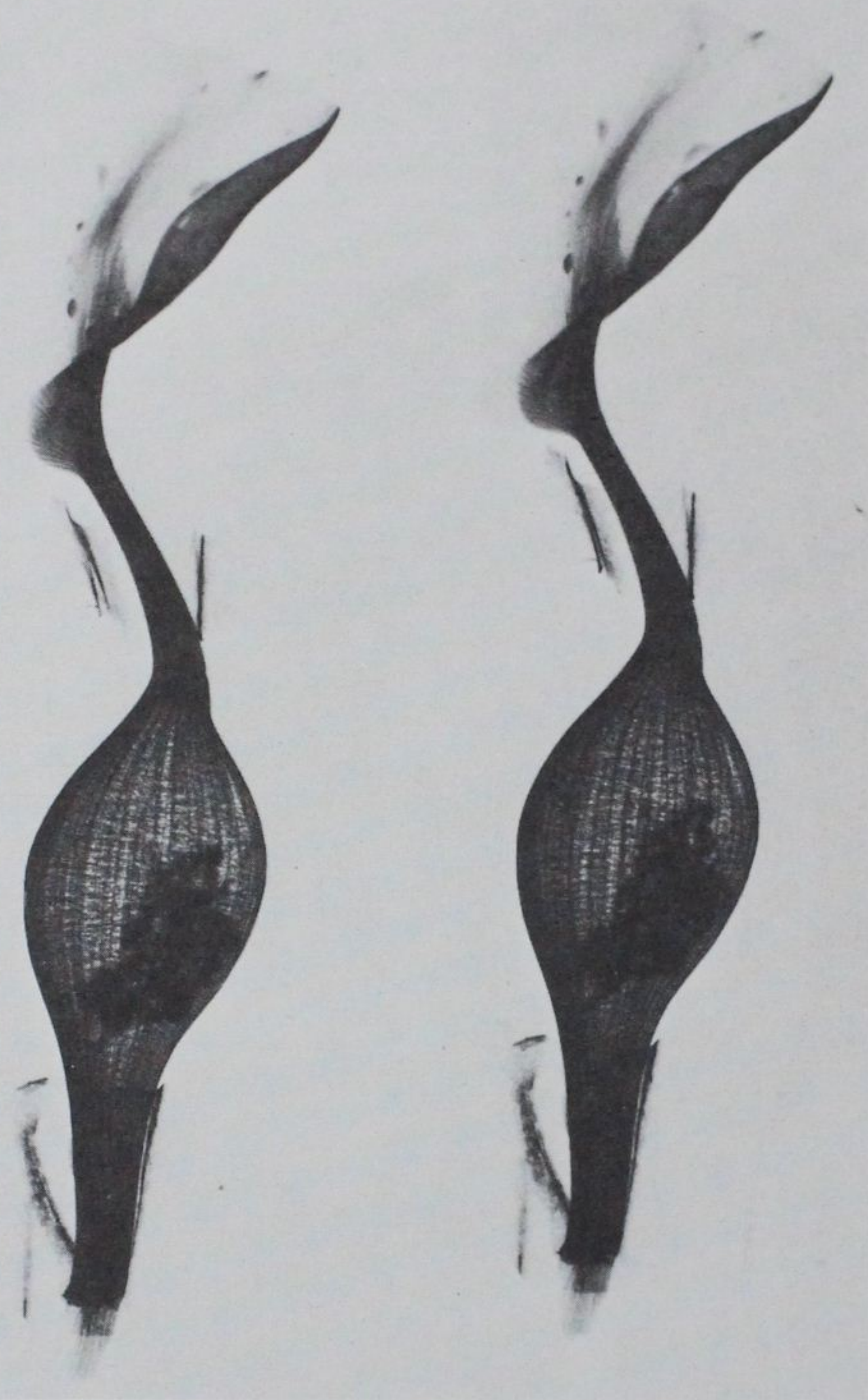

Figure 17. Stero pairs of X-ray images of a waterhyacinth leaf showing the internal damage resulting from the feeding activity of a young $S$. albiguttalis larva. Externally, this leaf showed no symptoms that would indicate that a larvae had been burrowing within it. When viewed through a steroscope, the images will appear threedimensional. The darkened area is the result of the deposition of water in the damaged tissue 
51. As the larvae feed and grow, they progressively move from the periphery of the rosette toward the center. The fifth instar larvae may create extensive tunnels through several petioles, generally exiting at the base of one and entering the contiguous appressed base of the next. They will frequently burrow down the youngest petiole and excavate the apex of the rhizome destroying the apical bud (Fig. 18). Since the growth of the shoot is monopodial, once this bud is destroyed the shoot is no longer capable of producing new leaves. Late instar larval damage is illustrated in Fig. 19 which is a radiograph of the petiole bases of the leaves from a single plant arranged from left to right in order of increasing age. The petiole to the extreme left is the youngest and shows the extensive damage caused by the feeding of a 5 th instar $S$. albiguttalis larva.

\section{Discussion}

52. This section contains primarily preliminary data from ongoing studies but which is sufficiently complete, at present, to provide a general understanding of the biology and life history of S. albiguttalis. Previous studies have described developmental times and periods of various activities in terms of days. Because many of these stages are brief, more definitive data on a finer time scale is needed. Through the use of specialized and innovative procedures we hope to ultimately determine the precise times of occurrence of many of the major events in the life history of this insect. We also hope to determine the effects of temperature on the timing of certain critical life history phenomena. The following paragraphs summarize the data obtained thus far.

53. The life cycle necessarily begins with the emergence of the adult from the pupa. The pupa is contained within a silken cocoon in a waterhyacinth 


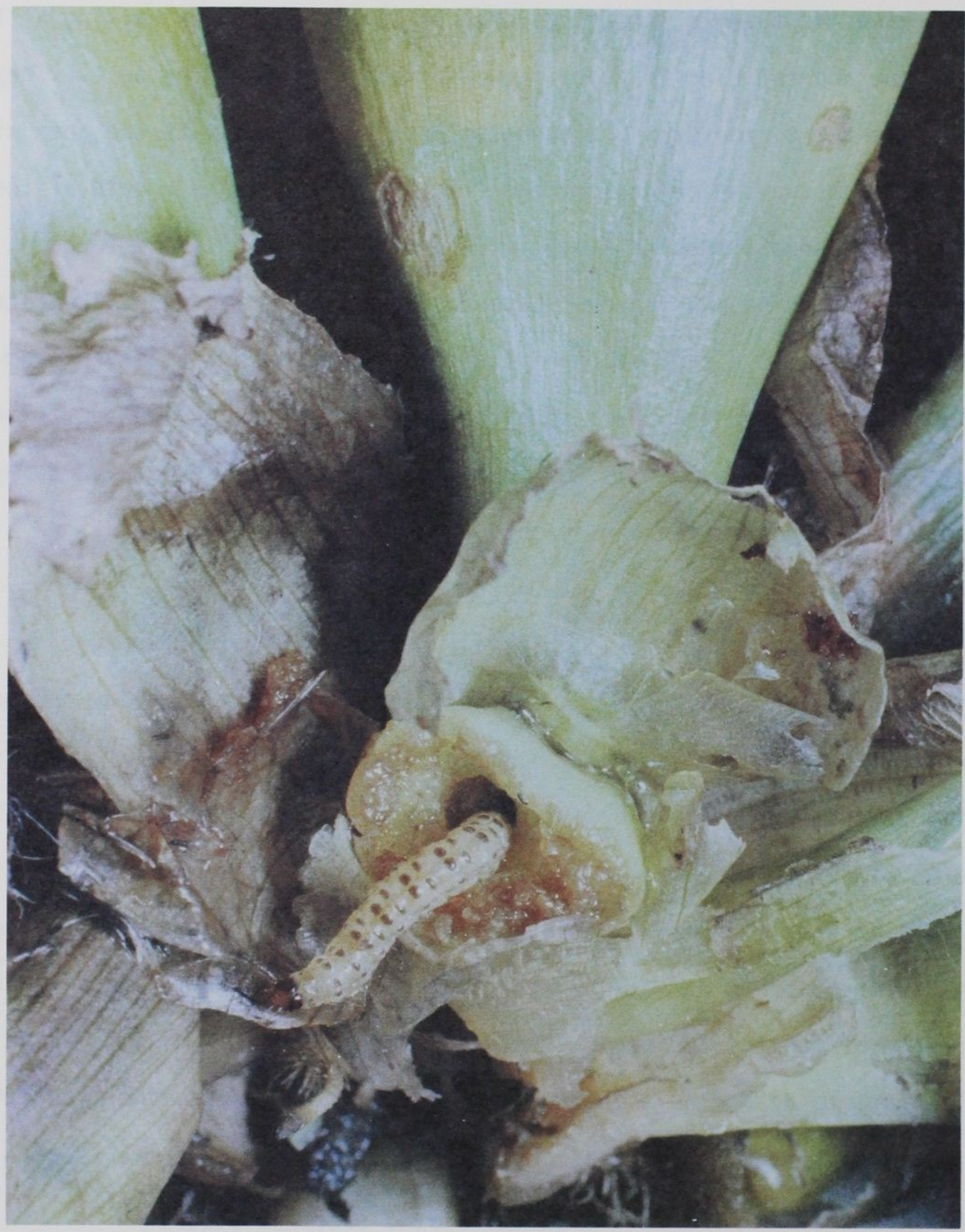

Figure 18. A 5th instar S. albiguttalis larva feeding on the apical bud of a waterhyacinth plant thus destroying the meristematic tissue which is responsible for the vertical growth of the shoot 


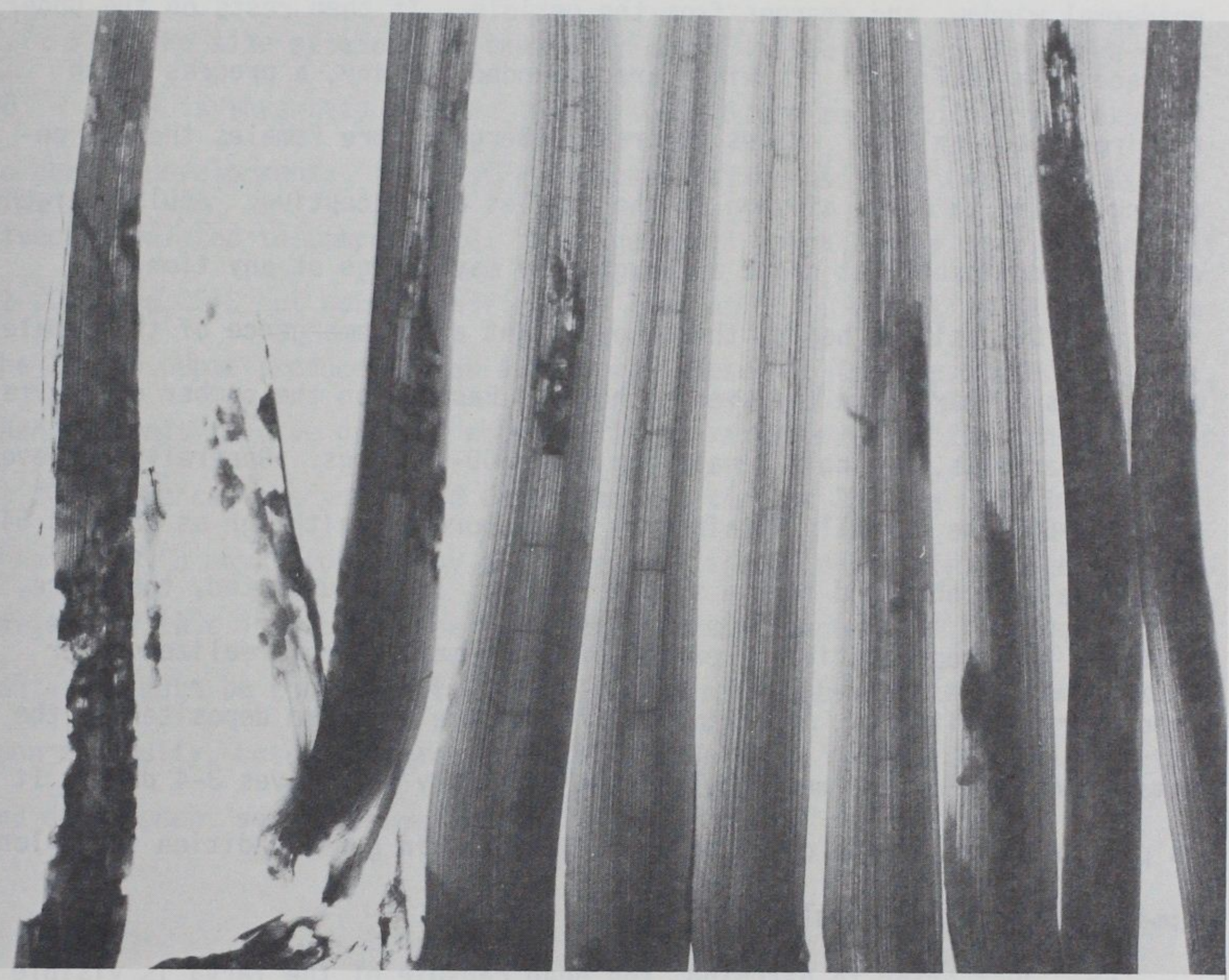

Figure 19. A radiograph which illustrates the selection of leaves by a 5th instar $S$. albiguttalis larva. The images are of the petiole bases of all the leaves from a single waterhyacinth plant and are arranged from left to right in order of increasing age. The damage to the three youngest leaves is the result of the feeding activity of a single $S$. albiguttalis larva. Note that the youngest leaf is most heavily damaged and a new leaf that was beginning to develop (the "wrapper" leaf) has been completely destroyed 
petiole. The cocoon is elongated on the anterior end in the form of a passage extending from the pupal chamber to a small window in the petiole epidermis. Upon eclosion, the adult exits through this passage, bursts the epidermal window, and emerges from the petiole. It then rests on the under surface of a leaf until its wings are expanded and dry, a process which requires about an hour. Males generally emerge before females thereby enabling mating to occur as soon as the females are receptive. Adult emergence occurs predominantly at night al though they may emerge at any time.

54. Oviposition begins the second night after emergence of the female and occurs primarily in the evening hours. Based upon the number of oocytes in the ovarioles, a single female may bear 600-700 eggs. Generally, however, only 400-500 are normally obtained in the laboratory although as many as 646 eggs have been obtained from a single female. It is suspected, therefore, that the full reproductive potential of the female is not realized under laboratory conditions. Approximately $70 \%$ of the eggs are deposited by the female two days after emergence and she generally only lives 3-4 days. It is possible that if she could be kept alive and in good condition for a longer time, many more eggs could be obtained.

55. Just prior to hatching, the head capsule of the larva is visible through the chorion and the egg appears black. Eclosion did not occur at $20^{\circ} \mathrm{C}$ and it is possible that the embryos are in a quiescent state at that temperature. Optimal eclosion occurs at $25^{\circ}-30^{\circ} \mathrm{C}$ and requires $4-6$ or 3 - 4 days, respectively. The total generation time is ca. 30 days at $25^{\circ} \mathrm{C}$, but varies inversely with temperature and is nearly twice as long at $20^{\circ} \mathrm{C}$ as it is at $30^{\circ} \mathrm{C}$.

56. Larval survival does not seem to be temperature dependent within 
the range of $20^{\circ}-30^{\circ} \mathrm{C}$ but $35^{\circ} \mathrm{C}$ seemed to be beyond the maximum tolerable threshold for this species. Larvae did not survive beyond 8 days and eggs failed to hatch when held at this temperature.

57. The size attained by the fully grown larvae (within the range of $20^{\circ}-30^{\circ} \mathrm{C}$ ) is inversely related to the temperature regimen they are exposed to during development. Interestingly, pupal size does not seem to be as directly related to temperature. Average pupal weights were nearly identical at $20^{\circ} \mathrm{C}$ and $25^{\circ} \mathrm{C}$ but were significantly less at $30^{\circ} \mathrm{C}$. If it is assumed that the larger pupae produce larger adults and these, in turn, produce more eggs, then fecundity may be greater when the larvae are reared at $20^{\circ}$ and $25^{\circ} \mathrm{C}$ than at $30^{\circ} \mathrm{C}$. Hence, the prolonged developmental time at $25^{\circ}$ (ca. $25 \%$ longer than at $30^{\circ} \mathrm{C}$ ) may be offset by the larger size attained by the pupae (ca. $50 \%$ larger) if this increased size reflects increased fecundity. Further experimentation must be conducted to directly determine the effects of temperature upon fecundity, but it appears that $25^{\circ} \mathrm{C}$ is near the optimum for the growth and development of $S$. albiguttalis. 
Section III. Procedures for culturing and rearing Sameodes albiguttalis.

\section{Introduction}

58. The utilization of Scomeodes albiguttalis (Warren) in a waterhyacinth management program is likely to require some degree of rearing to provide insects for subsequent release. In some instances, such as in areas where only a single release is necessary, pupae will be received which must be held until the adults emerge and oviposit and the eggs hatch, thereby enabling the release of first instar larvae. In other instances, such as in areas where releases must be made each year, it may be advisable to build and maintain a viable self-perpetuating colony. This section details and explains procedures found useful for rearing $S$. albiguttalis. For the most part, these procedures have been developed on a trial and error basis, and not by true experimentation. A great deal can be improved upon and ultimately probably will be but, for the present, the following methods are certainly adequate for most needs.

\section{Acquiring an Initial Stock}

59. To begin a population of $S$. albiguttalis, it is necessary to obtain a supply of insects to form the nucleus of a new colony. These may be obtained from an agency which already has an established colony or by field collecting in an area where a population has become established. Either way, a variety of stages may be obtained, each of which must be handled somewhat differently. Ultimately, the success of any colony depends upon male and female adults being present at the same time, in the same space, and in adequate numbers to ensure mating and self-perpetuation. When the founder population is quite small, this may not occur if the emergence of the adults is asynchronous. It is best, therefore, to obtain large numbers of a single instar to start with and thereby synchronize the initial population ensuring 
that total adult emergence will occur within as narrow a time span as possible. It is far easier to obtain large numbers of eggs than any other instar and it is recommended that these be used to start a new colony or field population. To obtain eggs, it may be necessary to first obtain either pupae or adults.

\section{Collecting and Rearing Pupae}

60. The occurrence of pupae in the field may be very erratic and sporadic both spatially and temporally. It is possible to spend hours at one location and collect very few, but collect dozens at a second location a short distance away. It is advisable, therefore, to check many localities until a "hot spot" is found which will yield a high return per unit of effort expended.

61. The most likely situation in which to find pupae is one in which an extensive "fringe" population of waterhyacinth exists. This may be defined as an area where the waterhyacinth mat borders open water and plants with inflated petioles dominate, at least along the edge of the mat. This should be contrasted with a continuous stand of tall plants completely covering the water. Sameodes is likely to be less abundant in the latter situation and certainly more difficult to find.

62. Once a fringe is located, the process of searching through the plants begins. At first it will probably be necessary to meticulously split nearly every petiole to determine if it contains a pupa. After a few are found and some degree of experience is gained, the most likely plants and petioles become obvious and can be selectively examined. Just prior to pupation, the larva forms a concavity into which to pupate and excavates an emergence tunnel to the surface leaving a thin layer of epidermis intact covering the 
opening. This "window" is evident as a small, round, hyaline area on the petiole (see Figures 20-22). If the adult has emerged, this window will be pushed out; if not, it will be intact. With a little practice, this can be used as a clue for locating pupae without actually splitting the petiole. It should be noted that the young larvae burrow just beneath the epidermis also creating hyaline windows, but these are generally irregular in outline whereas those of the pupae are round or oval.

63. The type of petiole may also serve as a clue for finding pupae. Although they will pupate within the elongate petioles, they seem to be more common within the inflated type. Generally, they are not in the youngest or oldest petioles, or in those which are necrotic or waterlogged. They are most likely to be found in inflated petioles which externally appear to be in good condition (Fig. 22).

64. Once the cocoons are found, it is best not to completely remove them from the petiole but rather to remove the piece of the petiole to which the cocoon is attached. The petiole pieces should be placed on damp filter paper in a painted pie pan with the cocoon facing up and a piece of plate glass placed over the pan (Fig.23). If condensation forms on the glass, the filter paper is too wet and it should be allowed to dry somewhat. The filter paper should never be permitted to completely dry out, however. The moist paper and the moisture from the pieces of plant will maintain a high humidity in the pan and the majority of the adults will emerge within a week.

65. If it is desired to sex the pupae so as to segregate emerging males and females, the pupae must be removed from their cocoons. This is accomplished by soaking them in a $0.5 \%$ sodium hypochlorite solution ( $10 \%$ commercial bleach) for ca. 10 minutes to soften the silk, and then gently removing the 


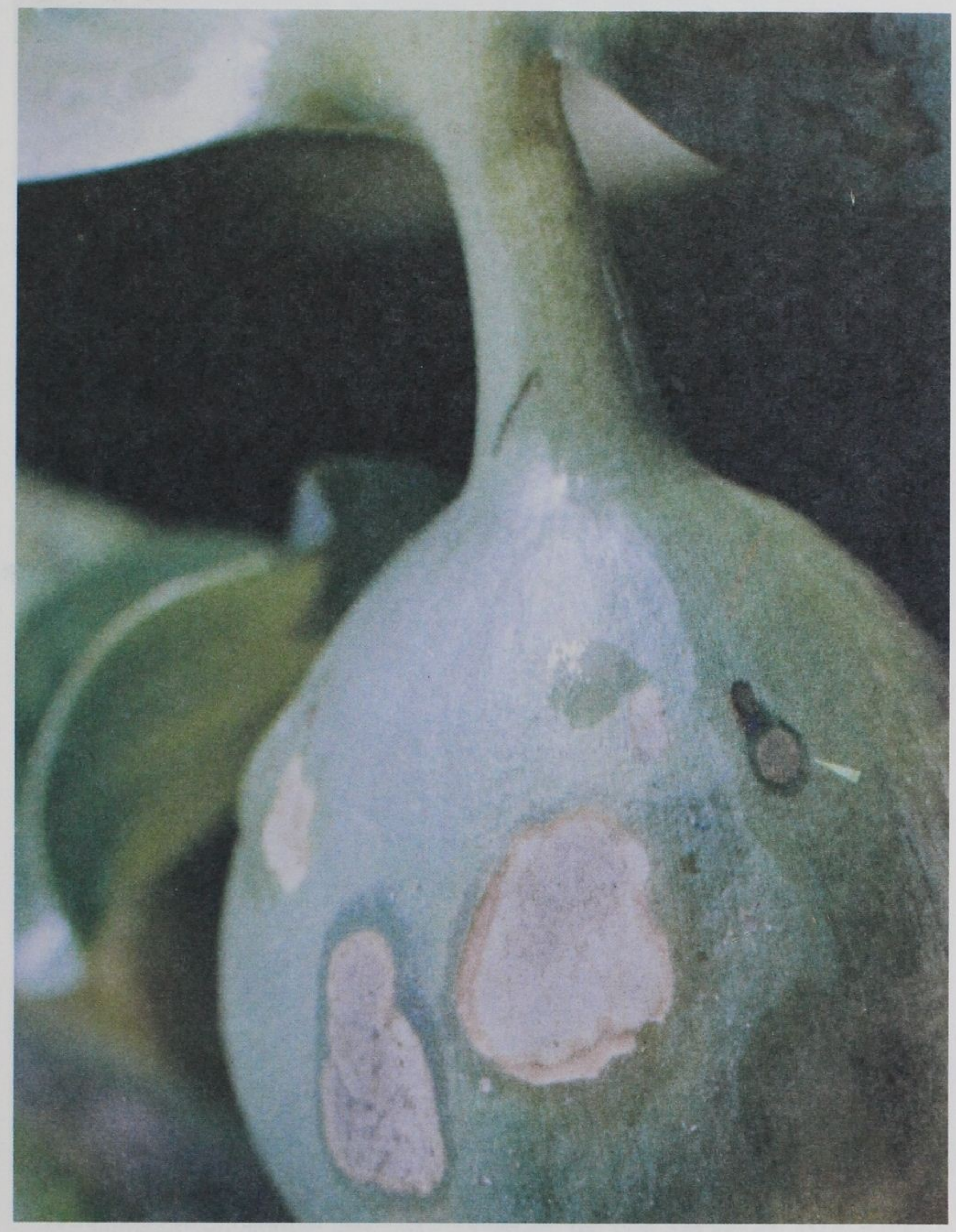

Figure 20. The "window" of a $S$. albiguttalis pupa evident on the surface of a waterhyacinth petiole as a round, hyaline spot in the epidermis 


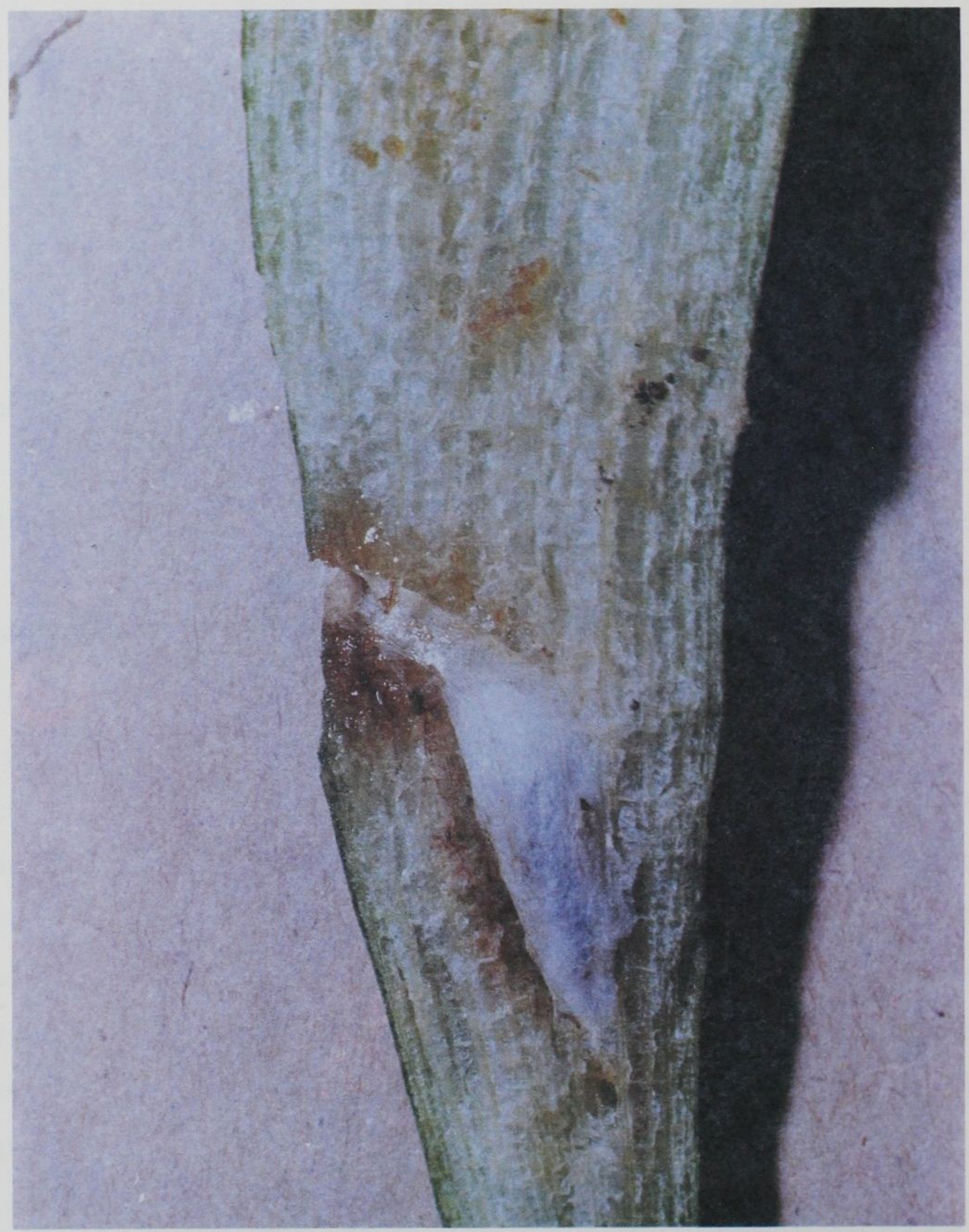

Figure 21. A S. albiguttalis cocoon within a waterhyacinth petiole which has been split open to show the silken emergence tunnel leading to the "window" on the external surface of the petiole. This permits egress of the adult upon emergence from the pupa 

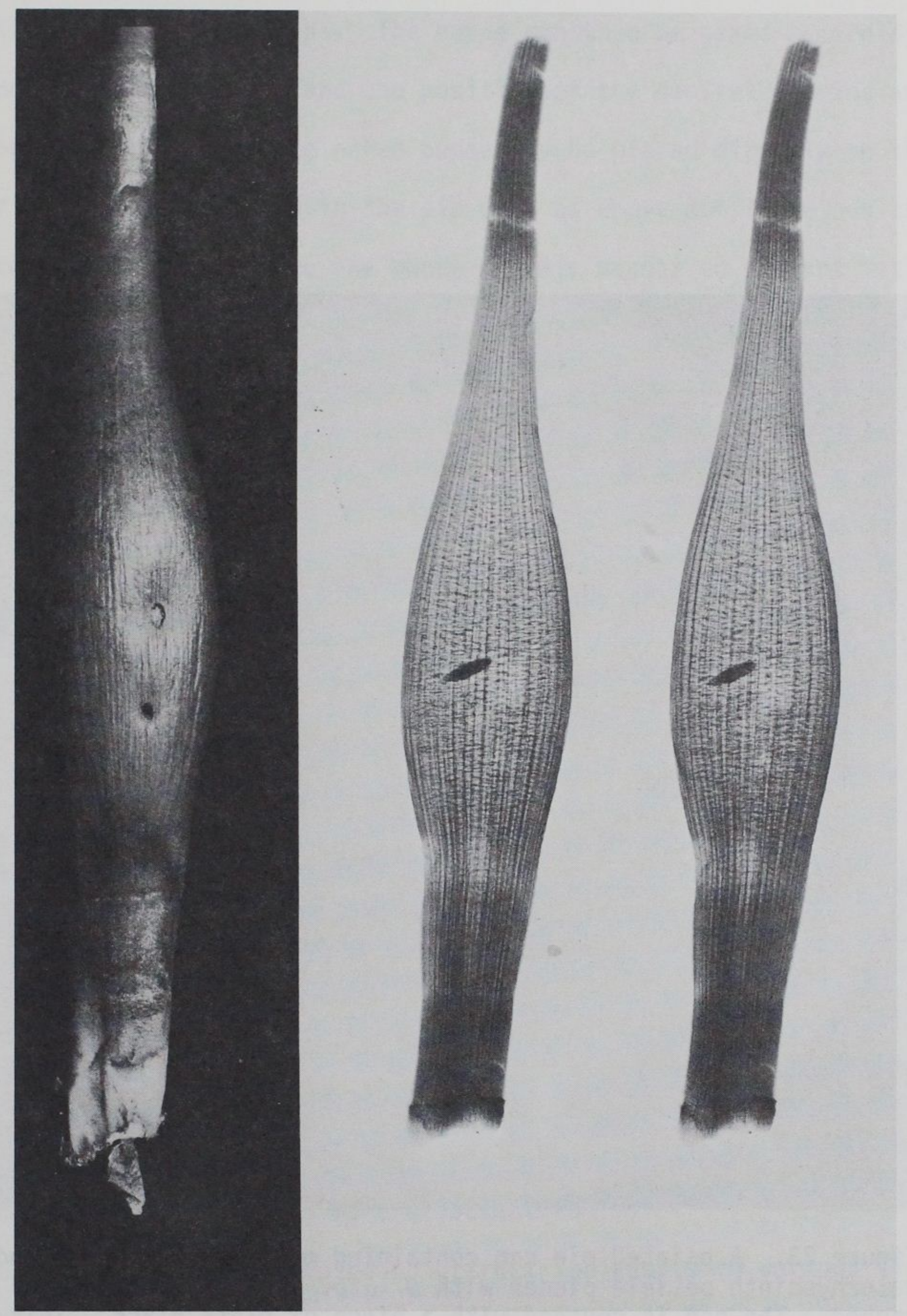

Figure 22. A photograph (1eft) and a stereo-pair radiograph (right) of the same waterhyacinth petiole. The photograph shows the hole created by the larva as it entered the petiole and the hyaline exit window formed prior to pupation. The radiograph shows the pupa within the petiole. Note that this was a previously undamaged petiole which the larva entered apparently only for the purpose of locating a suitable pupation site 


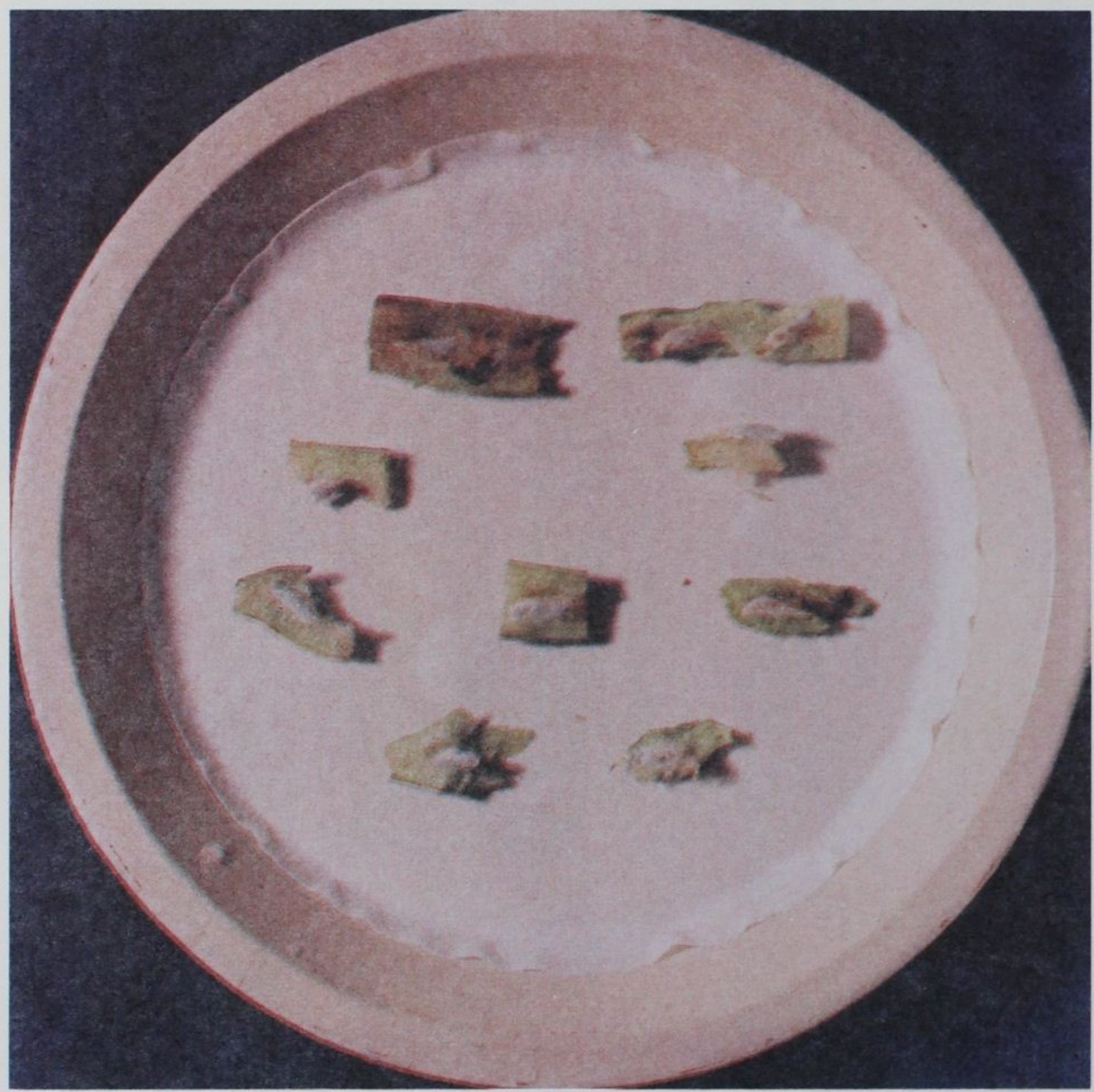

Figure 23. A painted pie can containing moist filter paper and waterhyacinth petiole pieces with $S$. albiguttalis cocoons attached. The pan is covered with a piece of plate glass. This arrangement is used for rearing adults from the pupae 
silk with fine-tipped forceps. The pupae can then be sexed according to the length of the antennae and the position of the genital opening as described in Section I. The naked pupae may be placed directly on the moist filter paper and held in the pie pans as above until the adults emerge. It is convenient to separate the pupae in this manner to prevent mating and oviposition from occurring in the emergence pans.

66. A second procedure has been used to rear pupae but it is somewhat more complicated. Several ca. 0.25-in.-diam by 0.75-in.-deep holes are drilled into a 2-ft-thick fir block.* The block is soaked at least 24 hours in water, drained for at least an hour, and the naked pupae are placed, anterior end up, in the holes. The block is then placed in a glass-covered cage. The moisture in the wood keeps the pupae in a humid environment and the adults emerge through the hole in the block and into the cage where they are easily captured.

\section{Obtaining Adults}

67. By far the easiest way to obtain adult $S$. albiguttalis is by collecting and rearing pupae. Occasionally, adults may be flushed in the field when walking through the waterhyacinth with watershoes thereby disturbing the vegetation and causing the adults to take flight. Even if seen, however, they are extremely difficult to net. If caught, they are almost always males, the females being apparently more reluctant to fly.

68. We have also attempted to attract the adults to various lights at night. They do not seem to be attracted to black lights, florescent lights, or incandescent lights under ordinary circumstances. If they are disturbed at night, however, they are readily flushed and will then fly to a light.

* A table of factors for converting U. S. customary units of measurement to metric (SI) is presented on page 9. 
We have had a great deal of success by running an airboat through the waterhyacinth mats at night to flush them. A light on the bow attracts them to the boat. By slowly running the boat through the plants, both males and females are flushed. They then fly towards the light and land on the fore deck where they are easily trapped in a vial or petri dish. This method seems to be most successful shortly after dark and activity seems to cease before midnight.

\section{Obtaining Eggs}

69. Being virtually impossible to collect eggs from the field, it is best to collect or rear adults and obtain eggs by inducing them to oviposit. This is easily accomplished and several thousand eggs may be obtained from a few pairs of adults. A simple oviposition cage using a waterhyacinth lamina as a substrate (Fig. 24) is constructed as described in the following paragraph.

70. A $9-\mathrm{cm}$ piece of filter paper is placed in the bottom of a 15- by 100$\mathrm{mm}$ petri dish, moistened, and pressed into the edges of the dish to prevent the adults from crawling under it. A waterhyacinth lamina is severed from the petiole at the isthmus and the distal end trimmed to enable the basal portion to fit in the petri dish bottom. The epidermis is stripped from the thick, basal portion of the lamina thereby exposing the aerenchyma. The leaf is placed in the petri dish with a pair of adult moths and, after mating, the female may literally fill the exposed aerenchyma with eggs. Each day the leaf containing new eggs is removed, placed in a separate petri dish, and a new leaf is placed in the oviposition chamber with the adults. This continues for as long as the female remains alive. If the male dies before the female, he should be replaced with another male. The leaf containing the eggs is kept on moist filter paper in a petri dish until the larvae begin 


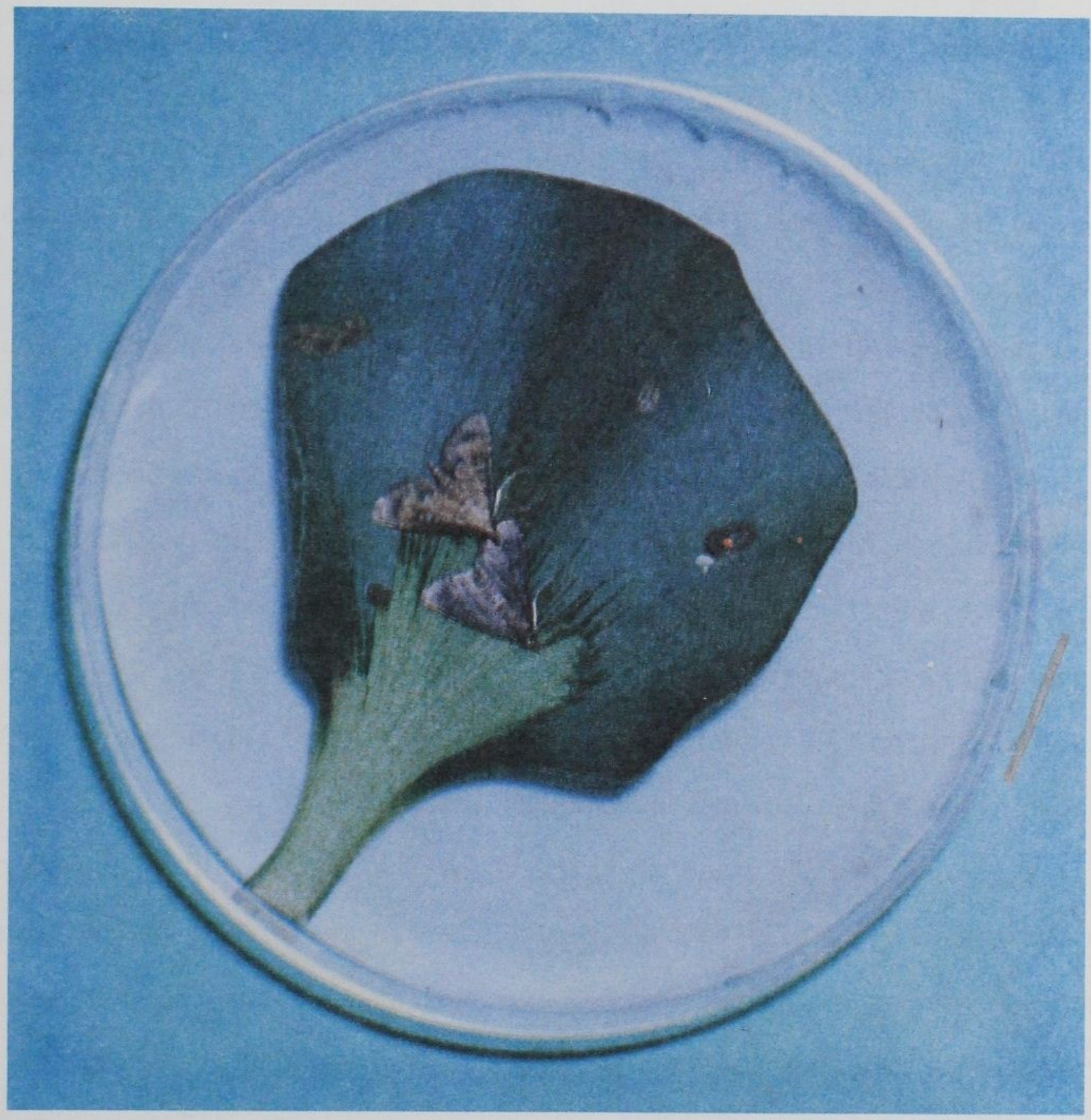

Figure 24. A plastic petri dish containing moist filter paper, a piece of waterhyacinth lamina with a portion of the epidermis removed, and a pair of $S$. albiguttalis adults. The female will readily oviposit in the exposed aerenchyma of the lamina 
to eclose. The neonates should not be handled individually because they are easily injured. Instead, the lamina piece containing the larvae should be handled as a unit.

\section{Starting a Greenhouse Colony}

71. Before a colony of S. albiguttalis can be established, it is necessary to obtain a healthy culture of waterhyacinth. Growing waterhyacinth is relatively easy but requires large, water-filled containers. If standard greenhouse benches are available, these may be increased in depth by constructing a frame of 1- by 12-in. redwood that will fit the inside dimensions of the bench. The open top boxes thus formed are lined with 4-mil polyethylene plastic film, filled with water, and fertilized with 20-20-20 water-soluble fertilizer (Peter's) and 6\% Fe equivalent iron chelate (Sequestrene $138 \mathrm{Fe}$ ) to achieve concentrations of $2 \mathrm{mg} \mathrm{P} / \ell$ and $1 \mathrm{mg} \mathrm{Fe} / \ell$. It is recommended that at least $50 \%$ of the water be drained and replaced and the tanks be refertilized at least monthly. The tanks should be stocked with small plants that should be allowed to grow for a few weeks to completely cover the available surface area before introducing insects.

72. Virtually any method of introducing the insects into the waterhyacinth culture will work. If, however, the larvae are placed on the plants. in such a manner that they are overly exposed to environmental extremes or to predators before they can burrow into the plant tissue (e.g. if they are simply placed on the uppermost leaves), a high mortality is likely to occur. It is recommended that the colony be seeded by inserting the lamina pieces containing eggs ready to hatch or neonates into the crown of a plant in the space between a partially opened new leaf and the central petiole which is ensheathed by the new leaf (Fig. 25). 


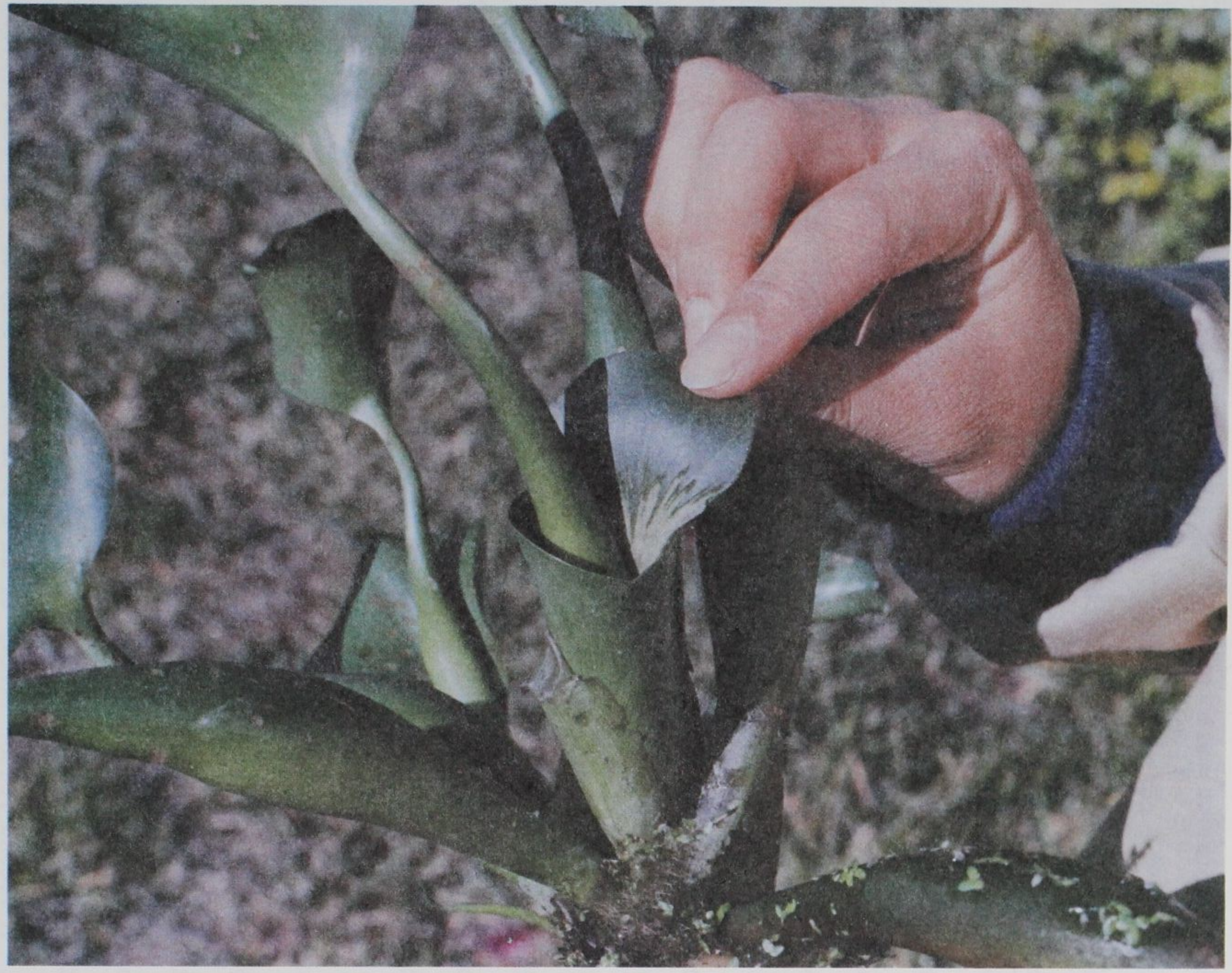

Figure 25. The method of inserting a piece of waterhyacinth lamina containing $S$. albiguttalis eggs or neonates between the central petiole and a newly emerging leaf of a waterhyacinth plant 
73. As the insect population increases, the condition of the waterhyacinth culture will begin to deteriorate. If this deterioration proceeds too far, the insects will be deprived of food and the population will decline. The insect population must therefore be continually culled to prevent it from exceeding the carrying capacity of the waterhyacinth culture. It is recommended that about 15 days after the original eggs have hatched, the colony be monitored by dissecting the plants. When the majority of the insects found are pupae, $50-75 \%$ of the plants should be harvested and the insects or the infested plants thus obtained should be used for field releases. The culture should then be restocked with fresh plants which will ultimately be reinfested by the remaining $25-50 \%$ of the insect population. This monitoring, thinning, and restocking process should be continued monthly thereafter.

\section{Discussion}

74. As noted earlier, the above procedures for the handling and rearing of $S$. albiguttalis will produce satisfactory results and serve as a starting point for those unfamiliar with the insect. Much can be improved upon, however, and innovative techniques should be attempted.

75. One of the most important factors in the laboratory stages of this process is the humidity maintained in the rearing containers. If it is too low, the plant material will desiccate. If it is too high, the plant material may decay and the growth of mold may be encouraged. It is essential, therefore, to keep damp filter in the containers but not allow it to be either wet or dry.

76. A second factor likely to be a problem in tropical and subtropical areas is predation by ants. They will invade laboratory cultures and kill 
everything from eggs to adults and precautions must be taken against them. Our solution was to house all laboratory containers in a sealed sleeve cage, add legs to the sleeve cage, and set the legs in vesicles containing mineral oil. The cage should not be allowed to come in contact with anything which the ants may use as a bridge to the cage. Commercial ant traps may be used in the area around the cage but, under no circumstances, should volatile insecticides be applied in the vicinity of the rearing area.

77. Three problems are likely to occur once a greenhouse culture is established. The first, mentioned above, is the deterioration of the plants resulting from excessive numbers of $S$. albiguttalis. The second is the buildup of other phytophagous species such as spider mites, waterhyacinth mites, army worms, Neochetina sp., thrips, etc., which are likely to be introduced on field-collected plants, will compete with S. albiguttalis for the available plant material. This buildup will also ultimately cause the deterioration of the waterhyacinth culture. The third problem is predators, particularly frogs, dragonflies, and spiders, which are also likely to build up to high levels and sharply reduce the Sameodes population. Since all of these problems take time to reach critical levels, they may be minimized by maintaining a rapid turnover rate in the harvesting and restocking operations, i. e., by continually removing and replenishing the plants. Since an acre of waterhyacinth can support many more insects than a greenhouse, it is wise not to attempt to retain a colony for too long but rather to liberate the insects as often as possible thereby producing extensive self-perpetuating natural populations. 
Section IV. The release and establishment of Someodes albiguttalis in Florida.

\section{Introduction}

78. Between September 1978 and June 1979, Someodes albiguttalis was liberated at several locations in Florida in an attempt to establish self-perpetuating field populations. These attempts met with varying results in terms of the success or failure of the release at the different sites. The purpose of this section is to examine the source of this variation and define the conditions under which the successful establishment of populations of these insects is most probable. In addition, the releases of $S$. albiguttalis made to date are summarized, several release techniques are evaluated, and the resultant establishment of several populations is documented.

\section{Methods and Materials}

\section{Parent stock}

79. Personnel of the USDA laboratory in Hurlingham, Argentina, collected pupae of S. albiguttalis from Dique Los Sauces, La Rioja Province, Argentina. After the parent stock was screened for pathogens, approximately 1000 eggs and 1190 larvae (progeny of the field-collected material) were shipped to the USDA Biological Control Quarantine Facility in Gainesville, Florida, they were received on 2 April 1976. The Gainesville laboratory held these insects for parasite exclusion and subsequently reared several generations in quarantine. Drs. E. Hazard and G. Allen screened the quarantine colony for pathogens. Federal and State agencies granted approval for the release of S. albiguttalis on 21 June 1977 and the Gainesville laboratory subsequently sent two shipments of 29 and 53 pupae to the USDA Aquatic Plant Management Laboratory in Fort Lauderdale, Florida. 
80. At Fort Lauderdale, 43 living pupae, 27 dead pupae, and 12 adults which had emerged in transit were received. The living pupae were retained on moist filter paper in glass-covered pie pans until the remaining 42 adults emerged. Individual pairs of adults were placed in petri dishes on moist filter paper. A waterhyacinth leaf with an area of epidermis removed was placed in each dish with the adults to serve as a substrate for oviposition. The leaves were checked daily; those with eggs (2464 total) were held in separate petri dishes until the larvae eclosed, and the neonates (2093 total) were transferred to a greenhouse culture of waterhyacinth.

Release methods

81. After a breeding colony of insects had become established, a portion of the infested plants was periodically removed for field releases. The following release methods were used:

1. Infested plants. Plants containing multiple instars of $S$. albiguttalis were removed from the greenhouse culture and transplanted directly to the field sites. A subsample of the infested plants was dissected and the number of Sameodes larvae and pupae counted to estimate the number of insects released.

2. Eggs. Pupae were removed from the greenhouse culture; the adults were reared and paired as described above. The leaves with eggs were placed within the furled central leaves of the plants in the field.

3. Neonates. As in \#2, but the eggs were held in the laboratory until the larvae eclosed and the neonates were released.

4. Pupae. As in \#2, but the pupae obtained were placed directly in the field amongst the plants. 
5. Adults. Adults reared from pupae collected at other sites or from the greenhouse were paired and held until mating occurred. The males and gravid females were subsequently released.

6. Various instars. Insects from the greenhouse were placed directly in the field (generally late instar larvae).

82. Release sites (Fig. 26) were selected arbitrarily, although we attempted to locate waterhyacinth populations which were relatively persistent and not subject to the aquatic weed control measures taken by local agencies. Waterhyacinth was not present at sites 7 and 11 and these sites were artificially stocked with uninfested plants before releasing the insects.

83. Subsequent to the releases, each site was checked at least monthly to determine if a perpetuating population of $S$. albiguttalis had become established. Establishment was verified only if individuals at least two generations (ca. 3 months) removed from the founder populations were recovered. The releases were considered failures if no evidence of the presence of the species was apparent 3 months after the last release. We also examined nearby waterhyacinth infestations to determine if the populations had moved or were dispersing.

84. In order to determine if host plant quality affected establishment, 10 plants were sampled from 18 of the 20 sites in June 1979 and the total leaf length, petiole length and diameter, lamina length and width of the third leaf (as counted from the center of the rosette), and maximum root length of each plant were measured. Previous observations had indicated that plants growing in poor conditions generally produced long roots, as 


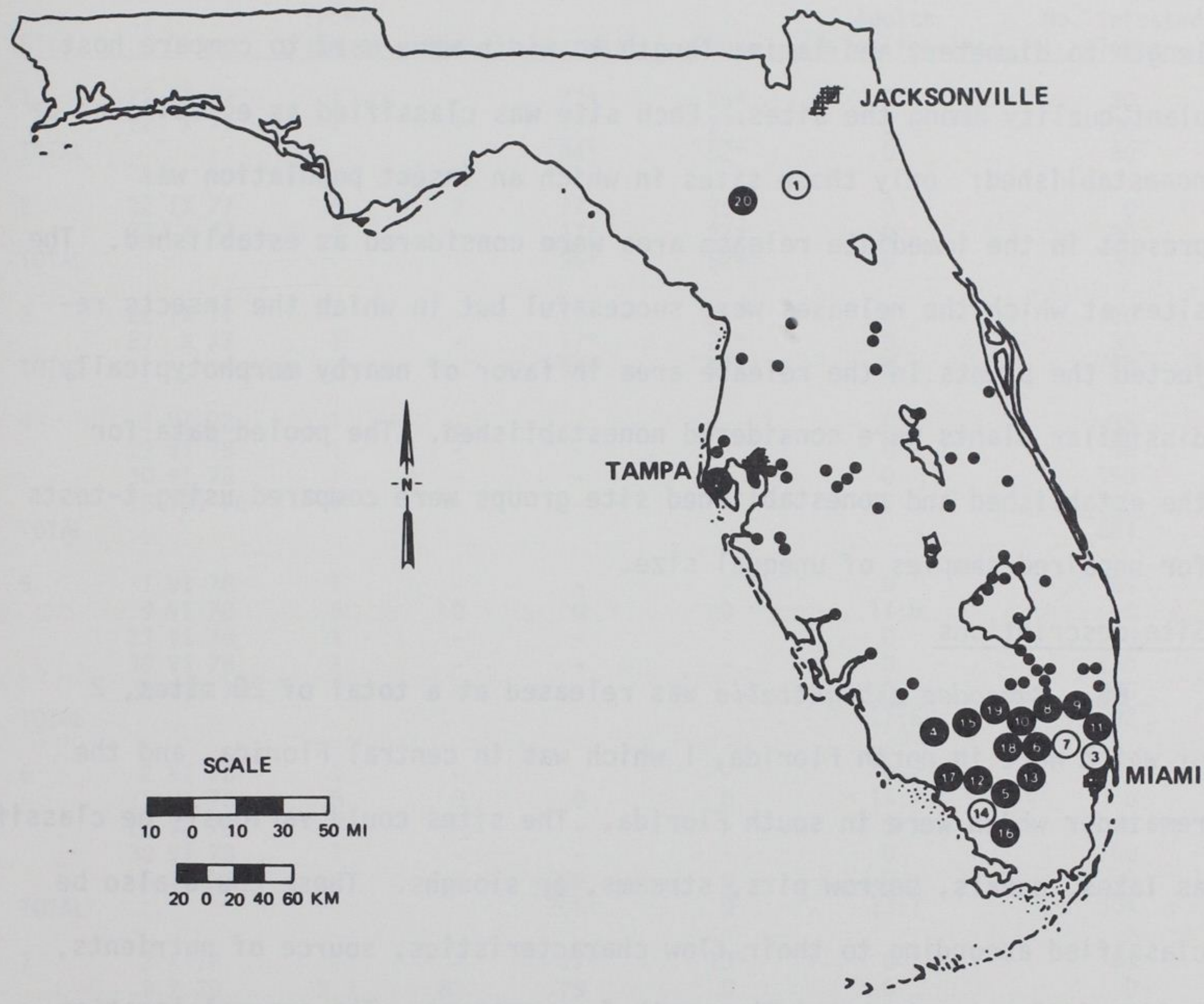

Figure 26. Populations of S. albiguttalis established in Florida by September 1979. Numbered circles represent the release sites; solid circles represent sites in which the releases resulted in the successful establishment of a population. Open circles represent those sites in which no establishment resulted. Solid dots represent populations that dispersed from and became established outside of the release areas 
compared to the length of the leaves, and had long, spindly petioles with narrow, lanceolate laminae. Waterhyacinth growing under optimal conditions displayed shorter roots, stouter petioles, and more reinform, orbicular leaves. Therefore, the ratios of the root length to leaf length, petiole length to diameter, and lamina length to width were used to compare host plant quality among the sites. Each site was classified as established or nonestablished: only those sites in which an insect population was present in the immediate release area were considered as established. The sites at which the releases were successful but in which the insects rejected the plants in the release area in favor of nearby morphotypically dissimilar plants were considered nonestablished. The pooled data for the established and nonestablished site groups were compared using t-tests for unpaired samples of unequal size.

\section{Site descriptions}

85. Sameodes albiguttalis was released at a total of 20 sites, 2 of which were in north Florida, 1 which was in central Florida, and the remainder which were in south Florida. The sites could variously be classified as lakes, canals, borrow pits, streams, or sloughs. These could also be classified according to their flow characteristics, source of nutrients, and predominant waterhyacinth growth form present. The general location of each site, designated by number, is illustrated in Fig. 26. A summary of the number of insects released and the type of release made is presented in Table 1. The site descriptions are as listed in the following paragraphs.

86. Site 1. Edgar, Putnam County: This site was in a small pond (<20 ha) from which water was pumped by a sand-processing plant, used in washing operations, and then returned to the pond. No input source or discharge outlet 
Table 1. Details of the Sameodes albiguttalis releases in Florida. Site numbers refer to Figure 26. Release technique numbers refer to the text in the methods and materials section ( $p p 73-74)$. Dashes indicate that no count or estimate of numbers was made.

No. S. albiguttalis released

\begin{tabular}{|c|c|c|c|c|c|c|c|}
\hline Site & Date & $\begin{array}{l}\text { Tech- } \\
\text { niques }\end{array}$ & Eggs & Larvae & Pupae & $\begin{array}{l}\text { Adults } \\
\text { (males: females) }\end{array}$ & $\begin{array}{l}\text { No. infested } \\
\text { Plants }\end{array}$ \\
\hline $\begin{array}{l}1 \\
\text { TOTAL }\end{array}$ & $\begin{array}{l}22 \text { IX } 77 \\
22 \\
\times\end{array}$ & $\begin{array}{l}1 \\
1\end{array}$ & - & $\begin{array}{l}77^{\star} \\
17^{\star} \\
94^{\star}\end{array}$ & $\begin{array}{l}25^{\star} \\
27^{\star} \\
52^{\star}\end{array}$ & $\begin{array}{l}0 \\
0 \\
0\end{array}$ & $\begin{array}{l}30 \\
30 \\
60\end{array}$ \\
\hline $\begin{array}{l}2 \\
\text { TOTAL }\end{array}$ & $\begin{array}{rrr}22 & \text { IX } & 77 \\
27 & \times 77\end{array}$ & $\begin{array}{l}6 \\
1\end{array}$ & $\begin{array}{l}0 \\
-\end{array}$ & $\begin{array}{l}77 \\
17^{\star} \\
94^{\star}\end{array}$ & $\begin{array}{l}25 \\
27^{\star} \\
52^{\star}\end{array}$ & $\begin{array}{l}0 \\
0 \\
0\end{array}$ & $\begin{array}{r}0 \\
30 \\
30\end{array}$ \\
\hline $\begin{array}{l}3 \\
\text { TOTAL }\end{array}$ & $\begin{array}{rrr}22 & \text { IX } & 77 \\
27 & \times & 77\end{array}$ & $\begin{array}{l}1 \\
1\end{array}$ & - & $\begin{array}{l}77^{\star} \\
17^{\star} \\
94^{\star}\end{array}$ & $\begin{array}{l}25^{\star} \\
27^{\star} \\
52^{\star}\end{array}$ & $\begin{array}{l}0 \\
0 \\
0\end{array}$ & $\begin{array}{l}30 \\
30 \\
60\end{array}$ \\
\hline $\begin{array}{l}4 \\
\text { TOTAL }\end{array}$ & $\begin{array}{llll}1 & \text { VI } & 78 \\
23 & \text { VI } & 78 \\
30 & \text { VI } & 78 \\
28 & \text { VII } & 78\end{array}$ & $\begin{array}{l}1 \\
1 \\
1 \\
1\end{array}$ & $\begin{array}{l}- \\
- \\
-\end{array}$ & $\begin{array}{l}- \\
-\end{array}$ & $\begin{array}{l}- \\
- \\
-\end{array}$ & $\begin{array}{l}0 \\
0 \\
0 \\
0\end{array}$ & $\begin{array}{r}35 \\
96 \\
150 \\
300 \\
581\end{array}$ \\
\hline $\begin{array}{l}5 \\
\text { TOTAL }\end{array}$ & $\begin{array}{rlll}1 & \text { VI } & 78 \\
9 & \text { VI } & 78 \\
23 & \text { VI } & 78 \\
30 & \text { VI } & 78 \\
28 & \text { VII } & 78\end{array}$ & $\begin{array}{l}1 \\
5 \\
1 \\
1 \\
1\end{array}$ & $\begin{array}{l}\overline{0} \\
\overline{-} \\
\overline{-}\end{array}$ & $\begin{array}{l}\overline{0} \\
- \\
- \\
-\end{array}$ & $\begin{array}{l}\overline{0} \\
- \\
- \\
-\end{array}$ & $\begin{array}{c}0 \\
11: 6 \\
0 \\
0 \\
0 \\
11: 6\end{array}$ & $\begin{array}{r}64 \\
0 \\
78 \\
150 \\
300 \\
592\end{array}$ \\
\hline TOTAL & $\begin{array}{rrr}2 & \text { VI } & 78 \\
13 & \text { VI } & 78 \\
23 & \text { VI } & 78 \\
30 & \text { VI } & 78 \\
5 & \text { IX } & 78\end{array}$ & $\begin{array}{l}1 \\
5 \\
1 \\
1 \\
3\end{array}$ & $\begin{array}{l}\overline{0} \\
\overline{-} \\
\overline{0}\end{array}$ & $\begin{array}{c}\overline{0} \\
- \\
\overline{-} \\
206 \\
206+\end{array}$ & $\begin{array}{l}- \\
\overline{0} \\
- \\
\overline{0} \\
\overline{0}\end{array}$ & $\begin{array}{c}0 \\
13: 7 \\
0 \\
0 \\
0 \\
13: 7\end{array}$ & $\begin{array}{r}64 \\
0 \\
90 \\
150 \\
0 \\
304\end{array}$ \\
\hline TOTAL & 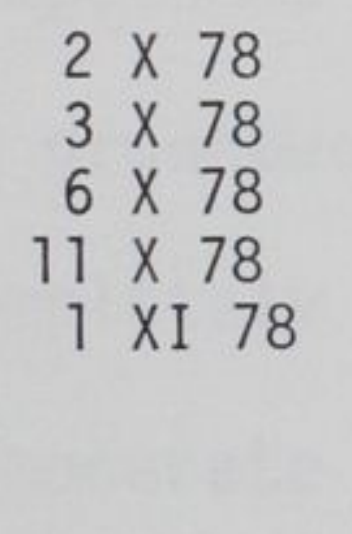 & $\begin{array}{c}1 \\
2,3 \\
3 \\
6 \\
6\end{array}$ & $\begin{array}{r}- \\
83 \\
0 \\
0 \\
0 \\
83\end{array}$ & $\begin{array}{c}27^{\star} \\
79 \\
133 \\
85 \\
53 \\
377 \\
\text { (Contin }\end{array}$ & $\begin{array}{c}13^{\star} \\
0 \\
0 \\
5 \\
0 \\
18\end{array}$ & $\begin{array}{l}0 \\
0 \\
0 \\
0 \\
0 \\
0\end{array}$ & $\begin{array}{r}64 \\
0 \\
0 \\
0 \\
0 \\
64\end{array}$ \\
\hline
\end{tabular}

* Refers to estimates based upon a subsample of the infested plants. These figures were not used in the grand total in order to avoid duplication with infested plant counts. 
Table 1. (continued)

No. S. albiquttalis released

\begin{tabular}{|c|c|c|c|c|c|c|c|}
\hline Site & Date & $\begin{array}{l}\text { Tech- } \\
\text { niques }\end{array}$ & Eggs & Larvae & Pupae & $\begin{array}{l}\text { Adults } \\
\text { (males: females) }\end{array}$ & $\begin{array}{l}\text { No. infested } \\
\text { Plants }\end{array}$ \\
\hline $\begin{array}{c}8 \\
\text { TOTAL }\end{array}$ & $\begin{array}{rl}12 & \times 78 \\
2 & X I 78 \\
13 & X I 78\end{array}$ & $\begin{array}{c}1 \\
1 \\
2,3\end{array}$ & $\frac{-}{35}$ & $\begin{array}{l}263^{*} \\
260^{\star} \\
424 \\
947\end{array}$ & $\begin{array}{r}238 * \\
60 * \\
0 \\
298\end{array}$ & $\begin{array}{l}0 \\
0 \\
0 \\
0\end{array}$ & $\begin{array}{r}125 \\
100 \\
0 \\
225\end{array}$ \\
\hline 9 & $13 \times 78$ & 1 & - & - & - & 0 & 100 \\
\hline 10 & $12 \times 78$ & 1 & - & $934 *$ & $16 *$ & 0 & 161 \\
\hline $\begin{array}{l}11 \\
\text { TOTAL }\end{array}$ & $\begin{array}{ll}22 & \text { VIII } 78 \\
12 & \text { IX } 78 \\
14 & \text { IX } 78\end{array}$ & $\begin{array}{l}3 \\
3 \\
3\end{array}$ & $\begin{array}{l}0 \\
0 \\
0 \\
0\end{array}$ & $\begin{array}{r}150 \\
16 \\
53 \\
219\end{array}$ & $\begin{array}{l}0 \\
0 \\
0 \\
0\end{array}$ & $\begin{array}{l}0 \\
0 \\
0 \\
0\end{array}$ & $\begin{array}{l}0 \\
0 \\
0 \\
0\end{array}$ \\
\hline $\begin{array}{l}12 \\
\text { TOTAL }\end{array}$ & $\begin{aligned} 7 \text { XII } 78 \\
11 \text { XII } 78\end{aligned}$ & $\begin{array}{l}2,3 \\
2,3\end{array}$ & $\begin{array}{l}165 \\
400 \\
565\end{array}$ & $\begin{array}{r}714 \\
530 \\
1244\end{array}$ & $\begin{array}{l}0 \\
0 \\
0\end{array}$ & $\begin{array}{l}0 \\
0 \\
0\end{array}$ & $\begin{array}{l}0 \\
0 \\
0\end{array}$ \\
\hline 13 & 11 I 79 & 2 & 590 & 0 & 0 & 0 & 0 \\
\hline 14 & 11 I 79 & 2 & 619 & 0 & 0 & 0 & 0 \\
\hline 15 & 16 I 79 & 2,3 & 1769 & 1052 & 0 & 0 & 0 \\
\hline 16 & 30 I 79 & 3 & 0 & 409 & 0 & 0 & 0 \\
\hline 17 & 30 I 79 & 2 & 4701 & 0 & 0 & 0 & 0 \\
\hline 18 & 2 II 79 & 1,5 & 5317 & 0 & 0 & $42: 24$ & 0 \\
\hline 19 & 2 II 79 & 3 & 0 & 1847 & 0 & 0 & 0 \\
\hline 20 & 23 III 79 & 3 & 0 & 11,784 & 0 & 0 & 0 \\
\hline & 24 III 79 & $\begin{array}{l}2,3 \\
4,5\end{array}$ & 35,984 & 5,361 & 31 & $120: 85$ & $\begin{array}{l}0 \\
-\end{array}$ \\
\hline TOTAL & & & 35,984 & 17,145 & 31 & $120: 85$ & 0 \\
\hline GRAND & TOTAL & & 49,663 & 22,973 & 61 & $186: 122$ & 2177 \\
\hline
\end{tabular}


was present; therefore, the only flow provided was from the pumping of the water to and from the plant. Waterhyacinth completely covered the pond in the release area and were very spindly in appearance and dry and tough in texture. The plants apparently benefited from the pumping operations because when pumping ceased in 1ate 1978, the plant condition deteriorated. The site can be classified as a shallow, stagnant, low nutrient, sandy bottom pond containing waterhyacinth plants with a generally unhealthy appearance.

87. Site 2. Sawgrass Lake, Pinellas County: Located near Pinellas Park just outside of St. Petersburg, this site was in a lake in a park administered by the county school system as a nature conservation area. The majority of the water supplied to the lake was from surface runoff from surrounding urban areas but a minor portion came from rather limited agriculture. This drainage water flowed into a lake through a canal at the northwest end and the discharge outlet was through a canal at the southwest end. Waterhyacinths covered nearly the entire lake and were generally very tall and robust. Both nutrients and flow were moderate but varied according to the seasonal patterns of rainfall.

88. Site 3. Borrow Pit, Broward County: This site was a large, waterfilled, impounded excavation with virtually no flow. Input to the pit was primarily groundwater with some runoff from surrounding agricultural land. It was completely covered with waterhyacinth which were tough and dry in texture, of moderate height, and generally spindly in appearance. The plants were extremely crowded, to the extent that during periods of low water they were suspended slightly above the water surface. Nutrients were probably low to moderate and the water was stagnant. 
89. Site 4. Stream near Copeland, Collier County: This was a small stream which drained the sawgrass marshes surrounding Fakahatchee strand and was probably enriched by pollutants from the sewage of nearby residential areas. Flow was moderate and the stream drained into the Tamiami Canal to the south. The section of the stream between U. S. 29 and Janes Memorial Drive was covered with tall very robust waterhyacinth plants. A limited fringe of small plants occurred at the edge of the mat to the south.

90. Site 5. Orchid Isles, Collier County: This was a slough in Gator Hook Strand fed by drainage from the Tamiami Canal and the surrounding Big. Cypress Swamp. The drainage water passed from Big Cypress to the Canal, through a bridge on U. S. 41 into the slough, and ultimately into Gator Hook Swamp in a generally north to south direction. The site was located near the bridge on the south side of U. S. 41. Flow rates were seasonally variable and dependent upon precipitation. The waterhyacinth growth was luxuriant during periods of high water but very retarded during drought.

91. Site 6. Conservation area 3A, canal L-67A, Dade County: This site was in the canal that extends from the Miami Canal $(C-123)$ to the southwest through the Everglades Conservation Area to the Tamiami Canal (see Fig. 27). It is formed by an earthen dike on the southeast side and drains the conservation area to the northwest through channels between earthen mounds which border that side. It also receives water from the Miami Canal which consists of runoff from extensive agricultural areas draining into Lake Okechobee to the north. It is therefore relatively high in nutrients. The site was originally between two of the earthen mounds on the northwest side of the canal about 1 mile southeast of the Dade-Broward County line. Waterhyacinth was growing ca. $20 \mathrm{~m}$ from the edge of the canal in a clearing surrounded by 


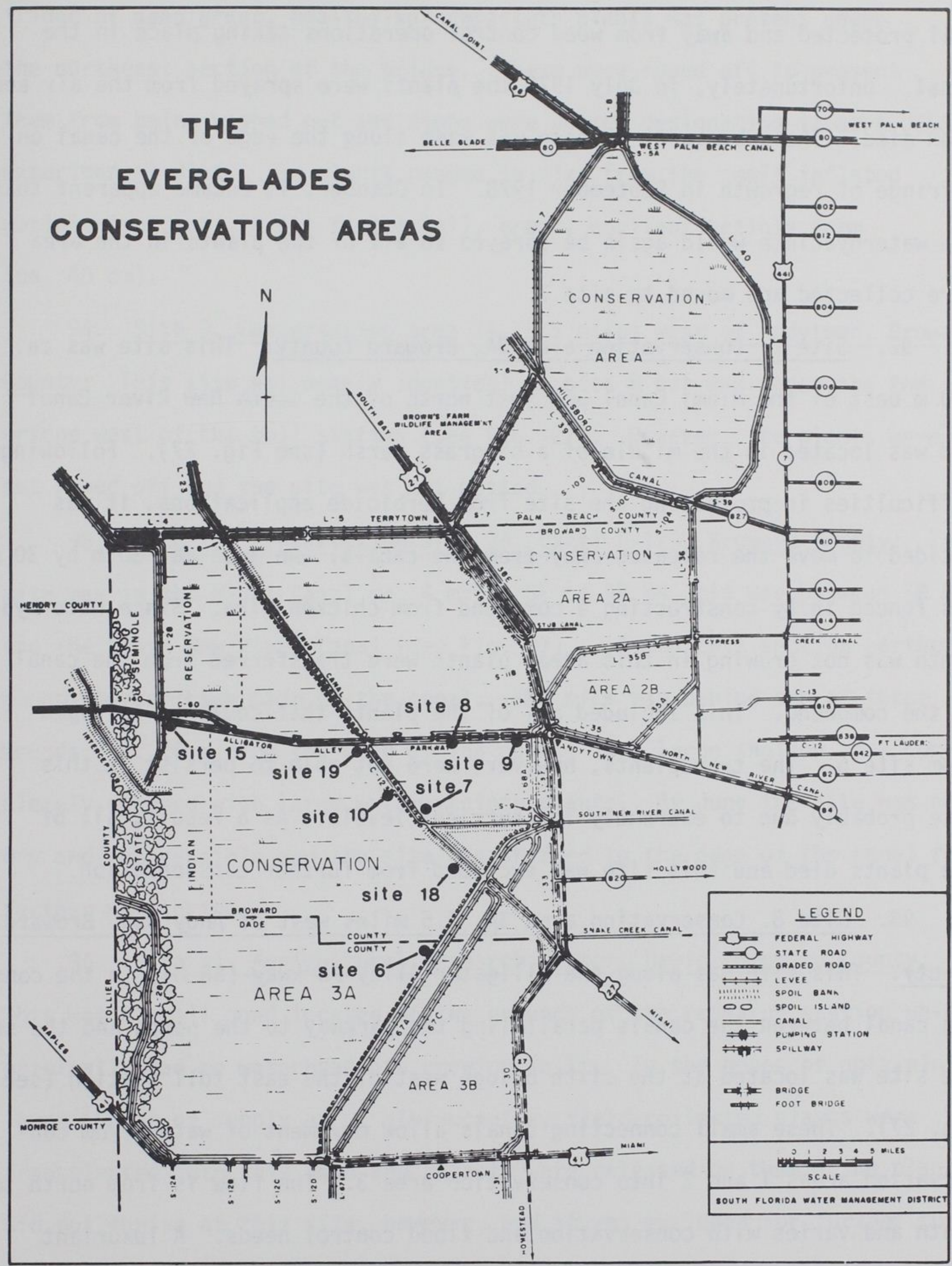

Figure 27. Locations of the eight release sites within the Everglades Conservation Area. These comprise the most successful releases and the most extensive populations of $S$. albiguttalis now established 
sawgrass. This area was chosen as a release site because it appeared to be well protected and away from weed control operations taking place in the canal. Unfortunately, in July 1978 the plants were sprayed from the air and soon died. The subsequent release was made along the edge of the canal on a fringe of regrowth in September 1978. In October, it became apparent that the waterhyacinth would again be sprayed so all of the plants in the area were collected and moved to site 7 .

92. Site 7. Conservation area 3A, Broward County: This site was ca. $300 \mathrm{~m}$ east of the Miami Canal and just north of the South New River Canal and was located in the middle of a sawgrass marsh (see Fig. 27). Following difficulties in protecting the site from herbicide applications, it was decided to move the releases away from the canals. An area ca. $30 \mathrm{~m}$ by $30 \mathrm{~m}$ was fenced in by constructing a compound from chicken wire. Since waterhyacinth was not growing in this area, plants were transferred from the canal to the compound. This included all of the plants that could be salvaged from site 6 . The transplants, however, were not able to persist at this site probably due to extremely low nutrient levels. As a result, all of the plants died and this site was excluded from further consideration.

93. Site 8 . Conservation area $3 A, 6.5$ miles west of Andytown, Broward County: This site was along the Alligator Alley Parkway (SR 84) in the connecting canal between the canals paralleling the parkway to the north and the south. The site was located at the sixth bridge west of the east toll station (see Fig. 27). These small connecting canals allow movement of water from conservation areas 1 and 2 into conservation area 3 . The flow is from north to south and varies with conservation and flood control needs. A luxuriant 
fringe of deep green, heal thy waterhyacinth plants was present under the northeast section of the bridge. These were roped off to prevent them from being washed out and signs were posted designating it as a USDA experimental plot. The plants ranged in size from the small inflated petiole type $(\mathrm{ca} .10 \mathrm{~cm})$ to the tall, erect, equitant petiole form (ca. $40 \mathrm{~cm}$ ).

94. Site 9. Conservation area 3A, 2.5 miles west of Andytown, Broward County: This site was nearly identical to site 8 but was under the 2nd bridge west of the toll station (see Fig. 27). However, the plants were not roped off and the site was not posted.

95. Site 10. Conservation area 3A, Canal C-123, Broward County: This site was in the Miami Canal ca. 4 miles SE of SR 84; mid way between SR 84 and the South New River Canal (see Fig. 27). Along this section earthen mounds border each side of the canal. The site was behind one of these mounds, ca. $20 \mathrm{~m}$ from the edge of the canal, in a large shallow area completely covered with large waterhyacinth plants. By June the site was nearly dry and inaccessible and the site was shifted to the edge of the canal for further monitoring.

96. Site 11. Agricultural Research Center, Davie, Broward County: This was a small pond located on the grounds of the research station which originally had no waterhyacinth growing in it. In the hopes of obtaining a large source of supply of $S$. albiguttalis, field-collected plants were transplanted into this pond and insects were released on them. The plants did not thrive at this site, however, and it was excluded for further consideration. 
97. Site 12. 3 miles west of Monroe Station, Collier County: This site was at a rest stop along U. S. 41 at which a boardwalk has been built through a portion of a cypress stand. Waterhyacinths were growing in the open water under the cypress canopy in the area enclosed by the boardwalk. The release point was ca. 7 - $8 \mathrm{~m}$ from the east end of the boardwalk where the plants ranged from $10-30 \mathrm{~cm}$ in height. Water flow varied seasonally and was in a north to south direction.

98. Site 13. 3 miles west of Dade-Collier Airport, Collier County: This site was a small stream on the south side of U. S. 41 which receives water from the Tamiami Canal. The flow runs from the north to the south but forks a short distance from the road to the southeast and the southwest. The release site was at this fork between the two branches of the stream and was under a cypress canopy. The plants varied tremendously depending upon the quantity of water present and the rate of flow. During drought the water became extremely low and the plants became stunted and rooted in the mud. During the rainy season, the plants were generally tall and luxuriant. Overall, this site was similar to site 5.

99. Site 14. 7 miles south of Monroe Station, Collier County: This site was in a canal parallel with SR 94 and extended south, perpendicular to the Tamiami Canal, and through Gator Hook Strand. The canal was ca. 10 $m$ wide and completely covered with waterhyacinths ranging from $30-80 \mathrm{~cm}$ in height. Water flow varied with rainfall and the resultant drainage from Big Cypress Swamp. The waterhyacinth mat was extremely dense and the plants were growing in very crowded conditions. The stand is quite old and has been present for several years, apparently undisturbed by control operations. 
The leaf petioles were very tough, fibrous, and dry in texture and plants with inflated petioles were not present.

100. Site 15. Conservation area $3 A, 24.5$ miles west of Andytown, Broward County: The release site was at the extreme west end of the canal running parallel to and south of SR 84 and was on the Seminole Reservation just east of levee L-28 (see Fig. 27). The waterhyacinth plants in this area were generally luxuriant, variable in size, and consisted of free-floating mats that were blown to the end of the canal by east winds. The release point was at a fringe of small plants $\mathrm{ca} .20 \mathrm{~cm}$ in height. The site was very similar to sites 8,9 , and 19 .

101. Site 16. 5 miles south of Monroe Station, Collier County: This site was in the primary slough through Sweetwater Strand ca. $50 \mathrm{~m}$ south of the point where it crosses SR 94. Being one of the primary drainage areas into Gator Hook Swamp, it is wet throughout the year and not as subject to seasonal fluctuations as many of the other sites. Flow is generally from the northeast to the southwest. The plants varied in size although most were small (ca. $20 \mathrm{~cm}$ ) with inflated petioles at the time the releases were made. The plants were growing under the cypress canopy and were shaded most of the day.

102. Site 17. 5 miles east of Ochopee, Collier County: This site was in a small creek just east of the Turner River Canal along SR 41. The current was very swift and the creek flowed from the north to the south. The plants were growing under overhanging shrubs and small trees and were in the shade most of the day. Most of the plants were small with inflated petioles although a few, which were retained in place by fallen trees, were quite large.

103. Site 18. Conservation area 3A, Broward County: This site consisted of a large population of waterhyacinths growing in an airboat trail 
just southwest of the Miami Canal (C-123). The surrounding area was predominantly sawgrass marsh (see Fig. 27). The plants in the middle of the trail were small with inflated petioles whereas those along the sides nearer to the sawgrass were ca. $60 \mathrm{~cm}$ in height. The flow in this area was slow and drainage was channeled to the southwest by the trail. The release point was at the edge of the trail in the taller plants.

104. Site 19. Conservation area $3 A, 11.5$ miles west of Andytown, Broward County: The release site was in a stand of waterhyacinth growing in a flat grass area just south of the Alligator Alley canal near its intersection with the Miami Canal (see Fig. 27). The plants were less than $20 \mathrm{~cm}$ in height. The water level was low at the time the insects were released and a few of the plants were rooted in the exposed mud. The water flow in this area was variable and was regulated by flood control structures.

105. Site 20. Lake Alice, Gainesville, Alachua County: This site was located on a lake on the University of Florida campus that covers an area of 33 ha. Approximately 20 ha was a marsh separated from 13 ha of open lake by a fence and a boardwalk. Although waterhyacinths once occurred abundantly on both portions, the effects of Neochetina eichhormiae and possibly Cercospora spp. have reduced it to a few hectares within the marsh. The average depth of the lake was $1.3 \mathrm{~m}$ while that of the marsh was $0.5 \mathrm{~m}$. The total storage capacity of the lake was $254 \times 10^{3} \mathrm{~m}^{3}$ at a level of $21 \mathrm{~m}$ mean sea level (ms 1 ), and the major source of water was effluent from the University sewage treatment plant (ca. 50\%), with the remainder from overflow of a small sinkhole, direct rainfall, and runoff. Discharge was regulated by weirs above deep wells. Nutrients were quite high due to the heavy sewage load input. At the time of release the plants were small $(16 \mathrm{~cm}$ ) 
with inflated petioles. Within 2 months, however, they had nearly quadrupled in size. A release area was staked out which was 12 by $6 \mathrm{~m}$ and was located in the marsh ca. $21 \mathrm{~m}$ east of the boardwalk. 


\section{Results, Insect Releases and Chronological Observations by Site}

Site 1

106. The first release at this site consisted of infested plants from the USDA colony established at the Gainesville quarantine facility. A subsample of the plants was dissected to estimate the number of larvae and pupae contained in the plants but no estimate of the number of eggs present was obtained. On the morning of 22 Sept. 1977, ca. $10 \mathrm{~m}$ from the shoreline, a portion of the waterhyacinth mat was removed and replaced with the plants infested with $S$. albiguttalis. The release area was marked. A second, similar release was made at the same point a month later (22 0ct. 1977).

107. Three weeks after the last release (10 Nov. 1977), the site and the transplanted waterhyacinths were examined. Two larvae (one alive and one dead) were found within the petioles and one was found feeding externally on a leaf. All were on the plants placed in the site and there were no signs of dispersal to the surrounding plants. The first frost of the year occurred on 12 Nov.; several frosts occurred in December which severely damaged the emergent portions of the plants in this site. Observations were therefore discontinued until the plants had recovered in the spring. The site was again examined on 10 March 1978 and no larvae or signs of larval damage were found. A maximum-minimum thermometer which had been placed at the release point indicated that the minimum air temperature for the interim was ca. $-5^{\circ} \mathrm{C}$. Subsequent examinations on 21 June and 18 oct. 1978 and 20 Feb. and 14 June 1979 revealed no evidence of establishment at this site or at nearby sites. It was concluded that the releases in this site failed to result in the establishment of a population of S. albiguttalis. 
108. At the time of the first release, there was no evidence of the presence of the waterhyacinth weevils (Neochetina spp.) at this site. In order to compare sites with and without weevils, precautions were taken to avoid the accidental introduction of Neochetina with Sameodes. Plants for sites 1,2, and 3 were all collected from the greenhouse at the Gainesville Quarantine Facility. They were divided into three equal lots and one lot was dissected to estimate insect numbers. The larvae and pupae thus obtained were used for the release at this site and were not accompanied by the original plant material. Instead they were inoculated into waterhyacinth petioles from a "clean" quarantine culture of plants. Petioles containing the insects were placed under the waterhyacinth canopy at the site (to protect them from exposure) on 22 Sept. 1977.

109. On 12 oct. 1977, the site was found to have been disrupted. The area of the mat in which the release was made had shifted ca. $30 \mathrm{~m}$. The desiccated petioles which originally contained the larvae and pupae were found, however, but no signs of $S$. albiguttalis feeding or larvae were evident. Red spider mite damage was abundant. Damage by Neochetina spp. was evident, indicating that the weevil was, in fact, present at this site.

110. A second release of infested plants was made on 27 Oct. 1977 in the same manner described for sites 1 and 3. On 11 Nov. 1977, the site was again examined and no insects or signs of damage were found. It was noted that the water level had increased and it was learned that this was in preparation for moving a work barge across the lake. The waterhyacinth in the canal on the northwest side had been treated with a herbicide and airboat trails were evident in the lake.

111. The site was again examined on 5 Dec. 1977 and again no signs 
of $S$. albiguttalis were found. Officials at the lake indicated that the plants in the release area would be removed with a dragline in order to launch the barge. Because of this total disruption of the site and the lack of any sign of the insects, observations were discontinued. On 20 June 1978, however, it was decided that one last examination would be made. At that time it was noted that the plants had regrown in the area where they were removed and three larvae and one pupa of $S$. albiguttalis were found ca. $10 \mathrm{~m}$ from the original release point. These were in extremely large plants $(70-80 \mathrm{~cm})$ at the mouth of the northwest canal. On 22 Aug. 1978, the fringe of small plants at the top of the canal nearest the culvert (ca. $300 \mathrm{~m}$ northwest of the release point) were examined and were found to be extensively infested with S. albiguttalis. On 8 Sept. 1978, a permanent 100-m transect was established which extended from the culvert through the middle of the canal towards the release point. Data were taken at $10-m$ intervals along this transect at monthly intervals until 24 May 1979 when heavy rains and two broken sewer mains washed all of the plants out of the canal into the lake. The data indicated that the population was heaviest at the fringe of small young plants but extended well into the larger, older plants further up the canal.

112. Originally, it was considered highly improbable that a population of $S$. albiguttalis would develop in this site. The number of insects released was small; the first release required the insects to move from the plant fragments to the surrounding plants; the type of plant present seemed unsuitable; and the release area was continually disturbed. In spite of these problems, a population did develop and has persisted until the present time (Jan. 1980). It was concluded that establishment had occurred in this 
site but the insect population moved from the release area to more suitable plants in the canal.

Site 3

113. The first release at this south Florida site was made on the same day as those at sites 1 and 2 (22 Sept. 1977). The source of insects and the release procedure were identical to the site 1 release. A second release was made on 27 0ct. 1977 which was identical to that described for site 2 on the same date. The site was examined on 17 oct., 31 0ct., 18 Nov., and 8 Dec. 1977, on 23 Mar. and 1 Aug 1978, and on 12 June 1979. No sign of $S$. albiguttalis was ever found except initially and only on the introduced plants in which empty cocoons were present indicating that adults had emerged. In Nov. 1977, a light trap was set up on the lake in an attempt to attract any adults present but none were recovered. It was concluded that the releases at this site did not result in the establishment of a population. Site 4

114. As of the spring of 1978 no positive results were evident at any of the original three release sites. It was decided, therefore, to make an intense effort at establishing several field populations of $S$. aZbiguttalis. Assuming that none of the northern releases were successful, it was also decided to make all subsequent releases in south Florida. This would restrict releases within a defined zone and provide a starting point from which to monitor the dispersal of subsequent generations. This site was the first selected for this purpose and a concerted effort was made to establish the insect there.

115. Four releases were subsequently made at this site on 1 June, 23 June, 30 June, and 23 July 1978, and a total of 581 infested plants were placed in the mat. It was thought that the use of infested plants would be the 
most effective type of release since it would result in minimal disturbance to the insects. Each time the site was examined, if no insects were found, a new release was made.

116. The first release consisted of 35 plants which were placed within the existent waterhyacinth mat. A screen cage $\left(1 \mathrm{~m}^{3}\right)$ was placed over the plants to protect and confine the insects. On 9 June, the cage was found to have been toppled over by a large rock and no insects were recovered. On June 23, still no indication was found that the insects were present, and an additional 93 infested plants were placed in the middle of the stream but not in the cage. On 30 June, there was again no positive evidence that a population had become established and an additional 150 infested plants were placed near the shore in the shade. The area was examined again on 28 July 1978 and eight empty cocoons and one dead pupa were found in the plants placed at the site on 30 June, but no living insects were found. The last release was made at that time which consisted of 300 infested plants placed in an area of open water.

117. Additional examinations were made in the release area on 27 Sept., 24 Oct., and 28 Nov. 1978, and on 1 Jan., 27 Feb., 20 Mar., 30 Apr., and 25 May 1979; no insects were recovered. On 25 May 1978, however, plants were collected ca. $1.5 \mathrm{~km}$ south of the release site and several larvae were found. On 19 June, the release site was again examined with negative results. Larvae were found, however, on the fringe of plants near the bridge at Janes Memorial Drive ca. $150 \mathrm{~m}$ south of the release point. These plants possessed very globose, inflated petioles. The site was, therefore, considered as one in which a population of $S$. albiguttalis became established in the same continuous waterhyacinth mat but not on the plants in the immediate release area. 
Site 5

118. The first release at this site was made on 1 June 1978, when 64 waterhyacinth plants, infested with Sameodes, were transplanted from the greenhouse culture to the field site. The plants were divided into two groups: 34 were placed in a screen cage with field plants and 30 were placed just outside of the cage. On 9 June, the site was examined with negative findings and 17 adults ( 11 males and 6 females) were released in the cage. Negative results again were obtained on 23 June 1978, and an additional 78 infested plants were transplanted in the site. These plants were examined on 30 June and S. albiguttalis larvae were found within the petioles. The plants in the cage were also examined and no signs of larvae or larval damage to the plants was observed. The area was then swept with an insect net and a single adult female was subsequently collected. An additional 150 plants were placed at the site in the shade of the cypress trees. The last release consisted of another 150 infested plants placed at the bridge near the road on 28 July 1978, after once again failing to locate any evidence that the previous releases had been successful.

119. Subsequent examinations on 27 Sept., 24 Oct., and 28 Nov. 1978 and 11 Jan. 1979 repeatedly produced negative findings, but on 16 Feb. 1979 a larva was found on a small plant with inflated petioles near the edge of the mat. Observations from $27 \mathrm{Feb}$. and $30 \mathrm{Apr}$. again indicated a lack of establishment, but on 5 June 1979 a population of small plants in the Tamiami Canal across the road (ca. $30 \mathrm{~m}$ ) from the release point showed signs of extensive damage by $S$. albiguttalis larvae and an adult female was collected. An examination of plants in the canal to the east and west of that point indicated that the population was restricted to that area and most likely 
originated from the releases in the adjacent site. This site was, therefore, considered established with the population originating from the releases but having moved to more suitable plants in an adjacent area.

Site 6

120. The initial release at this site was very similar to that at sites 3 and 4 . A total of 64 infested plants were placed in the site on 2 June 1978, with 28 plants placed inside a screen cage and the remainder placed outside and adjacent to the cage. On 7 June, the site was examined; no signs of $S$. albiguttalis could be detected either inside or outside the cage. A supplemental release of 20 adults (13 males and 7 females) was made on 13 June. The plants were examined again at that time and no indication of establishment was evident. On 23 June, the plants originally placed in the site on 2 June were examined and one pupa and a first instar larva were found. An additional 90 infested plants were placed in the release area on the same date. On 30 June, upon examining the site, an adult was collected and released and an additional 150 infested plants were placed in the mat. Two of these plants were dissected and six pupae were found in one and five pupae and several larvae in the other, which indicated that they were heavily infested. The plants in the cage were re-examined and again the presence of $S$. albiguttalis was not indicated. At this time it appeared, however, that a population was beginning to develop.

121. When the site was again examined on 28 July, the plants were showing signs of having recently been treated with a herbicide. The leaves were burned in a blotchy pattern, were beginning to reflex just below the lamina, and the odor of chemicals was evident. One larva and one pupa were found in the plants from the previous release. A subsequent release had been planned but was cancelled due to the herbicide application. By 
5 Sept. all of the plants in the release area had disappeared.

122. With the loss of the original release area, a secondary area was selected for further work. This consisted of a small patch of plants on the edge of the canal ca. 20 - $30 \mathrm{~m}$ from the original site. The plants were small and apparently represented an area of regrowth which was recovering from the past herbicide treatment. A total of 206 first instar larvae were placed on these plants on 5 Sept. 1978. An examination of seven of these plants on 15 Sept. found six larvae. Additional plants both above and below the site on the canal were examined and no signs of the insect were found. On 18 Sept. the site was rechecked and five larvae were found at the release point. On 2 oct., plants along the canal had again been treated with a herbicide but some of the plants in the release area had been missed. Two larvae and one pupa were found after dissecting five of these plants. Because of the potential for obtaining an established population here and the possibility that the plants would again be sprayed, the remaining plants at the release site were collected (64 total) and moved to a fenced compound in the middle of a sawgrass area in Conservation area $3 A$ (designated as site 7 ).

123. On 3 Jan. 1979, the plants had recovered from a repeated series of herbicide treatments which had been applied during October and November. One S. albiguttalis pupa was found in a plant along the edge of the canal at the new release site. On 8 Feb. 1979, larvae were found all along the canal bordering the earthen mound where the September release had been made. By late February plants along the entire length of the canal were showing signs of being infested with larvae. The site was considered to have a wellestablished, extensive $S$. albiguttalis population in spite of the many problems encountered in the area. 


\section{Site 7}

124. Because of increasing problems with protecting release sites from weed control operations, an attempt was made to establish a population of S. albiguttalis in the Everglades Conservation Area well away from the canal system and maintenance operations. An area of open, relatively deep water was located in a flat grass area well into the sawgrass marsh of Conservation area $3 A$. Since waterhyacinth was not naturally present here, it was necessary to transplant them to this site. A large, fenced compound was first constructed and plants were then collected from the Miami Canal (between the South New River and Alligator Alley Canals) and placed in the compound. In addition, 64 plants from site 6 were salvaged and placed among the other plants in the compound. A total of 79 eggs and 83 neonates were also placed on these plants at the same time. This procedure was completed on 3 oct. 1978. On 6 0ct., an additional 98 neonates as well as 35 greenhouse-collected larvae (various instars) were released. An additional release was made on 11 0ct. which consisted of 83 neonates and 2 larvae and 5 pupae collected from the greenhouse culture. All of the releases were made in the southeast corner of the compound. By 19 0ct., extensive larval feeding was noted on these plants and 6 plants were found with heavy damage to the central leaf. At this time, the introduced plants appeared to be yellowing.

125. On 1 Nov. 1978, the site was inspected and, from 12 damaged plants which were examined, 2 empty cocoons were found. The waterhyacinth plants were beginning to become chlorotic and appeared to be stunted. A final release was made the following day which consisted of 53 larvae collected from the greenhouse culture.

126. By 3 Jan. 1979, no signs of $S$. albiguttalis were present on any of 
the plants in the compound. The plant condition continued to decline, and by 14 Feb. 1979, they were so small and chlorotic it became apparent that they could not persist in that area. When the site was again checked on 6 June 1979, there were no plants present. The site was abandoned and it was concluded that nutrients are too low in the sawgrass marsh to support a population of waterhyacinth.

\section{Site 8}

127. This site was under a bridge in a small connecting canal between parallel canals north and south of Alligator Alley. There was considerable water flow through this small canal which continually washed the waterhyacinth stands downstream into the main canals. Had this occurred to the plants upon which the insects were released, it would have been impossible to locate the population for subsequent evaluation. The plants were, therefore, held in place by a line which was attached to the bridge piling and a stake on shore.

128. The first release at this site was made on 12 0ct. 1978 and consisted of 125 infested plants collected from the greenhouse culture. Prior to placing the plants in the site, 20 plants were dissected and a total of 42 larvae and 38 pupae were found. Based on an average of 2.1 larvae and 1.9 pupae per plant, it was estimated that the 125 plants contained ca. 263 larvae, 238 pupae, and an unknown quantity of eggs. The infested plants as well as the insects removed from the sample were then placed among the waterhyacinths below the bridge.

129. By 1 Nov., it appeared that a S. albiguttalis population was established at this site. One fourth instar larvae, two pupae, and one empty cocoon were found in the "wild" plants at the site and larvae and pupae were still present in the introduced plants. In addition, two adult males were 
collected among the plants. A second release of 100 infested plants was made the next day (2 Nov.) to augment the developing population. This release consisted of an estimated 260 larvae and 60 pupae (based on a sample of 10 plants). The last release was made on 13 Nov. 1978 and consisted of 424 neonates and 35 eggs.

130. The site was again examined on 22 Nov. 1978 and abundant larval damage was evident. Six plants collected at the edge of the mat showed extensive signs of late instar damage. One plant was found ca. $13 \mathrm{~m}$ from the release point with first instar larvae feeding on the leaves. The population appeared to have declined (based on the extent of larval damage observed) by 12 Dec. and an examination of $30 \mathrm{plants}$ failed to recover any larvae. However, three adults were sighted and one male was collected, which verified the presence of a population.

131. By 3 Jan. 1979, abundant damage to the plants was again obvious. Ten damaged plants were collected and a single larva was found. On 13 Feb. 1979 most of the plants in the area had been sprayed but the posted release point was spared. By 7 June, S. albiguttalis and the signs of their activity were present throughout the area. The site was considered well established. Site 9

132. This site was very similar to site 8 in terms of location, the type of plants present, and the type of release made. Only one release was attempted, which was made on 13 oct. 1978, and consisted of 100 infested plants. Because so few plants were available, none were sacrificed to estimate the number of insects present although the average per plant was probably similar to that estimated for site 8 the previous day.

133. Although the plants at this site were also originally held in place 
by a line, the line was stolen and by 1 Nov., ca. $50 \%$ of the plants had drifted out of the area. The plants that had been introduced were still present, however, and larvae and pupae were in them. By 22 Nov., only a few plants which were held in place by a stand of cattail remained in the site. An examination of these plants revealed no sign of S. albiguttalis. A re-examination on 3 Jan. 1979 again yielded negative results. By 12 Feb., the area had been treated with herbicides but larval damage was present on the few remaining plants. An examination of 18 leaf petioles resulted in the recovery of four larvae. By 7 June 1979, damage was present throughout the area and the site was considered established.

Site 10

134. The only release at this site was made on 12 0ct. 1978 behind one of the levee mounds; it consisted of 161 infested plants collected from the greenhouse culture. A sample of 10 of these plants contained 58 larvae and 1 pupa for an estimated total release of 834 larvae and 16 pupae. When the site was examined on 1 Nov., the plants which were released could not be found. The waterhyacinth mat was very extensive, all of the plants were tall, and the growth was luxuriant.

135. No signs of $S$. albiguttalis larvae or damage could be found when the site was examined on 22 Nov. 1978, on 3 Jan. 1979, or on 8 Feb. 1979. On 9 Feb., however, plants along the canal (ca. $30 \mathrm{~m}$ distant of the release point) were examined and seven larvae were collected. Larvae were collected on 14 Feb., when two were found in 14 petioles examined. By 6 June 1979, the original site was inaccessible because of low water. The plants along the canal were, therefore, considered to be representative of the site and were used for the verification of establishment. Since the insect was present 
throughout the area at this time, the site was considered established. Site 11

136. This site was originally intended to be used as an on-station source of insects for the release program. Waterhyacinth did not normally grow in the pond so it was stocked with field-collected plants. Because of the naturally low nutrient concentration, artificial fertilization was required to keep the plants in good condition. Several releases were made in the pond. In addition, when insects were removed from plants from the greenhouse or other field sites, the remaining plant material was placed in the pond. This was to enable any unhatched eggs or overlooked larvae to survive. Also, when the plant material in the greenhouse began to deteriorate, it was removed and discarded in the pond. In short, the pond was a repository for surplus insects and plant material, and detailed records were not kept on the numbers released. A population did become established but, by that time, the site was no longer needed as a source of insects. As a result, it became neglected and the plants were no longer fertilized. The plant condition consequently deteriorated and the insect population disappeared. No conclusions could be made regarding the conditions leading to the establishment of the population due to the extremely artificial situation. The site was excluded from further consideration. Site 12

137. On 7 Dec. 1978, 714 neonates and 165 eggs were placed in the small, inflated petiole-type plants present at this site. Four days later (11 Dec.), an additional 530 neonates and ca. 400 eggs were released. The eggs from the previous release were checked and it was found that only a few hatched and the remaining eggs did not appear to be developing. By 11 Jan. 1979, one petiole with obvious S. albiguttalis damage was found, but no 
larvae or pupae were recovered. The situation was unchanged on $30 \mathrm{Jan}$. and the first larva was collected on 16 Feb. from a small group of plants stranded in a dry area resulting from the low water levels prevalent through the region. Because of its small size, however, it was not possible to positively identify it as $S$. albiguttalis.

138. On 5 June 1979, an adult male was observed resting on a waterhyacinth petiole in the site but an attempt to capture it failed. Damage apparently caused by $S$. albiguttalis larvae was present but no larvae or pupae were found. By 19 June, the amount of larval damage had significantly increased on the young plants although the larvae could still not be found. An adult male was collected, however, which finally verified the presence of a population in this site. It was considered to be established both in and around the original release point.

Site 13

139. A single release of 590 eggs was made at this site on 11 Jan. 1979 by placing lamina pieces containing the eggs under the wrapper leaf in the middle of the hyacinth plants. When the site was checked on 16 Feb., only 16 petioles were examined in order to avoid undue disturbance of the site. Several petioles showed signs of $S$. albiguttalis larval damage and two head capsules were found although no larvae were recovered. Subsequent re-examinations on 25 May, 5 June, and 19 June 1979 recovered several larvae and pupae each time. The site was considered to be well established and the population was obviously perpetuating.

\section{Site 14}

140. On 11 Jan 1979, leaf fragments containing eggs were pinned to the waterhyacinth plants growing in the canal. A total of 619 eggs were placed among the plants in this manner. All of the plants were tall at this 
site and the canal was completely covered with the waterhyacinth mat.

141. On 30 Jan. 1979, the leaf fragments were examined and no signs of the eggs or larvae were present; repeated examinations failed to recover any insects. The last observation at this site was made on $20 \mathrm{Dec}$. 1979, and no evidence of an established population was detected. It is felt that the dry, tough texture of the plants present at this site made them unsuitable for $S$. albiguttalis. This was one of the few sites at which the release attempts failed completely.

Site 15

142. On 16 Jan. 1979, 1769 eggs and 1052 neonates were placed on small waterhyacinth plants at the west end of the canal south of and parallel to SR 84. When the site was re-examined on 7 Feb., it was found to have been treated with herbicides. Plants were examined which had been missed by the spray crews and three second or third instar S. albiguttalis larvae were found. On 8 Mar., signs of extensive larval damage were present in the vicinity of the release point. In addition, a canal north of SR 84 (canal C-60) was checked at a point ca. $1.7 \mathrm{~km}$ from site 15 and plants with pupae were found. There were indications that $S$. albiguttalis was also present at several intermediate points between the $\mathrm{C}-60$ find and site 15 . The site was considered well established and a viable population was still present when the site was last examined on 7 June 1979.

Site 16

143. On 30 Jan. 1979, 409 first instar S. albiguttalis laryae were released in this site ca. $50 \mathrm{~m}$ from the road at a point where the stream widens from ca. $8 \mathrm{~m}$ to $20 \mathrm{~m}$. At that time, the water was partially covered with small plants of the inflated petiole form. On $27 \mathrm{Feb}$, the release was checked and it was found that the number of plants in the site had 
nearly doubled. Several plants showed signs of larval damage but no larvae or pupae could be found. By 5 June, the site was completely covered with waterhyacinth plants which had grown tall in response to the crowded conditions. An adult male was observed and collected at that time. On 17 June, a second adult male was collected and plants along the margin of the site were noted to be extensively damaged by $S$. aZbiguttaZis larvae. It was concluded that an insect population was well established at this site. Site 17

144. On 30 Jan. 1979, several waterhyacinth plants at this site were checked to determine if a dispersing population of $S$. albiguttalis had become established. No evidence of such a population was found; therefore, 4701 eggs were placed among the plants in the site by pinning lamina pieces containing eggs to the central petioles of individual plants.

145. The site was again checked on 27 Feb. and no evidence of the presence of a population was detected. The lamina pieces were recovered and examined and it was noted that all of the eggs had hatched. On 20 Mar., the number of waterhyacinth plants had increased and again no signs of S. albiguttalis were found on the plants.

146. By 5 June, most of the plants in the site were tall and only a few with inflated petioles could be found. An adult S. albiguttalis was observed but an attempt at capturing it failed. Again, no evidence of the presence of a population was obtained. On 2 Aug., however, the tall plants were meticulously examined and several early instar larvae were found in the central petioles and newly emerging leaves of these large plants. It was concluded that a population was and had been established at the release point for some time but, due to the size and density of the plants, they were difficult to find when the insects were present in low numbers. This was 
one of the first positive signs that $S$. albiguttalis will, in fact, infest the larger plants.

Site 18

147. On 2 Feb. 1979, 5317 S. albiguttalis eggs were placed on waterhyacinth plants at this site by inserting lamina pieces containing the eggs between the central petiole and the partially furled "wrapper" leaf of individual plants. Many of the adults (24 females and 42 males) from which the eggs were obtained were still alive and these were also released at the site in a 1 - by 1 - by $1-m$ screen cage. The cage was removed 6 days later and ca. 300 eggs were recovered which had not hatched. No signs of the larvae were observed.

148. On 14 Feb., the area was surveyed and extensive larval activity was noted in the Miami Canal ca. $35 \mathrm{~m}$ from the release point. No larvae or larval damage was evident on the plants at the release point, but the plants had become quite large and any signs of activity would have been difficult to locate. The site was repeatedly checked at monthly intervals until 7 June 1979 when larvae and larval damage were found within the plants at the release area. The site was considered established.

Site 19

149. Several previous releases of $S$. albiguttalis had been made in Conservation area $3 \mathrm{~A}$; however, no signs of larval activity had been noted in this sector. On 2 Feb. 1979, therefore, 1847 neonates which were contained on lamina sections were placed on the small plants present in this site. When the release was checked 12 days later, 10 damaged petioles were found as well as a single larva. The lamina sections used in the release were examined and it appeared that the larvae had successfully evacuated to the adjacent plants. None of the larvae were recovered. Approximately $100 \mathrm{~m}$ east of the release point, however, signs of larval feeding were evident. 
Since it was too soon for the insects released to have completed a generation and dispersed to this area, it was surmised that these were from a previous release. The Miami Canal was then checked just north of SR 84 and larvae were found in an area ca. $30 \mathrm{~m}$ from the canal on a 20 - by $30-\mathrm{m}$ stand of small plants $(<20 \mathrm{~cm})$.

150. When the site was re-examined on 6 June, the entrance was found to be dry and the site inaccessible. No conclusions could, therefore, be made regarding the success or failure of the release in the precise release area. Extensive larval activity was found near the entrance to the site, however, on plants growing at the margin of the main canal. It was concluded that a population had become established in the area either from the original release or by the movement of a population from an earlier release. Site 19 was redesignated to this new location for further monitoring.

Site 20

151. During March 1979, a tremendous population of S. aZziguttalis had built up in the greenhouse which had to be thinned out to prevent problems with overpopulation in the colony. A series of decisions were made which led to a second attempt at establishing a population in northern Florida using these insects. Several hundred pupae were, therefore, collected from which a total of 140 pairs of adults were subsequently obtained. The adults were placed in petri dishes with lamina sections in order to obtain eggs. The first eggs were obtained on 15 Mar. 1979. On 23 Mar., all of the eggs, larvae which were beginning to eclose, and the remaining adults were taken to Gainesville. The neonates $(11,784$ total) were released immediately but many had not yet eclosed and the adults were still producing eggs. These were held until the following day when all of the remaining insects were released at the site. This included 35,984 eggs, an additional 5,361 neonates, 
31 pupae, and 205 adults ( 120 males and 85 females). These were all placed within a previously delineated $75-\mathrm{sq}-\mathrm{m}$ area in the waterhyacinth marsh.

152. The first postrelease examination was conducted on 6 April at which time extensive larval activity was noted and several pupae were found. A total of seven $S$. albiguttalis larvae were collected from a few plants in the release area. Many of the leaves of the plants on which the larvae were placed were beginning to wilt and the resultant brown coloration was very obvious from several metres distance. This initial examination was cursory so as to avoid excessive disturbance of the site. At the time of release the plants were $\mathrm{ca} .16 \mathrm{~cm}$ in height; they had not significantly increased at the 6 April examination, although the plant density was obviously greater.

153. The second examination was conducted on 17 April 1979. At this time the plants had increased in height to $\mathrm{ca} .22 \mathrm{~cm}$. The plant density had increased from an initial average of 75 plants/sq $\mathrm{m}$ to $110 \mathrm{plants} / \mathrm{sq}$ m. Larvae were again found in the plants within the release area.

154. On 17 May, the site was again examined; the plants had increased to $\mathrm{ca} .50 \mathrm{~cm}$ in height; the area was extensively searched; and only one 5th instar S. albiguttalis larva was found. Because this was obviously one generation removed from the founder population, the site was considered established since successful reproduction had apparently occurred.

155. On 14 June, the plants had attained a height of $\mathrm{ca} .55 \mathrm{~cm}$ and the density was ca. 80 plants/sq m. Although signs of old larval damage were present in the release area, no larvae, pupae, or adults were found. On 24 July, again, no insects were recovered. On 30 August, however, a single adult male was collected. It was concluded, therefore, that a population which was probably very small and difficult to locate in the large, dense plants, was established in the release site. 


\section{Discussion}

156. As a result of the releases of $S$. albiguttalis, populations a) became established within the site at the point of release, b) became established within the site but not at the point of release and on morphotypically dissimilar plants, c) moved and became established at a different site, or d) did not become established at all. The first (a) was the most clear cut result and the easiest to document. The second (b) was more difficult to document because of the greater search area involved resulting in a lesser probability of recovering the insects. The third (c) and the fourth (d) were exceedingly difficult to verify because if insects were found in a nonrelease site, the source of those insects could only rarely be ascertained; and if insects were not found in a release site, it is possible that more searching would have found them. Since every plant at every site could not be examined, the sites were repeatedly checked until it was reasonably certain that a population of insects was not present. U1 timately, populations were found at all sites except 1, 3, 7, and 14 .

157. The purpose of determining if populations of insects were present at the sites was twofold. First, to ascertain if a release was successful it was necessary to determine if a population was established at a given site. If either result (a) or (b) listed above was realized, the release was considered successful, i.e., it did result in establishment. Second, it was necessary to determine if the type of plant present in the area in which the insects were released was acceptable to them. In this case, the result was considered positive only if outcome (a) listed above was realized.

158. The range and extent of populations which ultimately became 
established are illustrated in Figure 26. The site numbers in the solid circles represent those at which it was possible to verify the presence of the insect within the site at least 3 months after the last release in that site. The open circles represent the sites at which establishment could not be verified. The dots represent the presence of populations which had dispersed outside of the release areas as of September 1979. By this time the insect had dispersed throughout the south and central portions of the state and were present in every major river system in that area. Those river systems include the Kissimmee, St. Johns, Manatee, Peace, Caloosahatchee, Myakka, Withlacoochee, Hillsborough, and Loxahatchee Rivers which comprise a total distance of ca. $1200 \mathrm{~km}$ and a total drainage area of ca. 50,000 sq km. In addition, S. albiguttalis populations are well established in most of the major lakes and canal systems in the state. It is not unrealistic to expect that populations of $S$. albiguttalis will have become established on nearly every suitable waterhyacinth infestation in Florida by the end of 1980 .

159. Although the releases were successful and S. albiguttalis populations developed in 16 of the 20 sites, those at sites $2,4,5$, and 16 did not persist at the actual point of release. Instead, they moved to nearby morphotypically dissimilar plants which indicated that the type of plant at the point of release was unsuitable. Since they did survive on these plants for at least the duration necessary for one generation to develop, it is logical to conclude that the selection of the different plant type was by the female searching for suitable oviposition sites. Site 2 was a prime example of this phenomenon. The insects were released on tall plants in the lake at the mouth of the feeder canal but subsequent observations indicated that the population was very sparse or nonexistent in that area. The 
waterhyacinth population extended from the lake up the canal ca. $300 \mathrm{~m}$ to the northwest in a continuous mat to a culvert at which the waterhyacinth mat ended. The fringe of plants bordering the mat consisted of much smaller plants with inflated petioles instead of the larger, equitant petiole type predominant throughout the lake. It was on this fringe that the insect population was ultimately found. A transect was established which extended from the culvert for $100 \mathrm{~m}$ toward the original release point and plant samples were taken at 10-m intervals along this transect. These data are illustrated in Figure 28. It is apparent that the insect population diminished as the distance from the fringe of small plants increased. It is not apparent, however, that the size of the plants directly affected the decrease in insect numbers since $S$. albiguttalis was present both in the large and small plants. Clearly the insect population moved ca. $300 \mathrm{~m}$ from the release point and the number of insects present was negatively related to the distance from the growing fringe.

160. The data from site 2 as well as observations at the other sites led to a suspicion that some unknown factor of plant quality was important in determining the suitability of a particular plant population to the insect. Plants which appeared to be lush, succulent, healthy, and vigorously growing seemed to facilitate establishment of the insect. Conversely, releases in sites with plants which seemed to be stunted or spindly, with a dry or tough texture, and not vigorous were either not successful or resulted in the movement of the populations to a different plant type. To determine if there were observable differences between the apparently suitable and unsuitable plants, measurements of various characteristics were taken from plants at the release points at each site. These are summarized in Table 2. 


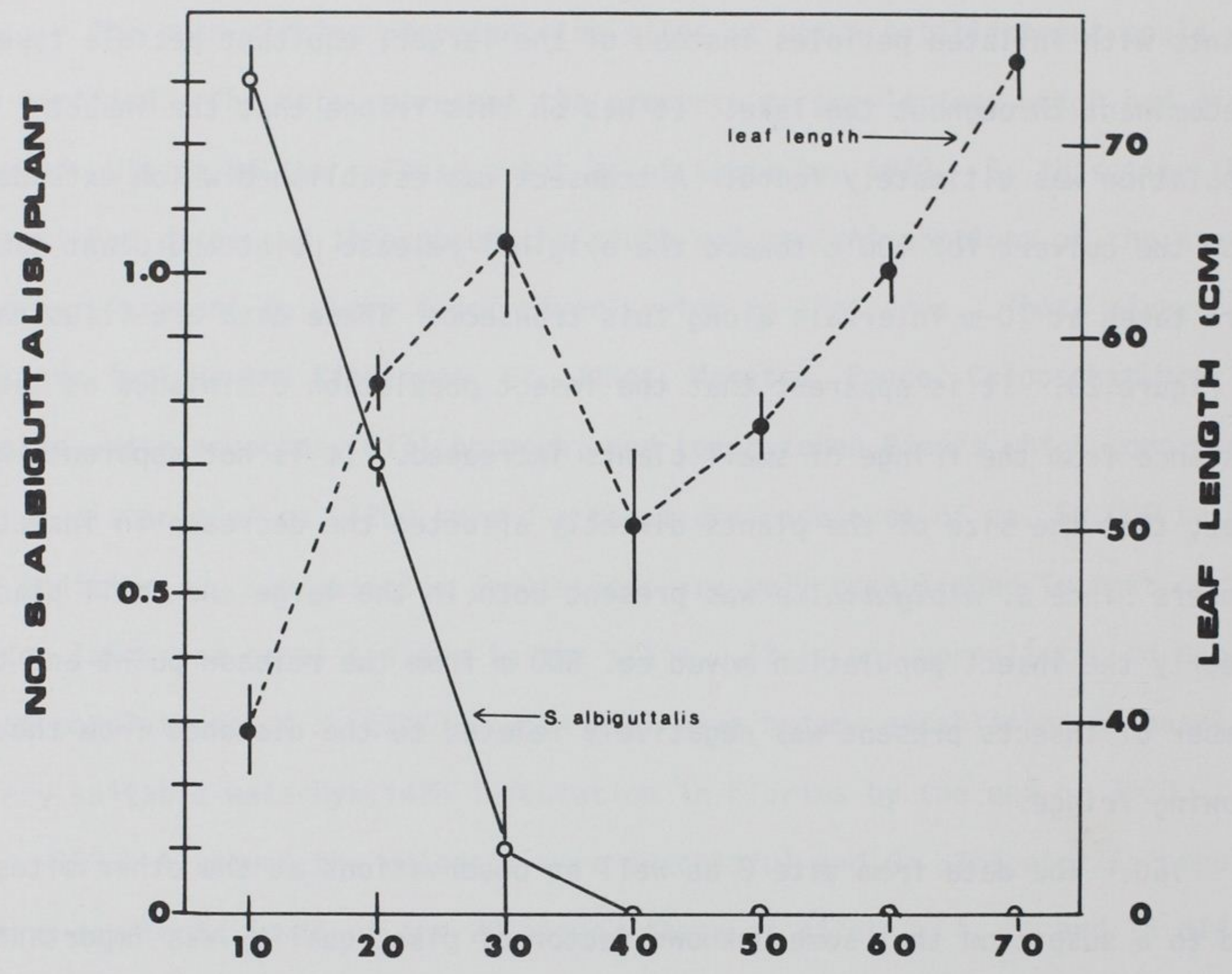

Distance fRom CulVERT (M)

Figure 28. Transect data taken at site 2 from the canal at the northwest side of the lake. The culvert was ca. $300 \mathrm{~m}$ from the original release point and the transect ran from the culvert towards the release point. A fringe of small plants with inflated petioles was present at the edge of the mat nearest the culvert. Since the waterhyacinths had been growing towards the culvert, these represented the youngest plants and the age of the plants increased as the distance from the culvert increased. The number of insects present along the transect was negatively related to the distance from the culvert, hence, to the age of the plants and apparently not to the size of the plants 
Table 2. A comparison of plant characteristics among sites and the ratios of characteristics considered indicative of plant quality. Plants which were apparently suitable to the insects are indicated with an asterisk (*). The data for all sites represent an average of 10 plants except for sites 12 an 116 which are averages of 20 and 9 plants, respectively. The data are pooled below for all suitable and unsuitable plants and compared by using a $r$ - test of unpaired data for unequal sample sizes ( $n=120$ and 69 , respectively). The $P$ represents the probability of obtaining a larger $T$ under the nuil hypothesis (i.e. no difference between groups). The data are presented as means \pm 1 standard deviation.

Root lun,th Leaf length Petiole length Petiole diam. Lamina length Lamina width Root:leaf len. Petiole len.:diam. Lamina len.:diam

\begin{tabular}{|c|c|c|c|c|c|c|c|c|c|}
\hline Site & $(\mathrm{cm})$ & $(\mathrm{cm})$ & $(\mathrm{cm})$ & $(\mathrm{cm})$ & $(\mathrm{cm})$ & $(\mathrm{cm})$ & 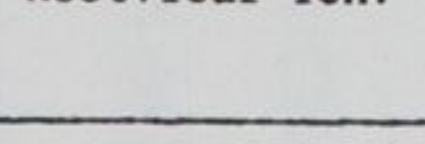 & 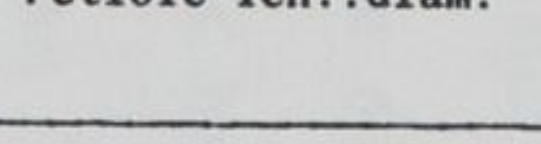 & 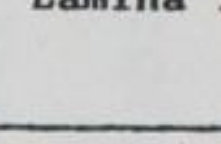 \\
\hline 1 & $27.7 \pm 1: .3$ & $31.4 \pm 4.4$ & $23.9 \pm 3.6$ & $1.4 \pm 0.2$ & $7.5 \pm 1.0$ & $6.8 \pm 0.8$ & $0.9 \pm 0.5$ & $18.1 \pm 3.6$ & $1.1 \pm 0.2$ \\
\hline 2 & $60.1 \pm 19.6$ & $65.0 \pm 6.5$ & $52.6 \pm 4.6$ & $2.2 \pm 0.5$ & $12.4 \pm 2.5$ & $9.6 \pm 1.5$ & $0.9 \pm 0.3$ & $25.2 \pm 3.9$ & $1.3+0.1$ \\
\hline 3 & $36.7 \pm 11.4$ & $65.4 \pm 9.5$ & $52.5 \pm 8.2$ & $1.9 \pm 0.4$ & $12.9 \pm 1.6$ & $10.2 \pm 1.7$ & $0.6 \pm 0.3$ & $28.1 \pm 5.5$ & $1.3+0.1$ \\
\hline 4 & $45.4 \pm 14.0$ & $82.9 \pm 4.8$ & $79.1 \pm 5.1$ & $3.3 \pm 0.4$ & $13.0 \pm 2.4$ & $8.5 \pm 2.5$ & $0.6 \pm 0.2$ & $31.9 \pm 5.7$ & $1.6 \pm 0.6$ \\
\hline 5 & $31.9 \pm 7.1$ & $52.2 \pm 5.8$ & $40.8+5.7$ & $1.9 \pm 0.3$ & $11.4 \pm 1.6$ & $9.2 \pm 1.4$ & $0.6 \pm 0.2$ & $22.3+4.8$ & $1.2 \pm 0.1$ \\
\hline 6* & $31.0 \pm 8.4$ & $44.8 \pm 4.1$ & $32.5 \pm 2.5$ & $2.3 \pm 0.9$ & $12.3 \pm 2.5$ & $11.8 \pm 1.7$ & $0.7 \pm 0.2$ & $15.7+4.8$ & $1.0 \pm 0.2$ \\
\hline $8^{*}$ & $29.9 \pm 7.0$ & $30.0 \pm 13.1$ & $21.8 \pm 10.4$ & $1.7 \pm 0.4$ & $8.2 \pm 2.8$ & $8.1 \pm 1.2$ & $1.2 \pm 0.5$ & $13.7 \pm 5.8$ & $1.0 \pm 0.2$ \\
\hline $9^{*}$ & $27.6 \pm 10.3$ & $20.3 \pm 7.7$ & $14.2 \pm 6.1$ & $1.6 \pm 0.3$ & $6.1 \pm 1.7$ & $6.9 \pm 1.9$ & $1.4 \pm 0.5$ & $9.4+4.6$ & $0.9 \pm 0.1$ \\
\hline $10 *$ & $17.8 \pm 13$. & $39.8 \pm 12.0$ & $31.1 \pm 9.0$ & $1.8 \pm 0.7$ & $8.6 \pm 3.1$ & $9.5 \pm 3.2$ & $0.4 \pm 0.2$ & $19.0+4.7$ & $0.9 \pm 0.1$ \\
\hline $12^{*}$ & $21.8 \pm 9.8$ & $45.4 \pm 10.3$ & $35.6 \pm 8.6$ & $1.5 \pm 0.3$ & $9.7 \pm 1.9$ & $9.0 \pm 1.1$ & $0.5 \pm 0.3$ & $23.1 \pm 4.0$ & $1.1 \pm 0.2$ \\
\hline $13 *$ & $23.3 \pm 10.7$ & $54.5 \pm 9.7$ & $43.6 \pm 7.7$ & $2.0 \pm 0.3$ & $10.8 \pm 1.9$ & $8.9 \pm 1.4$ & $0.4 \pm 0.2$ & $21.9 \pm 3.5$ & $1.2 \pm 0.2$ \\
\hline 14 & $31.0 \pm 8.8$ & $71.6 \pm 7.9$ & $57.8 \pm 6.9$ & $2.0 \pm 0.3$ & $13.8 \pm 1.1$ & $9.2 \pm 2.0$ & $0.4 \pm 0.2$ & $29.1 \pm 4.6$ & $1.6 \pm 0.3$ \\
\hline $15^{*}$ & $17.4 \pm 3.3$ & $20.6 \pm 5.4$ & $14.7 \pm 4.0$ & $1.3 \pm 0.3$ & $6.1 \pm 1.5$ & $7.0 \pm 1.6$ & $0.9 \pm 0.3$ & $11.8+4.4$ & $0.9 \pm 0.1$ \\
\hline 16 & $27.2 \pm 5.4$ & $65.4 \pm 12.1$ & $54.3 \pm 10.2$ & $1.3 \pm 0.2$ & $11.1 \pm 2.2$ & $8.1 \pm 1.0$ & $0.4 \pm 0.04$ & $41.8 \pm 3.9$ & $1.4 \pm 0.2$ \\
\hline $17^{\star}$ & $22.2 \pm 6.3$ & $47.7 \pm 7.4$ & $37.5 \pm 6.2$ & $1.8 \pm 0.4$ & $\begin{array}{l}10.3 \pm 1.8 \\
\text { (Cont 1nued) }\end{array}$ & $8.8 \pm 1.4$ & $0.5 \pm 0.2$ & $22.0 \pm 4.1$ & $1.2 \pm 0.1$ \\
\hline
\end{tabular}


Table 2. (continued)

Poot length Leaf length Petiole length Petiole diam. Lamina length Lamina width Root:leaf len. Petiole len.:diam. Lamina len.:diam

\begin{tabular}{|c|c|c|c|c|c|c|c|c|c|}
\hline Site & $(\mathrm{cm})$ & $(\mathrm{cm})$ & $(\mathrm{cm})$ & (cm) & $(\mathrm{cm})$ & $(\mathrm{cm})$ & & & \\
\hline $18^{*}$ & $28.0 \pm 8.8$ & $32.2 \pm 3.1$ & $23.5 \pm 2.5$ & $2.0 \pm 0.6$ & $8.7 \pm 1.5$ & $10.0 \pm 1.3$ & $0.9 \pm 0.3$ & $12.4 \pm 2.8$ & $0.9 \pm 0.1$ \\
\hline $19^{\star}$ & $29.4 \pm 18.8$ & $56.3 \pm 24.4$ & $45.7 \pm 21.5$ & $2.2 \pm 0.7$ & $11.8+5.9$ & $11.0 \pm 3.2$ & $0.5 \pm 0.2$ & $20.2 \pm 4.4$ & $1.0 \pm 0.2$ \\
\hline $20^{\star}$ & $9.1 \pm 3.7$ & $71.1 \pm 21.0$ & $57.9 \pm 18.9$ & $2.5 \pm 0.6$ & $13.2 \pm 4.1$ & $11.9+4.2$ & $0.1 \pm 0.04$ & $22.8+5.8$ & $1.1 \pm 0.1$ \\
\hline Suit. & $23.3 \pm 11.4$ & $42.3 \pm 18.6$ & $32.8 \pm 16.0$ & $1.8 \pm 0.6$ & $9.6 \pm 3.5$ & $9.3 \pm 2.6$ & $0.6 \pm 0.5$ & $17.9+6.5$ & $1.0 \pm 0.2$ \\
\hline $\begin{array}{l}\text { Un- } \\
\text { suit. }\end{array}$ & $37.3 \pm 16.2$ & $61.9 \pm 17.0$ & $50.2 \pm 15.0$ & $1.8 \pm 0.5$ & $11.7 \pm 2.6$ & $8.8 \pm 1.9$ & $0.6 \pm 0.3$ & $27.9 \pm 8.2$ & $1.4 \pm 0.3$ \\
\hline$T(P)$ & 5 $94(<0.001)$ & $7.21(<0.001)$ & $7.38(<0.001)$ & $0.14(>0.001)$ & $4.37(<0.001)$ & $1.40(>0.100)$ & $0.47(>0.500)$ & $9.20(<0.001)$ & $9.00(<0.001)$ \\
\hline
\end{tabular}


161. The plants which seemed to be suitable were characterized by significantly shorter roots, leaves, petioles, and laminae and smaller petiole length:diameter and lamina length:width ratios. Petiole diameter, lamina width, and the root length:leaf length ratios were not significantly different. The differences in lamina and petiole ratios indicated that suitable plants had more robust petioles ( 9 to $23 \times$ longer than wide) with reinform laminae (about as long as wide), whereas unsuitable plants had more spindly petioles (up to $42 \times$ longer than wide) with lanceolate laminae (longer than wide). Comparing the root:leaf length ratios with leaf length measurements reveals that these two characteristics were significantly correlated $(r=-0.87, P<0.01)$ within the suitable plant group but not correlated $(r=-0.42)$ within the unsuitable plant group. This indicated that the root:leaf length ratio was dependent upon the growth stage of the plant in the former but not the latter. In other words, at those sites in which the plants were apparently suitable for $S$. albiguttalis, the roots were generally shorter and did not vary a great deal in length with increasing leaf length. As a result, the variance in root:leaf length ratios was attributable primarily to leaf length. Those with shorter leaves were at an earlier growth stage but had a fully developed root system resulting in a high root: shoot length ratio. When plants of relatively equal leaf lengths are compared, it appears that the unsuitable plants had relatively larger root systems than the suitable plants.

162. These comparisons indicated that there is a high probability some types of plants are preferred by $S$. albiguttalis, and this preference is reflected in the varying consequences of the release attempts. It is surmised that the plants in the establishment sites differed to a significant 
extent from those in the nonestablishment sites. The measured characteristics reflect this difference but are not necessarily meaningful in themselves, being only morphotypic responses to environmental stimuli. Figure 29 represents the data from each of the sites plotted three-dimensionally and shows a clear separation between the establishment and nonestablishment site groups. It is apparent that comparisons of single characteristics do not reflect the actual differences in the types of plants from the various sites. For example, the root:leaf length ratios for the establishment sites ranged across the entire spectrum of values. However, those with the larger values (sites 6,8 , 9, 15, and 18) generally had stout petioles (length:diameter < 14) and short leaves $(<33 \mathrm{~cm})$. These characteristics typify healthy, young plants, growing in uncrowded conditions, with bulbous petioles which should be distinguished from stunted plants, with spindly petioles, short leaves, and long roots. Generally, plants of comparatively equal sizes had higher root:leaf length ratios at the nonestablishment sites than at the establishment sites although our observations are insufficient for valid comparisons. Several authors have noted that site characteristics of low nutrients or poor flow may be reflected in waterhyacinth plants by the development of larger root systems relative to the shoot (Anderson 1976; Morris 1974; Knipling et al. 1970; Haller and Sutton 1973). The characteristics of spindly petioles and lanceolate laminae may also be indicative of poor growing conditions.

163. The mode of release did not appear to be important in the ultimate establishment of the populations. In general, the release of first instar larvae produced the best results but all release techniques appeared to be satisfactory. The release which we assumed had the lowest probability of 


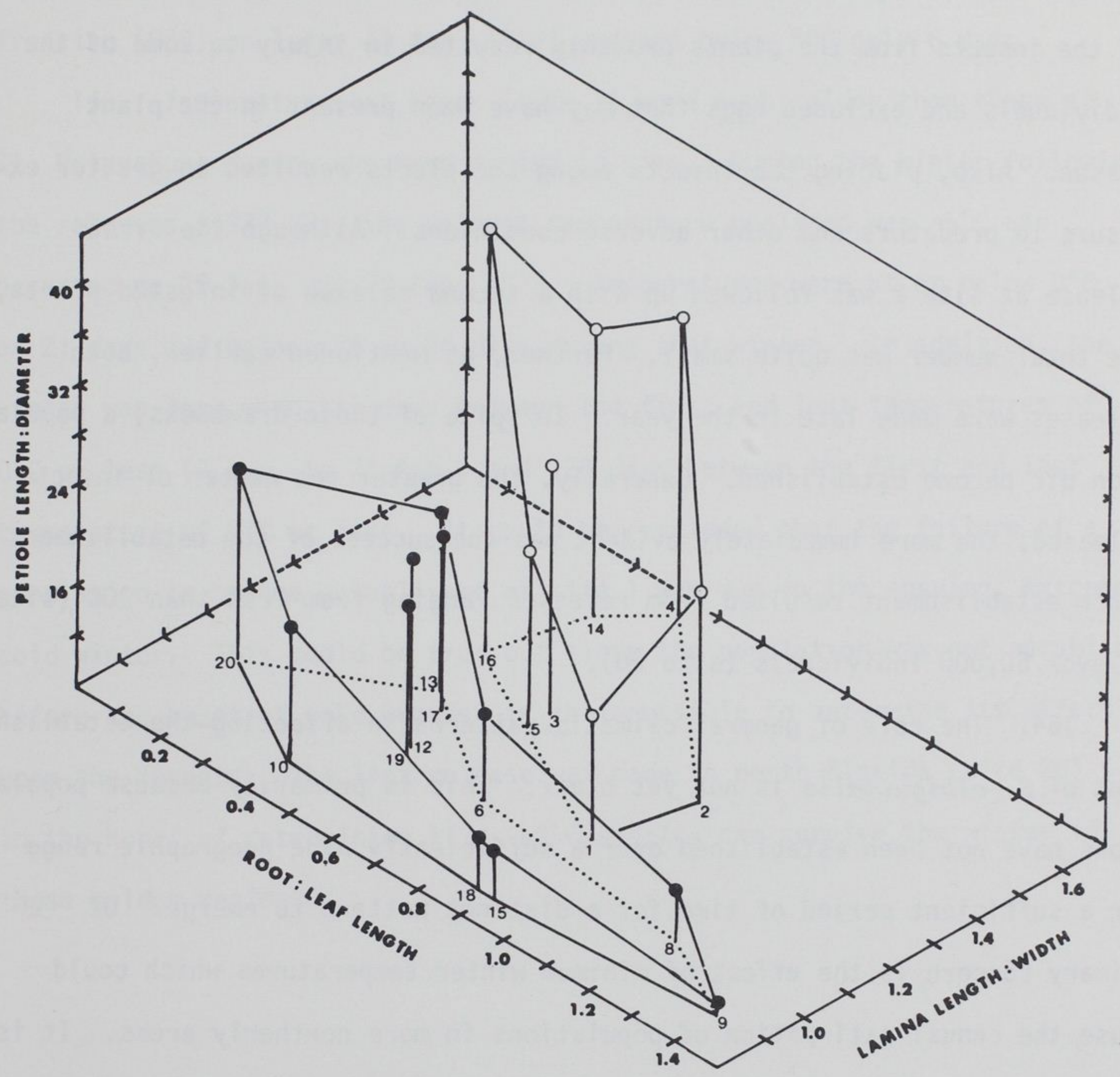

Figure 29. A comparison of three ratios of plant characteristics among sites grouped according to whether $S$. albiguttalis populations became established on the plants (solid dots) or failed to become established (open dots). High petiole length:diameter values are indicative of spindly petioles whereas low values are indicative of stout petioles. High lamina length:width values are indicative of lanceolate lamina whereas low values are typical of reinform laminae. All three are believed to be growth responses of the plant to environmental conditions wherein high nutrients and flowing water produce plants with reinform laminae, stout petioles, and short roots (relative to the length).

These are the type of plant seemingly preferred by $S$. albiguttalis 
success was that at site 2 in which late instar larvae and pupae were removed from the greenhouse plants and placed in the field site. Removal of the insects from the plants probably resulted in injury to some of the individuals and excluded eggs that may have been present in the plant tissue. Also, placing the insects among the plants resulted in greater exposure to predators and other adverse conditions. Although the first release at site 2 was followed up with a second release of infested plants, the total number was quite small. Further, as mentioned earlier, both releases were made late in the year. In spite of these drawbacks, a population dic become established. Generally, the greater the number of insects released, the more immediately evident was the success of the establishment since establishment resulted from releases ranging from less than 200 (site 2) to over 50,000 individuals (site 20).

164. The role of general climatic patterns in affecting the establishment of S. albiguttalis is not yet clear. This is primarily because populations have not been established over a sufficiently wide geographic range for a sufficient period of time for a distinct pattern to emerge. Of primary concern is the effect of minimum winter temperatures which could cause the annual extirpation of populations in more northerly areas. It is certain that the winter climate in south Florida is sufficiently mild since populations have persisted over at least a 12-month period. It also appears that populations are persistent in central Florida because, at site 2 , the insects have survived two winters. In neither of these areas, however, have the insects been exposed to sustained freezing temperatures. At St. Petersburg (site 2), the minimum temperature for the winter of 1977-78 was 
$2^{\circ} \mathrm{C}$ (10 Jan. 1978) and the temperature fell below $5^{\circ} \mathrm{C}$ on only 8 days the entire winter. During the winter of 1978-79, the temperature dropped to freezing $\left(0^{\circ} \mathrm{C}\right)$ on 1 day ( 3 Jan. 1979) and was below $5^{\circ} \mathrm{C}$ only 6 days.

165. Temperatures at Edgar (site 1) were much colder than those at St. Petersburg during the same period of time. During the winter following the releases (1977-78), the coldest temperature realized was $-5^{\circ} \mathrm{C}$ and occurred on $29 \mathrm{Jan}$. and $23 \mathrm{Feb}$. 1978. Temperatures were at or below $0^{\circ} \mathrm{C}$ on 21 days and below $5^{\circ} \mathrm{C}$ on 54 days during that winter. In addition, the winter was long with 111 days between the first and last temperatures of $0^{\circ} \mathrm{C}$ or less ( 7 Nov. to $25 \mathrm{Feb}$.) and 128 days between the first and last temperature of $5^{\circ} \mathrm{C}$ or less. It could be concluded that the failure of a population to become established at site 1 was due to the ensuing, extremely cold winter. This could be true but since the population was not established before the onset of cold weather it is impossible to determine its effect upon the insects. The last release was made in north Florida (site 20) in the hopes of determining if $S$. albiguttalis can survive the winter in these colder regions. 


\section{REFERENCES CITED}

Anderson, R. G. 1976. Comparative studies of the morphology and ecology of sexual reproduction of Eichhornia crassipes (Pontederiaceae). Ph.D. Disseration, Univ. Fla., Gainesville. 190 pp.

Bennett, F. D. and H. Zwolfer. 1968. Exploration for natural enemies of the waterhyacinth in northern South America and Trinidad. Hyacinth Control J. 7:44-52.

Biezanko, C. M. de, A. Ruffinelli, and C. S. Carbonel1. 1957. Lepidoptera del Uruguay, lista anotada de especies. Revista de la Facultad de especies. Revista de la Facultad de Agronomia (Montevideo, Uruguay) No. 46:p.31. (cited ex DeLoach and Cordo 1978).

Borror, D. J. and D. M. DeLong. 1971. An introduction to the study of insects. 3rd ed. Holt, Rinehart and Winston, New York. 812 pp.

Cordo, H. A. and C. J. DeLoach. 1978. Host specificity of Scomeodes albiguttalis in Argentina, a biological control agent for waterhyacinth. Environ. Entomol. 7:322-28.

DeLoach, C. J. and H. A. Cordo. 1978. Life history and ecology of the moth Someodes albiguttalis, a candidate for biological control of waterhyacinth. Environ. Entomol. 7:309-321.

Forbes, W. T. M. 1923. The Lepidoptera of New York and neighboring states. Primitive forms, Microlepidoptera, Pyraloids, Bombyces. Cornell University Agricultural Experiment Station Memori 68. 729 pp.

Haller, W. T. and D. L. Sutton. 1973. Effect of pH and high phosphorus concentrations on growth of waterhyacinth. Hyacinth Control J. 11:59-61. 
Hampson, Sir G. F. 1899. A revision of the moths of the subfamily Pyraustinae and family Pyralidae, pt. 2. Proc. Zool. Soc. London, p. 172-291. (cited ex DeLoach and Cordo 1978).

- 1918. Descriptions of new Pyralidae of the subfamily Pyraustinae. Ann. Mag. Nat. Hist. (9) 1:263-80. (cited ex DeLoach and Cordo 1978). Knipling, E. B., S. H. West, and W. T. Haller. 1970. Growth characteristics, yield potential, and nutritive content of waterhyacinths. Proc. Fla. Soil and Crop Soc. 30:51-63.

Morris, T. L. 1974. Waterhyacinth Eichhornia crassipes (Mart.)Solms: Its ability to invade aquatic ecosystems of Payne's Prarie. MS Thesis, Univ. Fla., Gainesville. 134 pp.

Perkins, B. D. 1974. Arthropods that stress waterhyacinth. PANS 20(3): $304-314$.

Perkins, B. D. and D. M. Maddox. 1976. Host specificity of Neochetina bruchi Hustache (Coleoptera:Curculionidae), a biological control agent for waterhyacinth. J. Aquat. Plant Manage. 14:59-64.

Peterson, A. 1962. Larvae of insects. Part I. Lepidoptera and plant infesting Hymenoptera. Edwards Bros. Inc., Ann Arbor, Mich. 315 pp.

Silveira-Guido, A. 1965. Natural enemies of weed plants. Final report. Unpubl. report, Dept. Sanidad Vegetal, Univ. de la Republica, Montevideo, Uruguay. 128 pp.

Silveiro-Guido, A. 1971. Datos preliminares de biologia y especificidad de Acigona ignitalis Hamps. (Lep. Pyralidae) sobre el hospedero Eichhomia crassipes (Mart.)Solms-Laubach (Pontederiaceae). Rev. Soc. Entomol. Argentina $33(1-4): 137-45$. 
Silveiro-Guido, A. and B. D. Perkins. 1975. Biology and host specificity of Comops aquaticum (Bruner) (Orthoptera:Acrididae) a potential biological control agent for waterhyacinth. Environ. Entomol . 4:400-4. Warren, W. 1889. On the Pyralidina collected in 1874 and 1875 by Dr. W. H. Trail in the basin of the Amazons. Trans. R. Entomol. Soc. London. pp. 227-295. 